University of Windsor

Scholarship at UWindsor

\title{
An investigation into the head and neck injury potential of three- year-old children in forward and rearward facing child safety seats.
}

\author{
Rita Francesca Turchi \\ University of Windsor
}

Follow this and additional works at: https://scholar.uwindsor.ca/etd

\section{Recommended Citation \\ Turchi, Rita Francesca, "An investigation into the head and neck injury potential of three-year-old children in forward and rearward facing child safety seats." (2004). Electronic Theses and Dissertations. 1101. https://scholar.uwindsor.ca/etd/1101}

This online database contains the full-text of PhD dissertations and Masters' theses of University of Windsor students from 1954 forward. These documents are made available for personal study and research purposes only, in accordance with the Canadian Copyright Act and the Creative Commons license-CC BY-NC-ND (Attribution, Non-Commercial, No Derivative Works). Under this license, works must always be attributed to the copyright holder (original author), cannot be used for any commercial purposes, and may not be altered. Any other use would require the permission of the copyright holder. Students may inquire about withdrawing their dissertation and/or thesis from this database. For additional inquiries, please contact the repository administrator via email (scholarship@uwindsor.ca) or by telephone at 519-253-3000ext. 3208. 
vestigation into the head and neck injury potential of ...

Turchi, Rita Francesca

ProQuest Dissertations and Theses; 2004; ProQuest

\title{
AN INVESTIGATION INTO THE HEAD AND NECK INJURY POTENTIAL OF THREE-YEAR-OLD CHILDREN IN FORWARD AND REARWARD FACING CHILD SAFETY SEATS
}

by

Rita Francesca Turchi

\begin{abstract}
A Thesis
Submitted to the Faculty of Graduate Studies and Research

Through Mechanical Engineering in Partial Fulfillment of the Requirements for The Degree of Master of Applied Science at the University of Windsor
\end{abstract}

Windsor, Ontario, Canada

2004

(C) 2004 Rita Francesca Turchi 


\author{
National Library \\ of Canada \\ Acquisitions and \\ Bibliographic Services \\ 395 Wellington Street \\ Ottawa ON K1A ON4 \\ Canada
}

Bibliothèque nationale du Canada

Acquisisitons et services bibliographiques

395 , rue Wellington Ottawa ON K1A ON4 Canada
Your file Votre référence ISBN: 0-612-92525-0 Ourfile Notre référence ISBN: 0-612-92525-0
The author has granted a nonexclusive licence allowing the National Library of Canada to reproduce, loan, distribute or sell copies of this thesis in microform, paper or electronic formats.

The author retains ownership of the copyright in this thesis. Neither the thesis nor substantial extracts from it may be printed or otherwise reproduced without the author's permission.
L'auteur a accordé une licence non exclusive permettant à la Bibliothèque nationale du Canada de reproduire, prêter, distribuer ou vendre des copies de cette thèse sous la forme de microfiche/film, de reproduction sur papier ou sur format électronique.

L'auteur conserve la propriété du droit d'auteur qui protège cette thèse. $\mathrm{Ni}$ la thèse ni des extraits substantiels de celle-ci ne doivent être imprimés ou aturement reproduits sans son autorisation.
In compliance with the Canadian Privacy Act some supporting forms may have been removed from this dissertation.

While these forms may be included in the document page count, their removal does not represent any loss of content from the dissertation.
Conformément à la loi canadienne sur la protection de la vie privée, quelques formulaires secondaires ont été enlevés de ce manuscrit.

Bien que ces formulaires aient inclus dans la pagination, il n'y aura aucun contenu manquant. 


\begin{abstract}
This research focused on the injury potential of children in forward and rearward facing configurations involved in frontal collisions. Experimental sled tests were completed following the requirements of the Federal Motor Vehicle Safety Standard (FMVSS) 213 using a Hybrid III 3-year-old dummy in a forward facing configuration restrained in a child restraint system (CRS) that employed a five-point seat belt. The Hybrid III 3-year-old dummy was equipped with three uniaxial accelerometers arranged in mutually perpendicular directions in the head and chest. Experimental sled tests were also completed for a rearward facing configuration, but the results were not applicable due to excessive rotation of the child safety seat toward the front of the sled which would not typically occur in a frontal crash. In addition the set-up did not allow for proper placement of the child dummy's legs and did not portray a realistic configuration of the child in the child safety seat. Using Finite Element Model Builder (FEMB) software and EASi-Crash Dyna, a numerical model employing a subset of the apparatus used in the forward facing experimental sled test was developed and numerically simulated using LS-DYNA. To verify the numerical simulations, the head and chest accelerations were compared to the experimental observations and it was found that there was a reasonable engineering correlation between the data. Further numerical simulations were completed to study the possible benefits of facing a 3year-old child in a rearward facing configuration during a frontal crash.
\end{abstract}

The injuries that were assessed included neck and head injury, as those types of injuries are the most devastating. It was determined that when the 3-year-old Hybrid III dummy model was in a rearward facing position, the child sustained less neck loads and head accelerations than the forward facing configuration. Through analysis of injury criteria, using neck loads and head accelerations, it was observed that a 3-year-old child sustained lower levels of neck injury criteria $\left(\mathrm{N}_{\mathrm{ij}}\right)$ and head injury criteria $(\mathrm{HIC})$.

In North America, the standard for restraining young children states that for a child under the age of 12 months, the child should be restrained in a child seat facing the rear of the vehicle. After 12 months of age, the child can then face forward. This study has developed information to consider if this standard should be addressed. 


\section{ACKNOWLEDGEMENTS}

The author is indebted to her academic advisor, Dr. William Altenhof, for his guidance throughout the duration of this research as well as for his boundless knowledge in the area of vehicle occupant injury and finite element modeling. The author would also like to like to thank participating members of Auto21, especially Dr. Andrew Howard and Aly Moses McKeag for their unlimited biological data of child injuries. 


\section{TABLE OF CONTENTS}

Title

Page

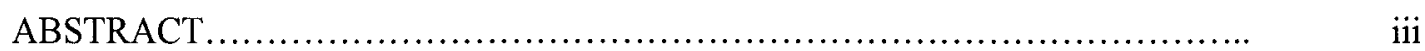

ACKNOWLEDGEMENTS.................................................. iv

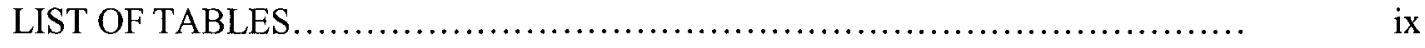

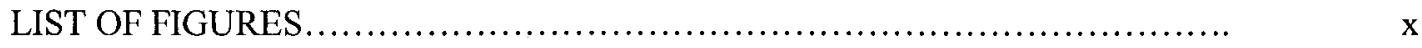

LIST OF APPENDICES.................................................... xiv

LIST OF ABBREVIATIONS...............................................

LIST OF NOMENCLATURE................................................. xvi

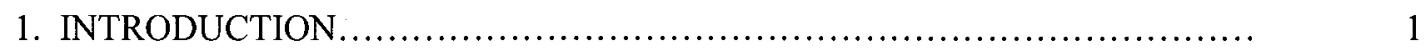

2. LITERATURE REVIEW ................................................. 3

2.1 Automotive crash statistics....................................... 3

2.2 Child Safety................................................... 4

2.2.1 Current child safety recommendations.......................

2.2.2 Social impact of child safety regulations......................

2.3 Clinical observations regarding child injury in

forward facing positions........................................ 11

2.3.1 Rear facing infant placed in front passenger

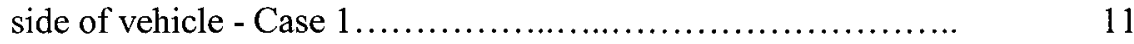

2.3.2 Toddler placed in front passenger seat of

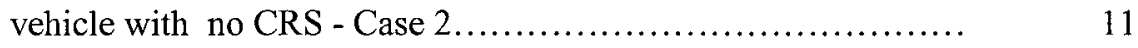

2.3.3 Forward facing 23-month-old child in rear of

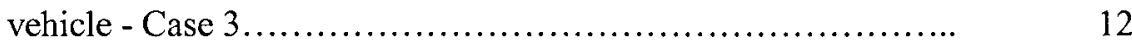

2.3.4 Forward facing 35-month-old child in rear of

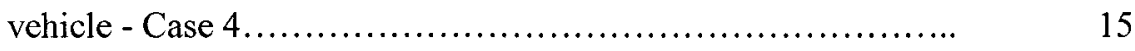

2.4 Injury........................................................ 20

2.4.1 Head injury in children during collison......................

2.4.2 Neck injury in children during collision....................... 25

2.4.3 The effect of time duration of force on injury 


\section{TABLE OF CONTENTS - continued.}

2.5 Current standards in automotive crash for children.................. 34

2.5.1 Federal Motor Vehicle Safety Standard 213.................. 34

2.5.1.1 Most important aspects of FMVSS 213................. 34

2.5.1.1.1 Dynamic test procedure.......................... 35

2.5.1.1.2 Dressing the Hybrid III dummies.................. 37

2.5.1.2 Injury criteria..................................... $\quad 37$

2.5.1.2.1 Head injury criteria............................. 37

2.5.1.2.2 Neck injury criteria............................. 39

2.5.2 Canadian Motor Vehicle Safety Standard 213................... 41

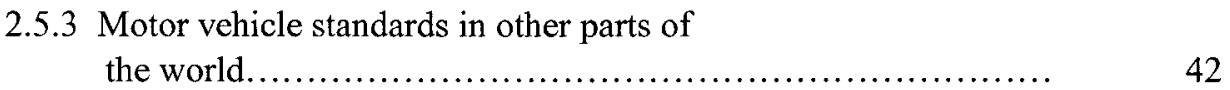

2.6 Crash testing................................................... 44

2.6.1 Crash test dummies........................................ 44

2.6.2 Hybrid III history and development........................ 44

2.6.3 Development of the FE model of the Hybrid III 49

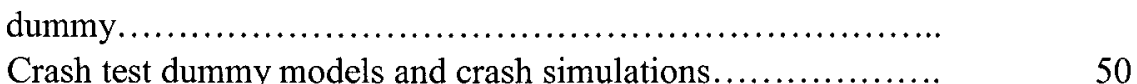

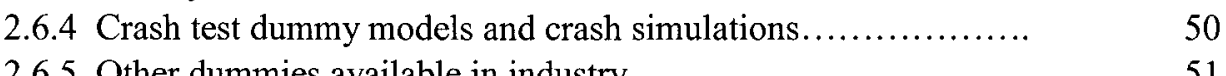

2.6.5 Other dummies available in industry ............................ 51

2.6.5.1 Side impact dummies................................. 51

2.6 .5 .2 CRABI........................................... 52

2.6.5.3 Rear impact dummies.............................. $\quad 52$

3. FOCUS OF RESEARCH.......................................... 53

4. EXPERIMENTAL PROCUDURE..................................... 54

4.1 Experimental crash testing - FMVSS 213 sled test................. 54

4.1.1 Forward facing sled test.................................... 56

4.1.2 Rearward facing sled test..................................... $\quad 58$

4.1.3 Data acquistion.......................................... $\quad 59$

4.2 Numerical simulations...................................... $\quad 60$

4.2.1 Preprocessing.......................................... $\quad 60$

4.2.1.1 Contact for the Hybrid III 3-year-old
dummy model $\ldots \ldots \ldots \ldots \ldots \ldots \ldots \ldots \ldots \ldots \ldots \ldots \ldots \ldots \ldots \ldots \ldots \ldots \ldots \ldots \ldots \ldots$

4.2.1.2 Joint characteristics................................. 61

4.2.1.3 Modeling of the child safety seat.......................... 62

4.2.1.4 Modeling of the seat belt............................... 64

4.2.1.5 Modeling of the clasps............................... 65

4.2.1.6 Modeling of the foam insert.......................... 65

4.2.1.7 General set-up of the system........................ $\quad 70$ 


\section{TABLE OF CONTENTS - continued.}

4.2.2 Extraction of data from Hybrid III 3-year-old dummy model.........................................

4.2.2.1 Head and chest accelerations............................ $\quad 72$

4.2.2.2 Upper and lower neck forces and moments............... 74

4.2.2.3 Analysis of forces and moments of the upper and lower neck................................ $\quad 74$

4.2.2.4 Head injury criteria.................................... $\quad 75$

4.2 .2 .5 Neck injury criteria.................................. $\quad 75$

4.2.2.6 Head, neck, and chest average accelerations.............. $\quad 76$

5. RESULTS AND DISCUSSION ....................................... 77

5.1 Finite element model verification...................................... $\quad 77$

5.1.1 Head accelerations.......................................... $\quad 77$

5.1.2 Chest accelerations.......................................... 81

5.1.3 Qualitative comparison of numerical and experimental observations.................................. 85

5.1.4 Discussion of numerical and experimental results................ 88

5.2 Numerical simulations of forward and rearward

facing configurations............................................ 89

5.2.1 Global energy balance....................................... 90

5.2.1.1 Hourglass energy...................................... 90

5.2.1.2 Sliding interface energy ............................. 90

5.2.1.3 Total, internal, and external energies.................... 92

5.2.2 Comparison of the forces and moments observed in the upper and lower neck...................... 94

5.2.2.1 Forward and rearward facing resultant upper neck forces.................................. 94

5.2.2.2 Forward and rearward facing resultant lower neck forces.................................... 96

5.2.2.3 Forward and rearward facing resultant upper neck moments............................... 97

5.2.2.4 Forward and rearward facing resultant lower neck moments.............................. $\quad 98$

5.2 .3 Head injury criteria...................................... $\quad 100$

5.2.4 Average head acceleration.................................. 103

5.2.5 Average chest acceleration.................................. 106

5.2.6 Neck injury criteria...................................... 108

5.2.7 Qualitative comparison of forward and rearward numerical simulations. 
TABLE OF CONTENTS - continued.

6. CONCLUSIONS AND FUTURE WORK..................................... 114

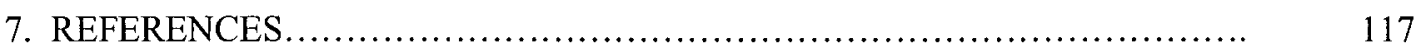

8. APPENDICES ............................................................... 121

APPENDIX A......................................................... 122

APPENDIX B ......................................................... 124

APPENDIX C ...................................................... 127

APPENDIX D ..................................................... 131

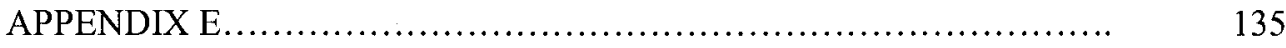

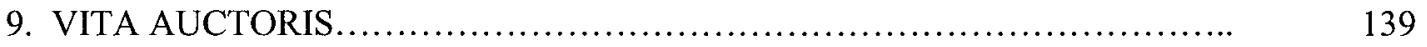

viii 


\section{LIST OF TABLES}

Table \#

1 One-year-old spine material properties.

2 Three-year-old spine material properties.

3 Six-year-old spine material properties.

4 Eleven-year-old spine material properties

5 Material properties of the cranial bone

6 Length and modulus scaling factors

7 Scaled adult protection reference values.

FMVSS 213 input accleration upper and lower limit coordinates.

MAIS score and associated injury.

10 Critical values for calculation of neck injury criteria of Hybrid III 3-year-old dummy

11 Types of internal contact algorithms used in Hybrid III

3-year-old dummy model

12 Hybrid III 3-year-old dummy model joint locations and parts joined.

13 Trial HU and SHAPE values used in foam study.

14 SAE J211 filters for Hybrid III dummy accelerometers and load cells

15 Summary of peak acceleration, time to peak acceleration, and duration of acceleration pulse for experimental and numerical results.

16 Summary of forces and moments observed in the neck of the Hybrid III 3-year-old child dummy model.

17 Probability of injury for forward facing and rearward

facing configurations.

18 Forward and rearward facing average head acceleration values for time durations.

19 Forward and rearward facing average chest acceleration values for time durations.

20 Forward and rearward facing average Nij for time durations. 


\section{LIST OF FIGURES}

Figure \#

$1 \quad$ Suggested modes of restraint for various ages and

Page

sizes of children .................................................. 5

2 Three types of convertible child safety seats....................... 7

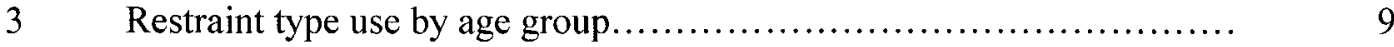

4 Photo of the final condition of the 1994 Honda Accord

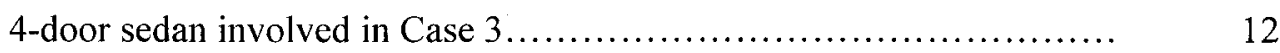

5 Schematic diagram of the dynamics of the collision in Case $3 \ldots \ldots \ldots \ldots . .13$

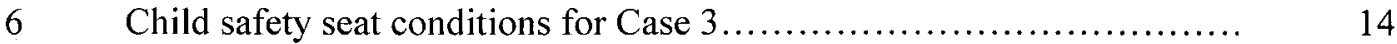

7 Occipitocervical dislocation in the 23-month-old male

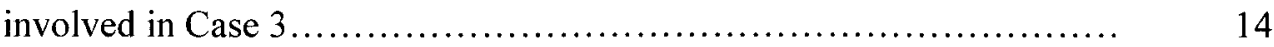

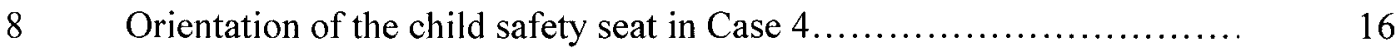

9 Schematic diagram of the dynamics of the collision in Case $4 \ldots \ldots \ldots \ldots . .17$

10 Final condition of the Toyota 4Runner involved in Case 4............. 17

11 Angulated fracture of the cervical spine (C2) in child

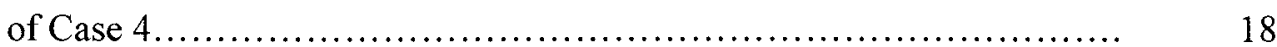

12 Typical cervical vertebrae for ages one, three, six, eleven, and adult............................................... 24

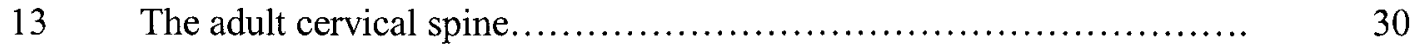

14 Axial neck tension - child dummy protection reference curves.

15 Impact tolerance for the human brain in forehead impacts against plane, unyeilding surfaces............................. 32

16 Whole body tolerance of rearward acceleration....................... 33

17 Bench seat used in FMVSS 213 crash testing.......................

18 FMVSS 213 input acceleration upper and lower

limit curves.................................................... 36

19 Probability of injury versus head injury criteria...................... 38

20 Bottom view of the skull illustrating occipital condyles................ 39

21 Side view of the base of the skull.................................. 39

22 Probability of injury versus neck injury criteria...................... 41 


\section{LIST OF FIGURES - continued.}

26 Fe models of the interior components and the polyvinyl componens of the Hybrid III dummy

29 Hybrid III 3-year-old dummy uniaxial accelerometers in the head and chest.

30 Side and front view of the Hybrid III 3-year-old dummy restrained in the five-point restraint child seat at the Graco crash test facility.

FMVSS 213 standard input accleration versus time curve

Side and back view of the Hybrid III 3-year-old dummy restrained in the five-point restraint child seat in the rearward facing position.

33 Meshed view and internal view of Hybrid III

3-year-old dummy model.

34 Meshed model of child safety seat illustrating isometric and top views.

35 Meshed seat belt and clasps model.

36 Typical load-deflection curve for urethan foams illustrating the linear, plateau, densification, and hysteretic regions.

37. Load versus deflection for trial numerical similations of urethane foams.

38 Experimental and numerical curve for foam model verification.

40 Hybrid III 3-year-old dummy model restrained in a five-point restraint in forward facing position....

41 Hybrid III 3-year-old dummy model demonstrating the directions in which the accelerations are measured. 


\section{LIST OF FIGURES - continued.}

42 Accelerometer locations in the head and chest of the Hybrid III 3 -year-old dummy model....................................

43 Upper and lower neck areas of the Hybrid III 3 -year-old finite element model................................. 74

$44 \quad$ Illustration of flexion and extension in the neck..................... 76

45 Experimental versus numerical local head accelerations

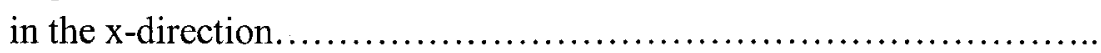

46 Experimental versus numerical local head accelerations

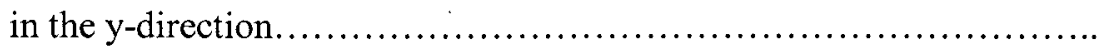

47 Experimental versus numerical local head accelerations in the z-direction

48 Experimental versus numerical local chest accelerations in the $\mathrm{x}$-direction.

49 Experimental versus numerical local chest accelerations in the $y$-direction.

50 Experimental versus numerical local chest accelerations in the z-direction................................................ 83

$51 \quad$ Numerical and experimental images at exact time increments........... 86

52 Hybrid III 3-year-old dummy model in forward and rearward facing configurations.

55 Normally shaped shell elements turn into distored elements through the hourglass effect....

53 Total, kinetic, internal, hourglass, and sliding energies versus time for the forward facing simulation.

54 Total, kinetic, internal, hourglass, and sliding energies versus time for the rearward facing simulation.

$56 \quad$ Resultant upper neck force for forward and rearward facing simulations.

57 Resultant lower neck force for forward and rearward facing simulations.

58 Resultant upper neck moments for forward and rearward facing simulations 


\section{LIST OF FIGURES - continued.}

59 Resultant lower neck moments for forward and

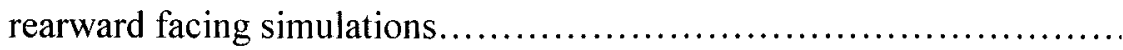

60 Head injury criteria - $\mathrm{HIC}_{15}$ for forward and

61 Head injury criteria $-\mathrm{HIC}_{36}$ for forward and rearward facing simulations.

62 Probability of injury versus head injury criteria $500 \mathrm{HIC}$ window

63 Forward and rearward facing average head acceleration and threshold acceleration versus time duration

64 Forward and rearward facing average chest acceleration versus time duration.

65 Normalized threshold axial neck force, forward $\mathrm{N}_{\mathrm{ij}}$, rearward $\mathrm{N}_{\mathrm{ij}}$, versus time

66 Average neck injury criteria and normalized threshold axial force versus time duration for forward and rearward facing configurations.

67 Forward and rearward numerical simulation images at exact time increments. 


\section{LIST OF APPENDICES}

Page

APPENDIX A - Abbreviated Injury Scale............................... 122

APPENDIX B - Contact Types....................................... 124

APPENDIX C - Numerical Algorithms.................................. 127

APPENDIX D - Material Models......................................... 131

APPENDIX E - Compressive Foam Study ............................... 135

xiv 


\section{LIST OF ABBREVIATIONS}

$\begin{array}{ll}\text { AIS } & \text { Abbreviated Injury Scale } \\ \text { CAD } & \text { Computer Aided Design } \\ \text { CMVSS } & \text { Canadian Motor Vehicle Safety Standard } \\ \text { CRABI } & \text { Child Restraint Air Bag Interaction Dummy } \\ \text { CRS } & \text { Child Restraint System } \\ \text { FE } & \text { Finite Element } \\ \text { FEMB } & \text { Finite Element Model Builder } \\ \text { FMVSS } & \text { Federal Motor Vehicle Safety Standard } \\ \text { FTSS } & \text { First Technology Safety Systems } \\ \text { GM } & \text { General Motors } \\ \text { H3 } & \text { Hybrid III Crash Test Dummy } \\ \text { ISO } & \text { International Organization of Standardization } \\ \text { MAIS } & \text { Maximum Abbreviated Injury Scale } \\ \text { NHTSA } & \text { National Highway Traffic Safety Association } \\ \text { NPTR } & \text { National Pediatric Trauma Registry } \\ \text { PRV } & \text { Protection Reference Value } \\ \text { QSS } & \text { Quality Safety Systems } \\ \text { RID } & \text { Rear Impact Dummy } \\ \text { SAE } & \text { Society of Automotive Engineers } \\ \text { SID } & \text { Side Impact Dummy } \\ \text { SORL } & \text { Seat Orientation Reference Line } \\ \text { TC } & \text { Transport Canada } \\ \text { UMTRI } & \text { University of Michigan Transportation Research Institute }\end{array}$




\section{LIST OF NOMENCLATURE}

$\begin{array}{ll}\mathrm{a} & \text { Acceleration } \\ \beta & \text { Decay Constant } \\ \mathrm{E} & \text { Modulus of Elasticity, Young's Modulus } \\ F_{\text {resultant }} & \text { Resultant Force/Load } \\ F_{x} & \text { Force in the x-direction } \\ F_{y} & \text { Force in the y-direction } \\ F_{z} & \text { Force in the z-direction } \\ F_{Z} & \text { Axial Tensile/Compressive Neck Force } \\ F_{Z C} & \text { Critical Axial Tensile/Compressive Neck Force } \\ H I C & \text { Head Injury Criteria } \\ H I C_{15} & \text { Head Injury Criteria in a 15ms window } \\ H I C_{36} & \text { Head Injury Criteria in a 36 ms window } \\ \mathrm{HU} & \text { Hysteretic unloading factor } \\ M_{\text {resultant }} & \text { Resultant Moment } \\ M_{x} & \text { Moment in the x-direction } \\ M_{y} & \text { Moment in the y-direction } \\ M_{Y} & \text { Bending Flexion/Extension Moment } \\ M_{Y C} & \text { Critical Bending Flexion/Extension Moment } \\ M_{z} & \text { Moment in the z-direction } \\ N_{i j} & \text { Normalized Neck Injury Criteria } \\ \rho & \text { Density } \\ \text { SHAPE } & \text { Unloading shape factor } \\ v & \text { Poisson's Ratio }\end{array}$




\section{INTRODUCTION}

The study of vehicle child safety has been an important issue in the minds of government, vehicle manufactures, and parents. There is substantial statistical information regarding injuries and death of children due to motor vehicle accidents. For instance, in a study released by Statistics Canada [1], it was determined that unintentional accidents are the leading cause of death of children in Canada. Furthermore, it was stated that automobile accidents account for the majority of unintentional deaths among children. In the year 2000, there were 32 deaths and 3,148 injuries due to automobile accidents for children between the ages of $0-4$ in Canada [1]. According to Sachs and Tombrello [2], the National Highway Traffic Safety Administration (NHTSA) estimated that approximately 30,500 children under the age of 5 were injured in motor vehicle crashes in 1997 in the United States, and 604 children under the age of 5 were killed. Almost 200 of the children who were killed were strapped into a child safety seat. Sachs and Tombrello [2] also determined that each year in the United States, 1,400 children under the age of 14 are killed in vehicle collisions and over 280,000 are injured. In a study released by the University of Michigan Transportation Research Institute (UMTRI) [3], Weber determined that young children are at risk for devastating head and neck injuries because of their fragile physiology. This is mainly due to the fact that the head of a young child makes up a large proportion of their weight. Consequently, the centre of gravity of the child is higher than that of an adult. In addition, small children are also prone to neck injuries due to the looseness of their neck muscles. In general, neck injury is thought to occur mostly due to rear-end collisions. However, Mousny et al. [4] found that almost one third of all neck injuries occur in frontal impacts in the United States. This finding suggests that there is more to be learned about children and their injuries in frontal impact vehicle collisions.

In Canada and the United States, the recommended standard for the seating of children in child safety seats states that children should remain rearward facing until the age of 12 months. After this age, governing bodies recommend that children may be positioned in a forward facing child safety seat. The injury potential for children over the age of 12 months in a frontal collision has never been tested in a rearward versus forward facing configuration. Howard et al. [5] studied the cervical spine injuries in children restrained in forward facing child safety seats and they determined that one should keep their child in a rearward facing child safety seat for as long as it is physically possible and comfortable for the child. North American manufactured child safety 
seats do not allow for proper legroom for older children whereas in other parts of the world, namely Sweden, children sit in rearward facing child seats until the ages of 3 and 4 . In a study by Skold [6], it was stated that the child safety seats in Sweden are manufactured in such a way that they are physically able to contain a 3-year-old child and can be properly restrained in a passenger vehicle. Skold suggested that the development of the rearward facing child safety seat for toddlers has reduced the risk of serious injuries.

In North America, there have been no accommodations made for children over the age of 12 months to sit comfortably in rearward facing child safety seats. To test the effects of a rearward facing seat on a 3-year-old child is physically impossible due to the size of child allowed to fit rearward facing. Based on this information, it appears that an investigation into the effects of forward facing and rearward facing child seats in a frontal impact situation may be potentially worthwhile. 


\section{LITERATURE REVIEW}

\subsection{Automotive crash statistics}

There have been several studies done to show the injuries and deaths of children due to automobile accidents. According to Tingval [7], unintentional accidents amongst children account for a greater percentage of injuries than all other factors combined. The proportion of accidents as a main cause of death has grown and today accidents account for more than $30 \%$ of the deaths among children 1-14 years of age in the United States. In a study by Durbin et al. [8], it was stated that motor vehicle crashes are the leading cause of death for children after the age of 12 months and up to the age of 9 and remains a pertinent health problem in the North America. In addition the FMVSS standards released by NHTSA in 2001[9], 202 child occupants under 5 years of age were killed while restrained in child restraint systems and 32,000 others were injured in the United States.

There is a substantial interest in improving the safety of children in passenger cars. Studies by Durbin et al. [8] found that existing child safety seats reduce the risk of fatal injury to young children. In Canada and the United States, the recommended standard for the seating of children in child safety seats states that children should remain rearward facing until the age of 12 months. It is at this age that the child is to be safe when in a forward facing position. However, in Sweden, the recommended practice is for children to remain rearward facing up until the ages of three and four $[3,6,7,10-12]$.

In a study completed by Langwieder et al. [13] in Germany determined that since the introduction of the compulsory use of child restraint systems in cars in the year 1993, restraint rates have risen constantly. These high restraint rates are expressed in a decrease in the number of children killed in cars.

Mousny et al. [4] found that in children younger than 11 years of age, motor vehicle accidents account for $38 \%$ of all cervical spine injuries. In addition to the unfortunate injuries and deaths, Desantis-Klinich et al. [14] found that head injury is the leading cause of health care costs in the United States. Even in minor frontal impacts (impacts that do not reach the accelerations of the FMVSS 213 standard requirements), infants have sustained serious head injuries [14] and neck injuries [4]. 


\subsection{Child safety}

\subsubsection{Current child safety recommendations}

There are recommended standards in North America regarding the restraining of children in passenger cars. The following is a brief introduction into the current standards and research contributing to developing the standards for restraining children in child restraint systems and other systems according to their age and size.

When used properly, child safety seats are life preservers. Research done by Yoganadan et al. [15] has suggested that child restraint systems can reduce an infant's risk of death by $69 \%$ and a toddler's by $47 \%$. Yet millions of children ride without the right kind of restraint. More than one thousand children die every year that are completely unbuckled. Understanding some basic safety seat principles can help protect child passengers.

In a study by Weber [3] dealing with rear facing restraint systems for children, it was stated that child safety seats that face the rear of the vehicle are very effective in preventing serious and fatal injuries to small children. They are especially effective in preventing injuries to the upper spinal cord. Injuries to the spinal cord are rare in young children but typically occur in children in forward facing child restraint systems. Weber [3] has found that stretching forces acting on the neck can be reduced by half when forward facing child dummies are turned to face the rear.

There are recommended standards that parents should practice when protecting their child in a vehicle. The standards vary according to the size of the child being restrained and are similar in Canada and the United States. These standards and accompanying figures were obtained through Shell: Kids in the Car [16], unless otherwise specified.

Rear-facing infant car seats are small and portable and fit newborns best (Figure 1a). These are not to be confused with infant carriers, which cannot be restrained in a vehicle. These rearward facing car seats are best suited for newborn babies until they reach one year of age or until they reach $9 \mathrm{~kg}$.

Convertible seats (Figure $1 \mathrm{~b}$ ) are those that can be converted from rearward facing to forward facing and are best suited for toddlers between the ages of one and four and who weigh between 9 and $18 \mathrm{~kg}$. 
Booster seats (Figure $1 \mathrm{c}$ ) are used as a transition to safety belts by older children who have outgrown the convertible child safety seat but have not reached the appropriate size to be properly restrained in an adult restraint system. It is also recommended that if the vehicle in which the child is to be restrained only has lap belts, a shield booster should also be used.

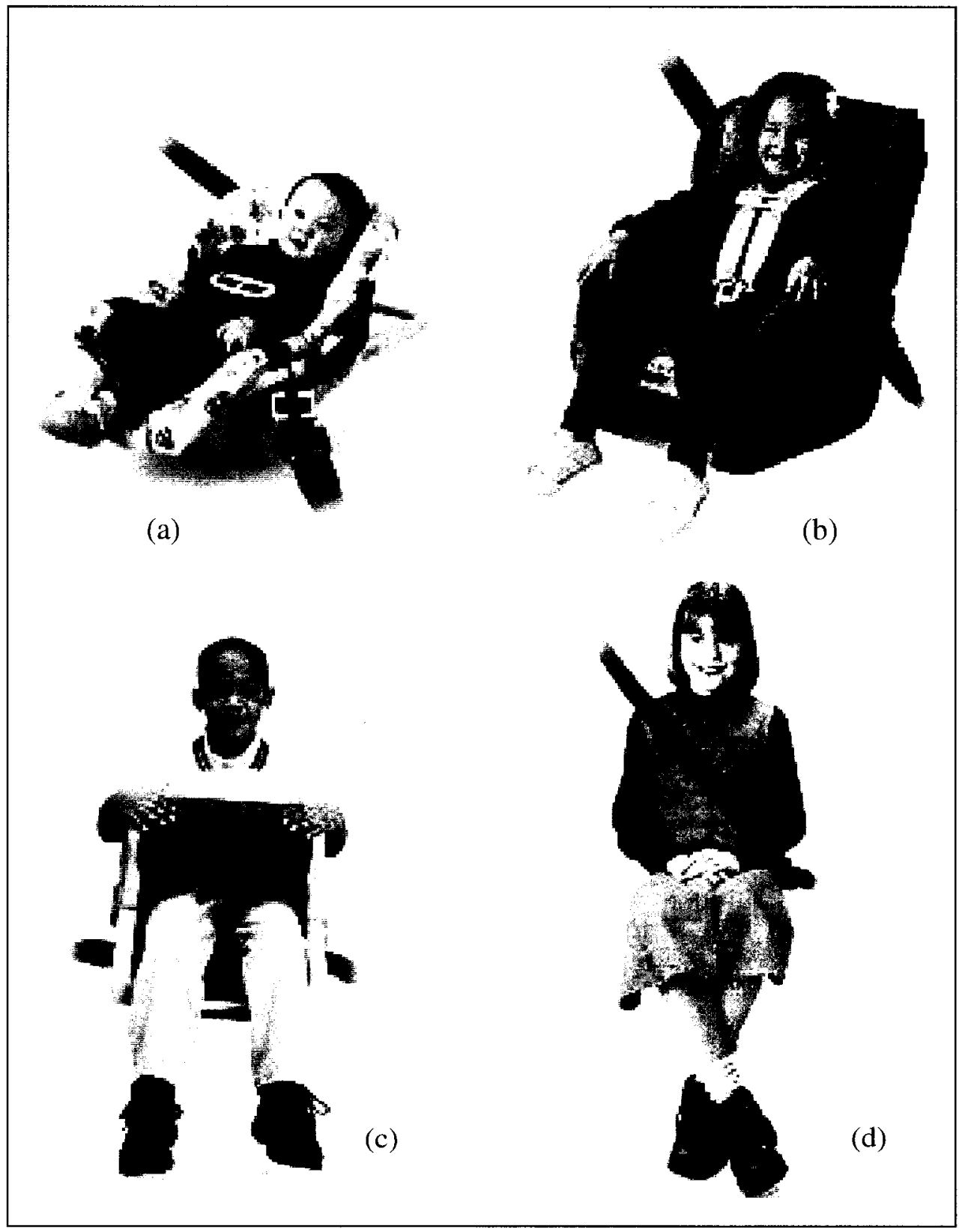

Figure 1. Suggested modes of restraint for various ages and sizes of children: (a) rear facing car seat, (b) convertible child safety seat, (c) booster seat with a shield booster is used when only lap belts are available, and (d) child weighing 36 $\mathrm{kg}$ or over eight years of age should fit properly in adult restraints [16]. 
Typically, children over $36 \mathrm{~kg}$ and eight years of age can fit correctly in lap/shoulder belts.

In a study carried out by Arbogast et al. [17], it was determined that in 1998, 140 children younger than 1 year of age were killed in motor vehicle crashes in the United States, and close to half of those children killed were restrained. Arbogast et al. [17] stated that the appropriate and correct use of child safety seats is essential and can reduce an infant's risk of death in a crash by $71 \%$. Furthermore, it was established that $80 \%$ of the safety seats observed had at lease one of six selected usage errors. These errors included incorrect seat orientation, incorrect use of vehicle seat belt, incorrect use of locking clip, harness not buckled, incorrect routing of harness, and incorrect use or fit of chest clip. Kullgren et al. [18] also found that in the United States, voluntary checkups showed that more than $95 \%$ of the safety seats inspected have one or more errors.

Research by Arbogast et al. [17] stated that most infants are safest in a motor vehicle when facing the rear of the vehicle. The majority of motor vehicle crashes are frontal impacts. In a frontal crash, the back of the rear-facing child safety seat supports the child's head, neck, and back. The American Academy of Pediatrics and NHSTA recommend that children ride facing the rear of the vehicle until they reach both one year of age and a weight of $9 \mathrm{~kg}$. This guideline was based on the fact that the infant's spine is not fully developed and therefore the child is at risk for spinal cord injury.

Convertible seats come in three harness types: the T-shield, the tray shield, and the five-point harness, as illustrated in Figure 2. Although all three types of harness meet the same FMVSS standards, the five-point harness typically fits best for an infant. The five-point harness can be adjusted to the infant's small body, allowing the forces of a crash to be better distributed.

Another contribution from Arbogast et al. [17] was that common misuse among parents using rear-facing infant seats is the use of additional products that did not come with the seat, known as aftermarket products. One common product is a pad that is placed behind the child's head and back. This product, as well as other products that do not come with the seat, is not covered by a current federal safety standard and thus is not crash tested to meet any specific criteria. 


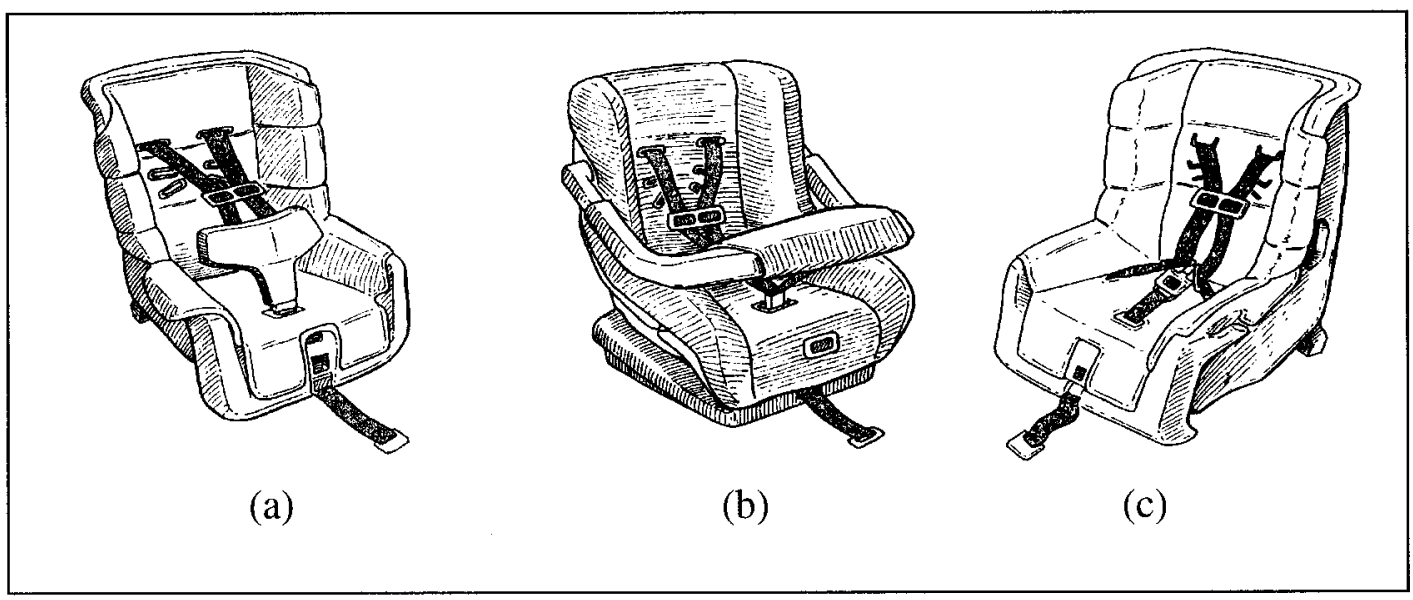

Figure 2. Three types of convertible child safety seats: (a) T-shield CRS, (b) trayshield CRS, and (c) 5-point CRS [17].

In a study by Gotschall and Luchter [19] assessing head injuries to vehicle occupants aged 0-5, it was found that a rear-facing child seat could benefit a young child in a crash. It stated that one of the purposes of motor vehicle occupant restraints is to alleviate the frequency and severity of head injuries in motor vehicle crashes. The federal standard for child restraint systems, FMVSS 213, provides testing and performance standards for the foam padding that is used in infant and child safety seats. The goal of this standard is to limit the acceleration levels experienced by the head and thorax of test dummies to levels intended to simulate fatal injuries to both of these regions. Weber's study [3] determined that although infant seats sold in the United States conform to U.S. federal standards, improvements in seat design and changes in the padding used to cushion the seat backs may offer important opportunities to provide better protection against non-fatal skull fracture.

Another noteworthy finding by Weber [3] stated that safety seat misuse may also contribute to the increased risk of skull fractures in infancy. Weber referenced that the National SAFE KIDS Campaign completed a study and found that for 17,500 restrained children, $30 \%$ of infant seats were not correctly adjusted to a 45 degree angle for the seat back and that $35 \%$ of seats did not have the harness straps adjusted securely enough. The combination of loose harness straps and a seat adjusted to an angle greater than 45 degrees can allow an infant's head to displace far enough such that the chin would impact its chest. 
According to Statistics Canada [1], trauma related to motor vehicle collisions remains the leading cause of death and injury to children in Canada. It has been discovered unintentional injuries are the leading cause of death among children and youth. Most of these unintentional injuries were due to motor vehicle accidents.

In a study by Skold [6], it was stated that young children, by virtue of their developing anatomy, require special consideration in terms of their effective restraint in motor vehicles. To this end, considerable effort is paid to developing stringent regulations, designing, and testing appropriate automotive systems, and advising vehicle users of the proper use of child restraints, seat belts, and supplementary airbag systems. Despite all such activities on the part of governments, the automotive industry, and traffic safety groups, nonuse or misuse of occupant restraint systems remains a considerable problem.

\subsubsection{Social impact of child safety regulations}

According to Winston et al. [20], parents expressed concern that their infants are uncomfortable in rear facing child safety seats or that they cannot see their children during the ride and consequently put their children in compromising positions while traveling in passenger cars. In a publication by Kullgren et al. [18], it was noted that some parents may also fear that if the child's legs are touching the back of the seat, the child could sustain ankle or leg injuries. However, this study determined that lower leg fractures have not been identified as a significant problem for children restrained in the rear facing child safety seats.

Diekema and Allen [21] found that the recommendation regarding the appropriate age to change the direction of a convertible safety seat is still debated. This study noted that parents should be encouraged to keep their children facing the rear of the vehicle for as long as possible while following the manufacturer's instructions for their child safety seat. In a study regarding children involved in motor vehicle crashes referred to by Kullgren et al. [18] called Partners for Child Passenger Safety, results showed that $30 \%$ of children less than 1 year of age were turned facing forward.

Kullgren et al. [18] also noted the angles at which child safety seats should be placed. Rear-facing infants should ride semi-reclined, at a $45^{\circ}$ angle, to keep the child's airway 
unobstructed during a car ride. This is particularly important for newborn babies. Seating the newborn too upright could cause the head to lean forward and potentially block the airway. Some parents have difficulty installing the child seat at this angle because most vehicle seats are tilted toward the rear of the vehicle, making the proper angle difficult to achieve.

Another noteworthy finding by Kullgren et al. [18] was that parents often prematurely graduate their children from the child safety seat to adult seat belts and also place them in the front passenger seat of a vehicle. Children prematurely placed into poorly fitting seat belts are at risk for fractures of the spine and serious intra-abdominal injuries, or what is known as seat belt syndrome. Furthermore, in a study by Huelke et al. [22], it was stated that children seated in the front passenger seat are at increased risk for serious or fatal head, neck, and other injuries due to airbag deployment.

Winston et al. [20] referred to a study carried out by a partnership between The Children's Hospital of Philadelphia and the State Farm Insurance companies and determined that child safety seats are primarily used for children ages 0-4. Figure 3 demonstrates the type of restraint systems used by children in various age categories.

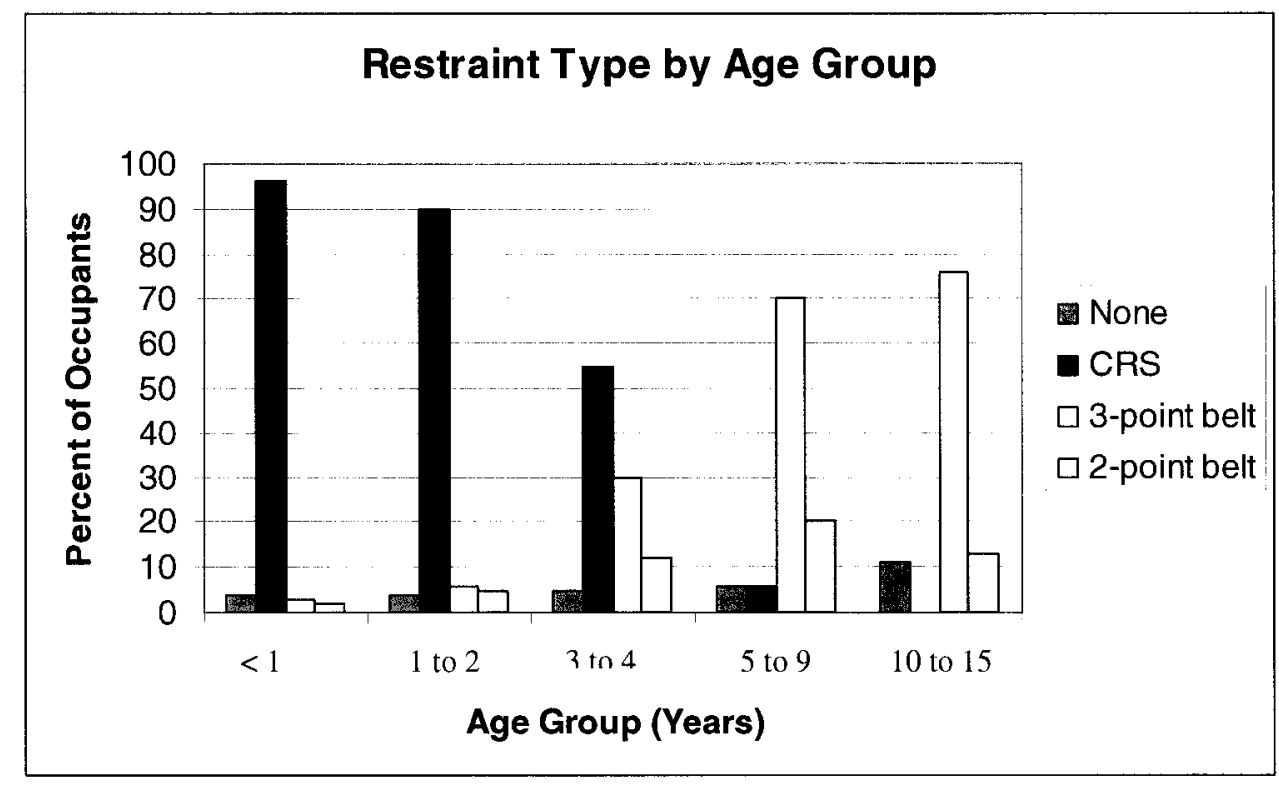

Figure 3. Restraint type use by age group [20].

Figure 3 illustrates that from the ages of $0-4$, child safety seats are used as a method of restraint. However, once the ages of 3 and 4 are reached, other restraint mechanisms are used such as three or two point belts. This may indicate premature graduation into more adult-type restraining 
mechanisms. Skold [6] stated that this is quite possibly a social problem as much as a biomechanics problem. Parents make judgments as to how to restrain their children based on several variables including size of the child, size of the child restraint system as well as child persistence to be treated, and therefore restrained, as an adult.

In Sweden, the age that a child remains sitting in a rearward facing child restraint system is around 3 and 4 years of age. If a child under the age of three is restrained in a forward facing child safety seat, it is considered as misapplication of a child safety seat by child safety experts in Sweden. In addition, they consider countries that have the standard of facing the child forward after the 1 year of age, such as in Canada and the United States, to have less developed child protection strategies [3,6,7,10-12]. According to BMW World [23], fewer than 2 children a year die in rear facing child safety seats. Other countries with low child fatality rates include the Netherlands, England, Norway, and Germany. It was previously mentioned that the death rates for children under the age of 5 in the United States and Canada are 604 and 32, respectively. The populations of the United States, Canada, and Sweden are 290 million, 32 million, and 8.9 million, respectively [24-26]. The percentage of child deaths compared to the total population of their respective countries was calculated and then normalized with respect to Sweden's death percentage. In doing this, it was determined that for every child that dies in a vehicle collision in Sweden, 4.45 and 9.27 children die in Canada and the United States respectively. 


\subsection{Clinical observations regarding child injury in forward facing positions}

This section investigates various cases where children were injured and even fatally wounded in vehicle collisions. The third and fourth cases arose from the author's affiliation with Dr. Andrew Howard, an orthopaedic surgeon at The Hospital for Sick Kids in Toronto and are noted as reference 27. These two cases studied in Toronto are quite specific and allowed for particular analysis of the injuries incurred by the young child passengers.

\subsubsection{Rear facing infant placed in front passenger side seat of vehicle - Case 1 [28]}

In this case, an infant less than one year of age, was properly positioned in the car seat and was also rear facing, following the recommended standard for a child of his age in Canada. However, the child was placed in the front passenger seat of the vehicle instead of in the rear seat. This child suffered a skull fracture and subdural haemorrhage caused by the deployment of the airbag.

\subsubsection{Toddler placed in front passenger seat of vehicle with no CRS - Case 2 [28]}

In this case, a four year old boy was sitting in the front seat and suffered a fractured left orbit and maxilla, laceration of the left scalp, bruising to the right arm, and a right brachial plexus traction palsy due to airbag deployment. The airbag accelerated the child's head against the vehicle interior.

Both of these children might have been spared the injuries they sustained if they were properly restrained. Although the injuries incurred to the children were attributed to airbag deployment, there are other factors involved. For instance, in Case 1, the child should have been placed in the rear seat of the car. It is believed that the child would have suffered less injury this way due to being placed away from the airbag as well as being far removed from the impact site of the crash. It is accepted practice to restrain young children, especially infants, in the rear of the vehicle. This can possibly be attributed to a social issue where the parent feels best if the child is seated close to him/her so that the child can be fed and looked after while driving.

In the case of the four year old boy in Case 2, the child might have been better restrained if placed in a booster seat as well as if he was placed in the rear seat of the vehicle. Again, this child's 
injuries might have been avoided if recommended restraint precautions were taken into consideration.

\subsubsection{Forward facing 23-month-old child in rear of vehicle - Case 3 [27]}

This particular collision involved a head on collision between a 1994 Honda Accord 4-door sedan and a 1988 Chevrolet Astro 3-door minivan. The condition of the Honda Accord is shown in Figure 4.

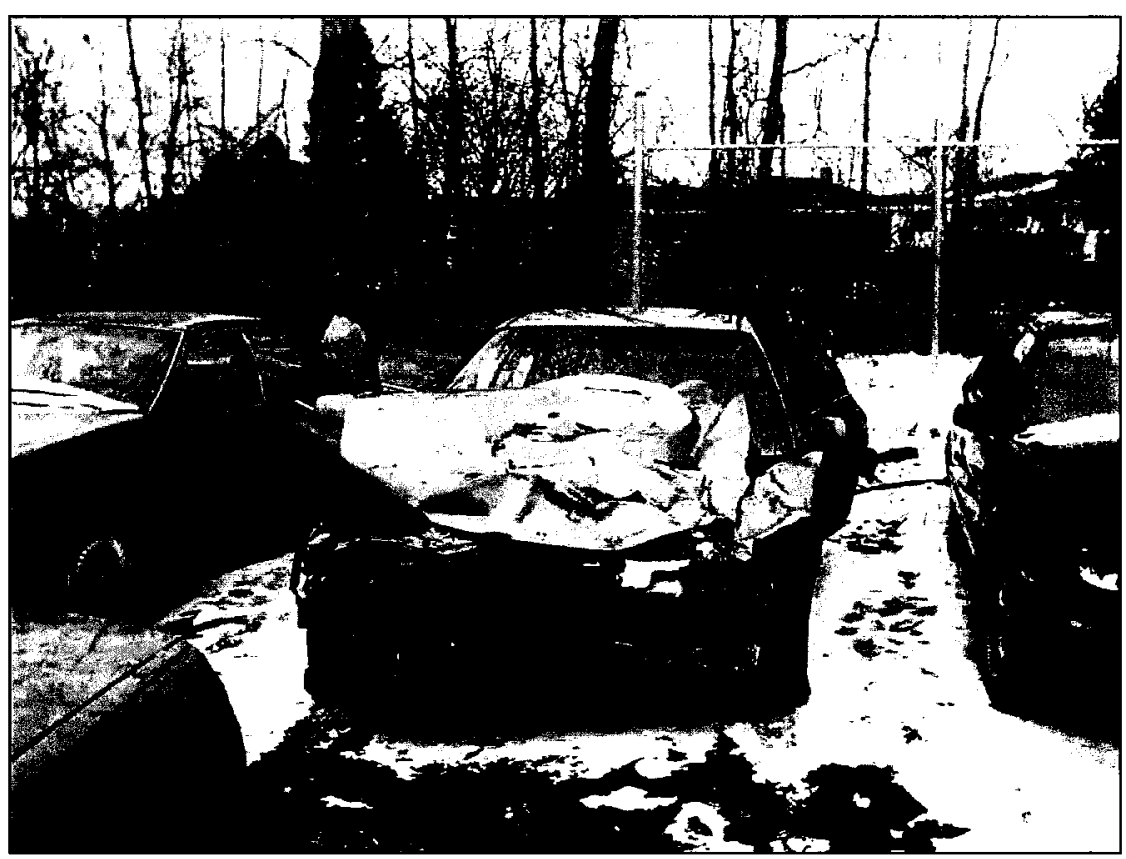

Figure 4. Photo of the final condition of the 1994 Honda Accord 4-Door sedan involved in Case 3 [27].

When driving on a snow covered roadway, an oncoming minivan lost control and crossed the median striking the Honda Accord. The Honda Accord sustained direct damage to the left portion of the front bumper. The approximate change in velocity for the Honda Accord was calculated as $40 \mathrm{~km} / \mathrm{h}$, classifying this as a severe collision. A schematic diagram of the dynamics of the collision is shown in Figure 5. The driver of the Honda Accord was a 38-year-old male restrained with the available 3-point belt. His injuries included a pneumothorax, chest contusions, fractured right hand, sprained ankle and chest contusions. The front seat passenger was a 35-year-old female who was 5 months pregnant and restrained with the 3 point seat belt. Neither she nor her fetus suffered any injuries in this collision. 


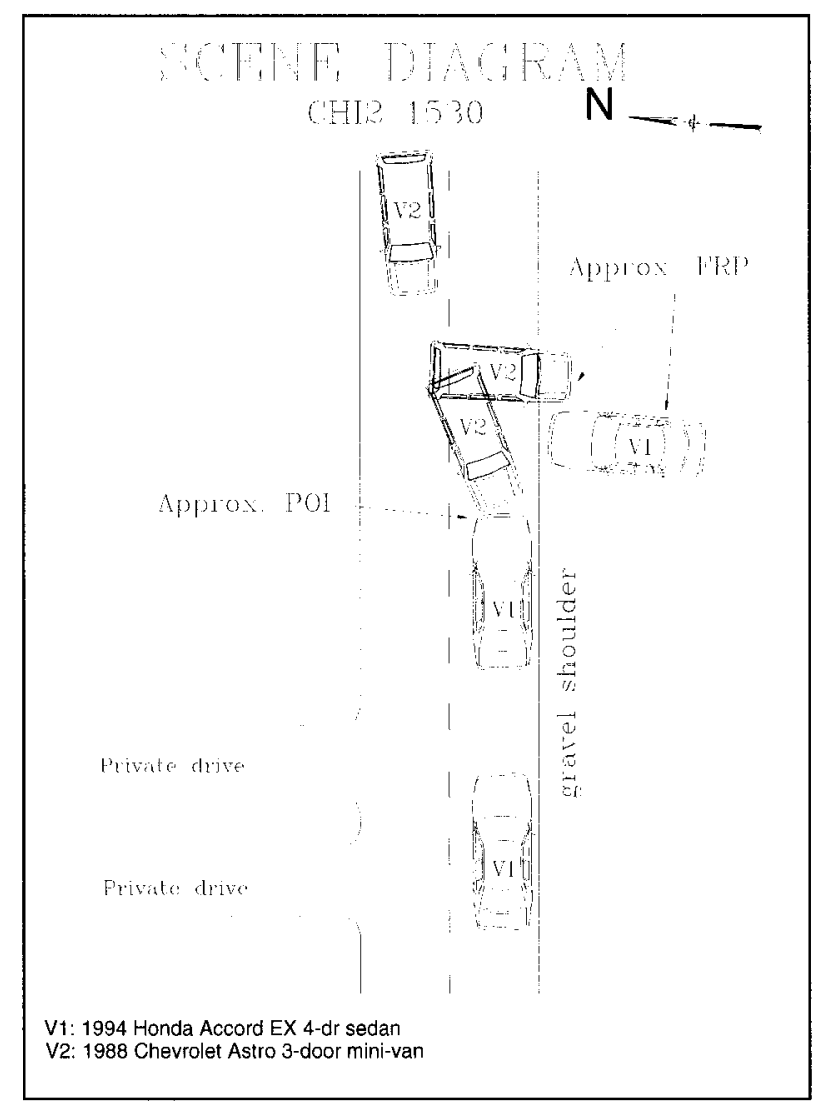

Figure 5. Schematic diagram of the dynamics of the collision in Case 3 [27].

A previously healthy 23 -month-old boy was riding in the rear center seat of the vehicle. The child was seated in a forward facing overhead shield style child restraint, which was attached to the vehicle using the locking tongue lap belt and the tether strap. This restraint was appropriate for the age and size of the child according to Transport Canada (TC) standards. Figure 6 illustrates the child safety seat involved in the collision as well as the previously mentioned tether bolt and strap. 


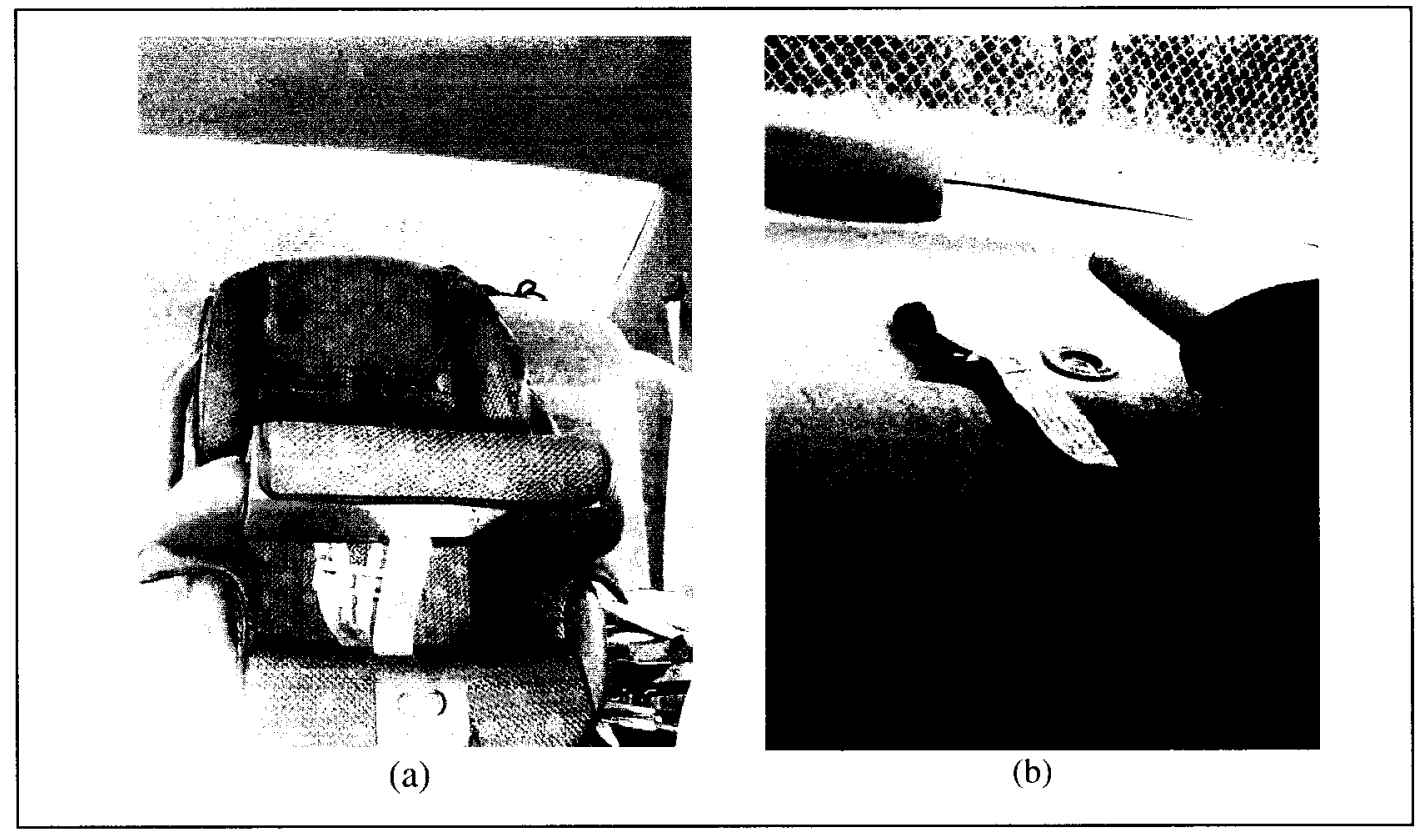

Figure 6. Child safety seat conditions for Case 3. (a) child safety seat involved in the collision, and (b) tether strap used which was attached to the back of the child safety seat and is anchored to the back shelf of the vehicle seat [27].

The 23-month-old boy suffered a fatal occipitocervical dislocation. This injury is illustrated by the arrow in the x-ray of his head and neck region in Figure 7.

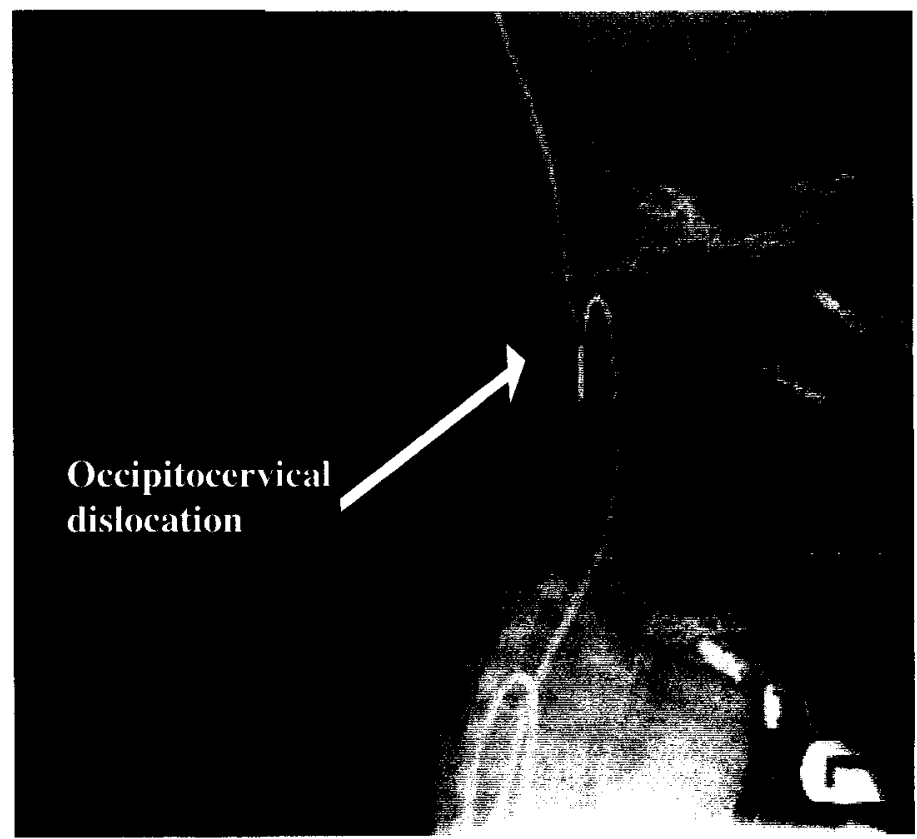

Figure 7. Occipitocervical dislocation in the 23-month-old male involved in Case 3 [27]. 
The young boy was removed from the vehicle at the scene and had shallow, infrequent breathing. The patient's initial Glasgow Coma Scale score was 3. The Glasgow Coma Scale is used to determine the severity of a coma. The scale ranges from 3 to 15,3 being the worst and 15 being the best. Paramedics incubated the child and transported him to the local hospital. At this location, he had spontaneous leg movements and was able to withdraw from painful stimuli. His pupils were dilated and fixed. The only external signs of trauma were a small laceration to the tongue and a small abrasion to the chin. A computed tomography (CT) scan showed cerebral edema. He was transferred to the regional pediatric trauma center. Physical findings at this hospital found bilateral lung contusions. On plain radiograph, there was evidence of an abnormal widened distance between the occipital condyles and C1 arch. On the CT scan there was evidence of atlanto-occipital dissociation, extradural and intradural hemorrhage and atlanto-axial sublaxation. The child went to the operating room where his tongue laceration was repaired and an intracranial pressure monitor was placed. He also received a left sided chest drain for bilateral lung contusions and a suspected pneumothorax. The child died three days after admission as a result of his injuries.

\subsubsection{Forward facing 35-month-old child in rear of vehicle - Case 4 [27]}

Another documented case where an appropriately restrained child sustained serious injuries involves a previously healthy 35-month-old female riding in the rear passenger side seat of a Toyota 4Runner. The child was seated in a forward facing five point child safety seat. The orientation of the child seat as it was positioned in the vehicle can be seen in Figure 8. This seat was properly restrained in the vehicle using the available three point belt and a tether strap. This restraint was appropriate for the age and size of the child. 


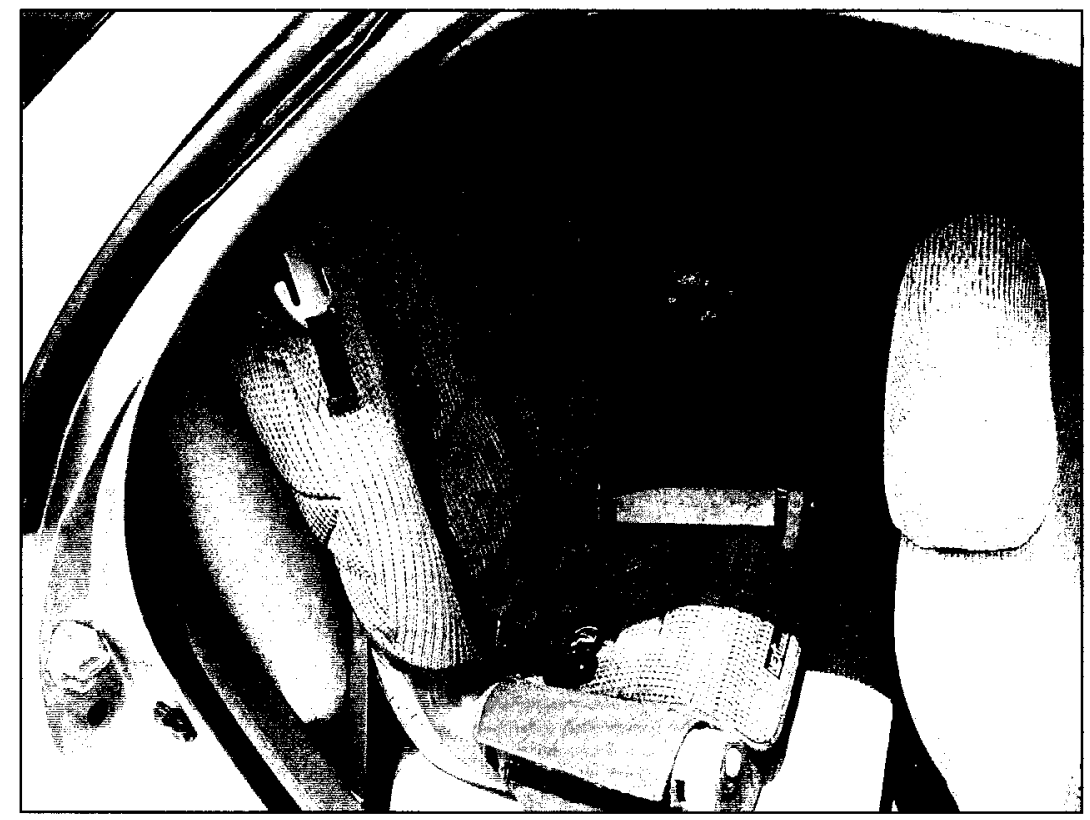

Figure 8. Orientation of the child safety seat in Case 4 [27].

The 4Runner was driving on a two-lane highway in heavy rain. The driver hydroplaned on the wet road, lost control of the vehicle and hit a rock protruding $60 \mathrm{~cm}$ up from the ground. Figure 9 is a schematic diagram illustrating demonstrates the dynamics of the single car collision. 


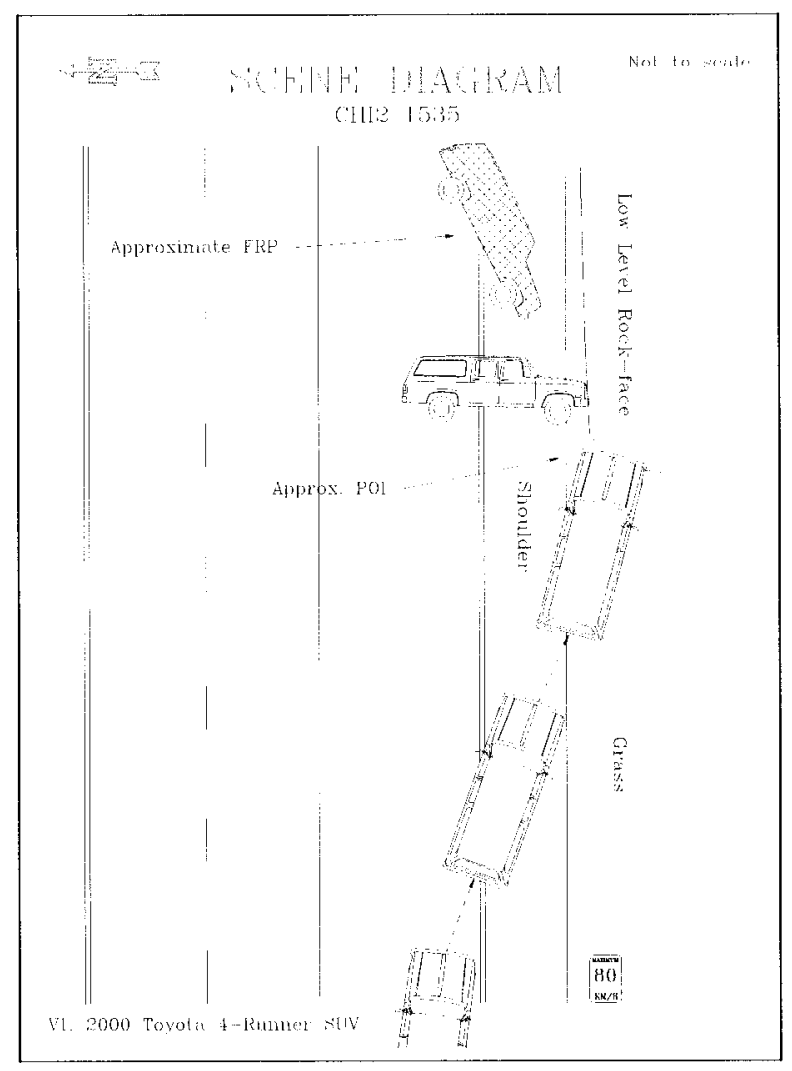

Figure 9. Schematic diagram of the dynamics of the collision Case 4 [27].

The change in velocity for the Toyota 4 Runner was calculated as $80 \mathrm{~km} / \mathrm{h}$, which categorized the collision as severe. The final condition of the Toyota 4Runner is shown in Figure 10.

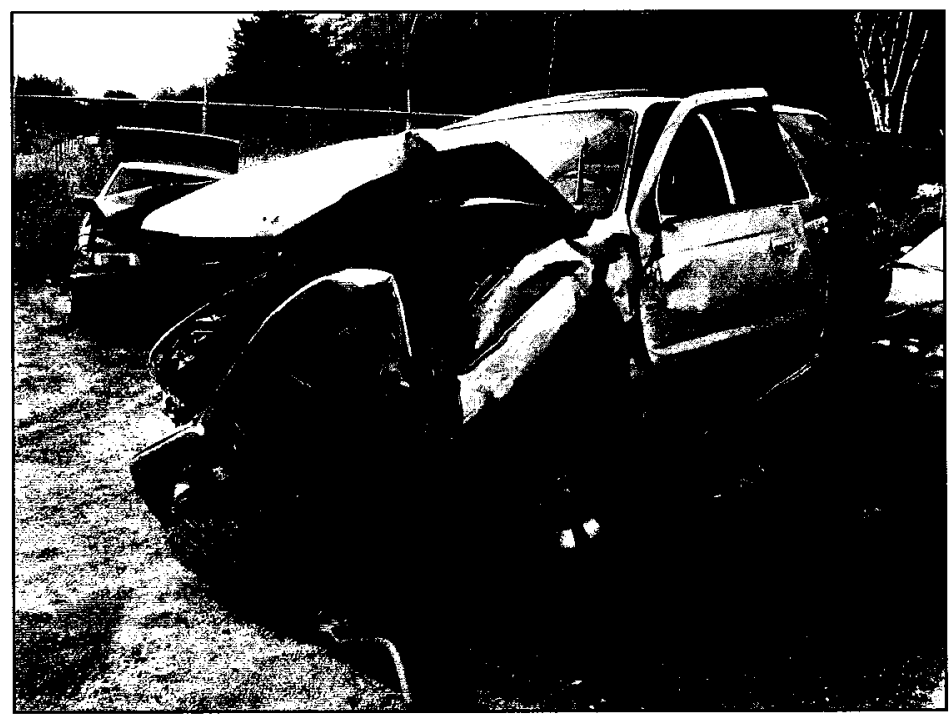

Figure 10. Final condition of the Toyota 4Runner involved in Case 4 [27]. 
The 35-month-old female was initially assessed at a small rural hospital. The only external sign of injury to the young child was a large abrasion to the chin and slight abdominal bruising. On an $\mathrm{x}$-ray, there was evidence of a $\mathrm{C} 2$ fracture through the base of the odontoid process. This is illustrated in Figure 11. The child was transferred by air to the regional pediatric trauma hospital. At this hospital a slightly comminuted C2 fracture at the base of the odontoid through the growth plate was confirmed by plain film and CT scan. There was soft tissue swelling but no spinal cord compression.

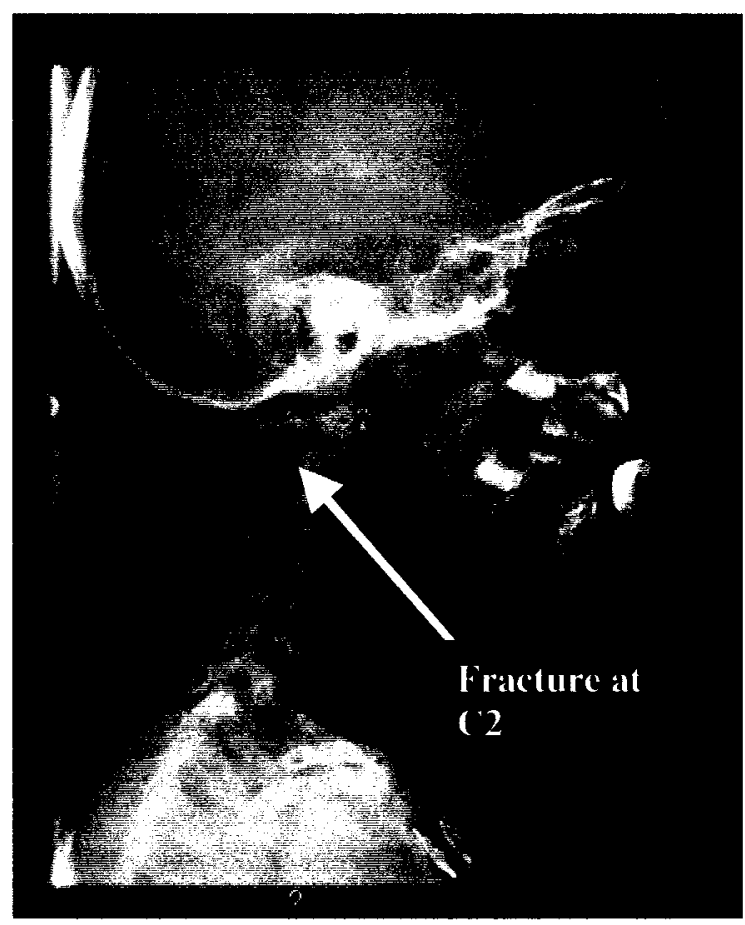

Figure 11. Angulated fracture of the cervical spine (C2) in child of Case 4 [27].

Research undertaken by Dr. A. Howard et al. [5], determined that motor vehicle crashes cause a large proportion of children's cervical spine injuries. Twenty percent of the injuries are fatal. This study focused on cervical spine injuries in children restrained in forward facing child restraints. It was stated that children facing the rear of the vehicle do not suffer from the same cervical spine injuries as those children that face forward. An interesting inference was made suggesting that "raising the age at which children are turned from rear to forward facing might prevent catastrophic neck injuries among North American toddlers [5]." In addition there were 
circumstances reported where children older than one year of age that are properly restrained and sustain cervical spine injuries. Interestingly, Dr. A. Howard et al. [5] found that there are no documented cases of fatal cervical spine injury to children who are restrained in rearward facing child safety seats. 


\subsection{Injury}

\subsubsection{Head injury in children during collision}

Gotschall and Luchter [19] determined that head injuries are the leading cause of injury, death, and disability among children in the United States in their study about head injuries to motor vehicle occupants encompassing the ages from 0-5 years. In fact, Weber [3] suggested that as many as three quarters of all traumatic deaths to children are the direct result of brain injury. Head injury was a common traumatic outcome among children and accounts for $26 \%$ of all injuries recorded in the National Pediatric Trauma Registry (NPTR) and 34\% of all injuries resulting in 4 or more functional limitations. It was determined that $49 \%$ of children admitted to a regional pediatric trauma center with Abbreviated Injury Scale (AIS) values equal to or greater than two (see Appendix A for AIS/MAIS injury scale) had experienced head trauma.

Gotschall and Luchter's study [19] determined that motor vehicle crashes are a major source of head injury to children. It was determined that $23 \%$ of the total head injuries to children aged $0-4$ years were traffic related. In Geneva, traffic related injuries were responsible for $15 \%$ and $17 \%$ of head injuries experienced by girls and boys, respectively, younger than 4 years of age. It was also reported that children $0-3$ years old sustained more skull fractures and more subdural hematomas than older children.

In a study regarding head injury criteria by Desantis-Klinich et al. [14], it was suggested that pediatric head injury criteria based on biomechanical testing are rare. Stating that children are not miniature adults, Desantis-Klinich [14] pointed out that the anatomical differences such as size and shape are obvious and others are not so evident. For example, impact tolerance is not something that can be scaled down from adult to child. Therefore, a child should never be estimated as a smaller adult. However, even today there is not accepted biomechanical data or impact tolerance on children. Huekle et al. [22] also suggested that even basic information on a child's anthropometric data is scattered and difficult to find. This is likely due to ethical reasons that would prohibit using child cadavers for such testing.

Weber [3] stated that injury to the skull and brain of a child differs significantly from that of an adult. One suggested possible reason for the differences in injury patterns between very young children, older children and adults is that the physical properties of the human body, such as 
overall mass distribution and the elasticity of the bones, undergo major changes from the birth through maturity. Also, at birth, the head comprises about one quarter of the body length, but by early adulthood, the head is only about one eighth of the body length.

Eman et al. [29] stated that infants and young children have a disproportionately large head, with a high center of gravity and a weaker neck structure resulting in relatively poor head support. Furthermore, in studies by Huelke et al. [22] and Lau et al. [30], it was stated that due to the large size of a child's head compared to its body, the weak cervical spine musculature, and ligametous laxity the infant could be subjected to uncontrolled and passive cervical spine movements and possibly to compressive or distraction forces in impact deceleration environments. These factors contribute to a high incidence of injury to the upper cervical spine.

Weber [3] noted that not only does the head change in size, it also changes in composition. The fetal skull, formed by the fusion of several cartilaginous plates, must be deformable enough to survive the birthing process. During the trauma of the birth process the parts of the skull undergo molding. Weber [3] ascertained that these changes in the composition of the head have an effect on the types of injuries that infants experience in response in traumatic experiences. Burdi et al. [31] determined that at birth the infant skull has open suture lines and the effect of trauma on the infant skull is local, with reduced transmission through the brain. As the skull develops, the suture lines are joined but ossification is incomplete. In this intermediate stage of development the skull will absorb some of the energy of trauma and lessen the forces transmitted to the brain. When the skull has become completely ossified it can be considered a rigid box. At this stage the forces of trauma are transmitted in all directions through the brain and its fluid envelope.

An overabundance of clinical, experimental, and mathematical investigations were conducted to mark out the response of the adult human load bearing systems under physiologic and traumatic loading. Widely accepted head injury criteria have been based on early studies of the skull and brain. Correspondingly, human spinal column studies have focused on adult tolerances under various modes of loading. Studies describing the tolerance of the adult human thorax/chest under frontal and side impact loading modalities also exist. Likewise, the tolerances of the upper and lower extremities have also been explored for adults. According to Skold [6], despite these efforts, a scarcity of this data remains for children. 
Since there is a lack of accepted biomechanical data for children, experts have had to resort to rather complex methods for injury estimation. There has been much work done to demonstrate how human tolerance developments can be applied to the child population. The author of this thesis will outline only the neck region to outline the clear differences between a child's neck and an adult's neck.

The following tables (Tables 1-4) show material properties of the spine for children aged one, three, six, and eleven. There is one material property in particular that change as the child increases in age. The disc annulus fibers stiffen from $400 \mathrm{MPa}$ to $475 \mathrm{MPa}$ as the child grows from one year to eleven years old.

Table 1. One-year-old spine material properties [15].

\begin{tabular}{ccc}
\hline Components & Young's Modulus (MPa) & Poisson's Ratio \\
\hline Vertibral centrum & 75.0 & 0.29 \\
Growth Plate & 25.0 & 0.40 \\
Costal Cartilage & 25.0 & 0.40 \\
Posterior elements & 200.0 & 0.25 \\
Posterior synchondrosis & 25.0 & 0.40 \\
Neurocentral cartilage & 25.0 & 0.40 \\
Disc annulus ground substance & 4.2 & 0.45 \\
Disc annulus fibers & $400(10 \%)$ & 0.30 \\
Articular cartilages & 10.4 & 0.40 \\
Synovial fluid (bulk modulus) & 1666.7 & $\mathrm{~N} / \mathrm{A}$ \\
Synovial membrane & 12.0 & 0.40 \\
\hline
\end{tabular}

Table 2. Three-year-old spine material properties [15].

\begin{tabular}{ccc}
\hline Components & Young's Modulus (MPa) & Poisson's Ratio \\
\hline Vertibral centrum & 75.0 & 0.29 \\
Growth Plate & 25.0 & 0.40 \\
Costal Cartilage & 25.0 & 0.40 \\
Posterior elements & 200.0 & 0.25 \\
Neurocentral cartilage & 25.0 & 0.40 \\
Disc annulus ground substance & 4.2 & 0.45 \\
Disc annulus fibers & $425(15 \%)$ & 0.30 \\
Articular cartilages & 10.4 & 0.40 \\
Synovial fluid (bulk modulus) & 1666.7 & $\mathrm{~N} / \mathrm{A}$ \\
Synovial membrane & 12.0 & 0.40 \\
\hline
\end{tabular}


Table 3. Six-year-old spine material properties [15].

\begin{tabular}{ccc}
\hline Components & Young's Modulus (MPa) & Poisson's Ratio \\
\hline Vertibral centrum & 75.0 & 0.29 \\
Growth Plate & 25.0 & 0.40 \\
Posterior elements & 200.0 & 0.25 \\
Disc annulus ground substance & 4.2 & 0.45 \\
Disc annulus fibers & $450(15 \%)$ & 0.30 \\
Articular cartilages & 10.4 & 0.40 \\
Synovial fluid (bulk modulus) & 1666.7 & $\mathrm{~N} / \mathrm{A}$ \\
Synovial membrane & 12.0 & 0.40 \\
\hline
\end{tabular}

Table 4. Eleven-year-old spine material properties [15].

\begin{tabular}{ccc}
\hline Components & Young's Modulus (MPa) & Poisson's Ratio \\
\hline Cortical shell & 6000.0 & 0.3 \\
Cancellous core & 100.0 & 0.2 \\
Endplate & 150.0 & 0.3 \\
Uncinates & 150.0 & 0.3 \\
Posterior elements & 1700.0 & 0.25 \\
Disc annulus ground substance & 4.7 & 0.45 \\
Disc annulus fibers & $475(25 \%)$ & 0.30 \\
Articular cartilages & 10.4 & 0.40 \\
Synovial fluid (bulk modulus) & 1666.7 & $\mathrm{~N} / \mathrm{A}$ \\
Synovial membrane & 12.0 & 0.40 \\
\hline
\end{tabular}

Howard [32] stated that annular fibers provide primary tensile strength. They are critical to the load bearing function of the disc. In young children, this disk has a jelly-like nucleus surrounded by strong annular fibers. Some fibers run vertically along the vertebra and others run around the circumference of a particular disc. When the spine is loaded in tension, the disc's nucleus provides shock absorption, damping, and the ability to move in some bending and rotation. The annular fibers are tensile elements that contain the soft disc and hold it together. Young children have a lot of growth cartilage. As the children grow, they make more annular fibers. Once a person reaches middle age, the annulus wears out and the nucleus dries out. 
Figure 12 shows the typical cervical vertebrae as viewed from the top (top row), side (middle row), and front (bottom row). The columns from left to right represent the vertebrae of a one year old, three year old, six year old, eleven year old, and that of a fully grown adult, respectively. Cartilage is shown in the light gray and bony components are represented by darker regions. Secondary ossification is represented by the darkest background. It is clear that there is an increase in the darkest regions as the age increases. This implies pictorially that as a person ages, their neck becomes stiffer, and therefore behaves differently.

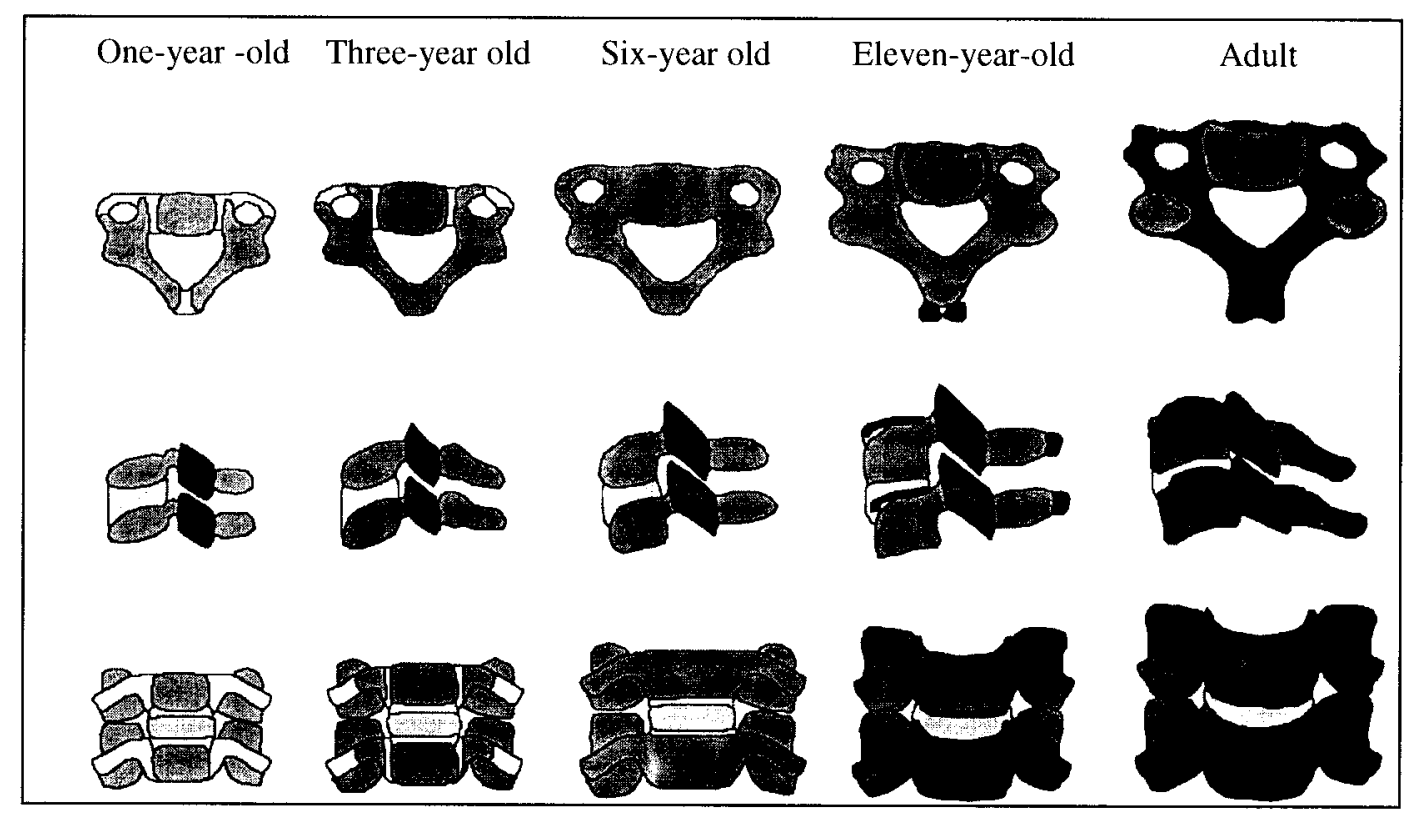

Figure 12. Typical cervical vertebrae for ages one, three, six, eleven, and adult [15].

The head region also undergoes mechanical changes with age. The skull, or cranial bone, increases stiffness with age. Table 5 illustrates these changes in material properties of the cranial bone. The stiffness ratio is calculated as a comparison to the skull stiffness of an adult.

Table 5. Material properties of the cranial bone [15].

\begin{tabular}{cccc}
\hline Parameter & Six-year-old & Three-year-old & 12-month old \\
\hline Elastic Modulus (GPa) & 7.363 & 5.722 & 4.398 \\
Stiffness Ratio & 0.733 & 0.588 & 0.312 \\
\hline
\end{tabular}


The changes in mechanical properties of the head, neck (and other regions of the body not explored here) demonstrate why child passengers cannot be restrained as adults in a vehicle.

\subsubsection{Neck injury in children during collision}

Although neck injury is mostly regarded as resulting from rear-end collisions, Mousny et al. [4] determined that almost one third of all neck injuries occur in frontal impacts in the United States. Protecting children in collisions renders several challenges because, compared with adults, they have less neck strength and their heads represent a higher proportion of their total body weight. These physical factors tend to exacerbate head and neck injuries. Furthermore, Gotschall and Luchter [19] found that when small children are restrained by regular seat belts instead of child seats, there may be excessive slack in the belts, and the children may not be snugly restrained. These and other misuses of restraints have been found to be prevalent among children in vehicle collision.

There have been concerns that a child's cervical spine could be pulled apart from the force on the head in a crash when the shoulders are held back. Parents have a misconception that a child's muscle strength when the child is sitting erect can overcome the force of a frontal crash [33]. In a $50 \mathrm{~km} / \mathrm{h}$ crash with a deceleration of $25 \mathrm{~g}$ 's, the head of a forward facing adult or child could experience up to 70 g's. It was stated by Weber [33] that even the strong muscles of crash volunteers from the military make little difference in such a severe environment.

In this study by Weber [33], it was also stated that adult cervical spines can withstand severe decelerations up to $100 \mathrm{~g}$ 's, and failure is almost always associated with fracture. A child's immature vertebrae consist of both bony segments and cartilage, and the ligaments are loose to accommodate for growth. This combination allows the soft vertebral elements to deform and separate under crash conditions, leaving the spinal cord the last link between the head and the torso. In a study by Huelke et al. [22], it was found that in autopsies of infants, the elastic vertebral bodies and ligaments allow for column elongation of up to two inches, but the spinal cord ruptures if stretched more than one quarter of an inch.

Weber [33] determined that the risk of spinal cord injury in children increases with crash severity and decreases with age. It was been noted that a child's skull can be separated from its spine by the force of a crash. Even more severe, the child's spinal cord could be severed. These severe 
types of injuries are rare. However, Weber [33] rationalized that it is possible to avoid these types of injuries by facing a child in a rearward facing child safety seat as long as possible. Child restraint systems that face the rear of the vehicle are very effective in preventing serious and fatal injuries to small children. In particular, rear facing child restraint systems are effective in preventing injuries involving the upper spinal cord. These types of injuries rarely occur, but when they do occur, it is when the child is facing forward. Weber's study regarding rear facing restraints for small child passengers [3] suggested that studies have shown that stretching forces acting on the neck can be reduced by half when forward facing child dummies are turned to face the rear.

Children of all ages have a tendency to squirm and move about, increasing their likelihood of being improperly positioned in any child restraint system. Gotschall and Luchter [19] determined that older children restrained by automotive or booster-seat restraint systems were more frequently out of position than younger children restrained in child seats. Clearly, properly restraining children is an important step in minimizing injury during vehicle crashes.

A study carried out by Langwieder et al. [13] involving risk of injury to children in cars based on the type of restraint that is used is noteworthy. This study was based on a German accident database that was created based on information from statistics about 593 restrained children between the ages of 0 and 11 travelling in cars. The statistics were based on approximately 18000 car accidents involving personal injury during the years 1990 and 1991 . Due to the fact that the database from which the study was designed is quite small in some cases, it should be noted that it is not possible to come to an overwhelmingly strong statistical significance. However, there are definite trends that exist. Primarily, when children are restrained by an adult seatbelt, not only do injuries occur more frequently, but the severity of the injury is greater compared with a child restraint system or a 3-point belt with booster seat. Skold [6] found that this applies to injuries to the head are which tend to be extremely destructive and even fatal. His study also determined that injuries to the head were most frequent regardless of the type or configuration of restraint. Injuries to the neck followed in second place. 


\subsubsection{The effect of time duration of forces on injury potential}

In a document released by NHTSA and written by DeSantis-Klinich et al. [34], it was stated that the duration of time to which one is subjected to a force or torque has an effect on the potential injury incurred. This study attempted to generate injury criteria for children and protection reference values for child dummies. The term injury criteria references humans and protection reference (PRV) values applies to crash test dummies.

There are a number of ways to estimate injury criteria. The first method is through volunteer testing. Humans can be suited with the appropriate instrumentation and subjected to impact conditions. Measurements are taken based on injury sustained or lack of injury. The problem associated with this method is that humans can only be taken to the point of minor injuries. For example, it is not possible to determine the fatal skull fracture load of a human being. Another problem associated with this method is that inaccuracies may result from attaching the instrumentation in such a way that it does not injure the volunteer. This implies that the instrumentation is not necessarily in the exact position where the forces that cause injuries should be measured. In addition, every volunteer is different and responds differently to impact circumstances. The fact that the volunteers know that they would be subjected to impact is a cause for error because there are the effects of muscle tension and physical reaction that may not necessarily take place in a real vehicle collision situation. Essentially, injury thresholds cannot be determined exclusively using this method. Furthermore, children do not volunteer for this type of impact testing due to the unethical nature of live child testing.

A second method to determine injury criteria is through cadaver testing. Cadavers can be tested to fatal impacts and high accelerations. After crash testing is complete, an autopsy could show the injuries sustained. The problem with this method is that most cadavers are of an older age (mainly seniors) than a volunteer would be. Their physical being has somewhat diminished and therefore their bodies are unable to give a response corresponding to the average population. In addition, signs of injury such as pain and loss of consciousness are not available from cadavers.

Thirdly, animals can be used to estimate a human's response. Typically are used to study injuries sustained from a vehicle crash. Of course, the main problem is to determine how to relate the animal data to humans. 
Another way to determine injury criteria is through accident reconstruction. If the accident was well documented in terms of the manner in which it occurred, as well as the injuries sustained by the passengers, then accidents can be reconstructed with crash test dummies. The injury data obtained by the dummy is compared to the injury data of the human. However, dummies are not perfectly biofidelic and can only be used to approximate occupant response.

A combination of these techniques have led to the development of injury criteria for adults and for protection reference values for the $50^{\text {th }}$ percentile dummy. There have been only eleven cadaver tests on children that have been reported [34]. Animal testing can generate more information because of the closeness in size to children, but anatomy differences exist still. Reconstruction of accidents is a more viable method of assessing child injury. Since there is so little biomechanical data on children, it is difficult to have a child dummy perfectly represent the actual child.

An additional way to develop injury criteria or PRV for children is by scaling adult data. This has been accomplished by using geometry, mass, and biomechanical material property ratios through dimensional analysis. This method assumes that children and adults have similar geometries, which is less appropriate for small children. However, there is such a lack of biomechanical properties of children and it has become an essential way in developing design specifications for constructing child dummies.

In addition to different body proportions, there are structural differences that make children different from adults. For example, at birth, the skull is flexible and consists of six sections called fontanelles. These sections eventually fuse together as the child ages. The skull of an infant deforms easily under load compared to that of an adult. This may make the child less susceptible to fracture. However, this may make children vulnerable to other injuries. The fontanelles allow for volume changes that are not possible in the skull of an adult. They provide a method for pressure to escape if needed. This fact means that the rigid skull assumption used when scaling down the head injury criteria of adults. In this study, it is stated that the injury criteria for the acceleration of the head and chest are scaled down from adult to child. However, the protection reference values are slightly higher for the child dummies than for the adult dummies. To obtain injury criteria and protection reference values for children and child dummies, often, the adult injury criteria and protection reference values are scaled based on geometry ratios. Table 6 illustrates the scaling factors for the various ages of child and child dummies. 
Table 6. Length and modulus scaling factors [34].

\begin{tabular}{|c||c|c|c|c||c|c|c|c|}
\hline \multicolumn{1}{|c||}{ Ratios } & \multicolumn{4}{c||}{ Human Data } & \multicolumn{4}{c|}{ Dummy Data } \\
\cline { 2 - 9 } & $\mathbf{5 0 t h}$ & $\mathbf{6 Y O}$ & $\mathbf{3 Y O}$ & $\mathbf{1 2 M O}$ & $\mathbf{5 0 t h}$ & $\mathbf{6 Y O}$ & $\mathbf{3 Y O}$ & $\mathbf{1 2 M O}$ \\
\hline Head Length (LH) & 1 & 0.8985 & 0.8683 & 0.8207 & 1 & 0.8985 & 0.8683 & 0.8207 \\
\hline Neck Length (LN) & 1 & 0.671 & 0.6214 & 0.5758 & 1 & 0.671 & 0.6214 & 0.5758 \\
\hline Chest length (LC) & 1 & 0.5515 & 0.488 & 0.4456 & 1 & 0.5515 & 0.488 & 0.4456 \\
\hline Bone Modulus (EB) & 1 & 667 & 0.474 & 0.322 & 1 & 1 & 1 & 1 \\
\hline Tendon Modulus (ET) & 1 & 0.96 & 0.85 & 0.7 & 1 & 1 & 1 & 1 \\
\hline
\end{tabular}

Table 7 shows the scaled adult protection reference values. There is a column called "Formula" which describes the scaling factor used to obtain the child injury values.

Table 7. Scaled adult protection reference values [34].

\begin{tabular}{|c|c|c|c|c|c|c|c|c|c|}
\hline \multirow{2}{*}{ Parameter } & \multirow{2}{*}{ Formula } & \multicolumn{4}{|c|}{ Human Data } & \multicolumn{4}{|c|}{ Dummy Data } \\
\hline & & 50th & $6 Y O$ & $3 Y O$ & 12MO & 50th & $6 Y O$ & 3YO & 12MO \\
\hline Head Acceleration (g) & EB/LH & 85 & 63 & 46 & 33 & 85 & 95 & 98 & 104 \\
\hline $\mathrm{HIC}$ & $\mathrm{EB}^{2} / \mathrm{LH}$ & 1000 & 522 & 278 & 139 & 1000 & 1174 & 1236 & 1345 \\
\hline HIC time 1 (ms) & $\mathrm{LH}^{-\mathrm{EB}^{0.5}}$ & 15 & 16.5 & 18.9 & 21.7 & 15 & 13.5 & 13 & 12.3 \\
\hline HIC time $2(\mathrm{~ms})$ & $\mathrm{LH}^{\mathrm{EB}} \mathrm{B}^{0.5}$ & 36 & 39.6 & 45.4 & 52.1 & 36 & 32.3 & 31.3 & 29.5 \\
\hline Neck Tension $(\mathrm{N})$ & $E T^{*} \mathrm{LN}^{2}$ & 3300 & 1426 & 1083 & 765 & 3300 & 1486 & 1274 & 1094 \\
\hline Neck Compression (N) & $\mathrm{ET}^{*} \mathrm{LN}^{2}$ & 4000 & 1729 & 1313 & 927 & 4000 & 1801 & 1545 & 1326 \\
\hline Neck Shear (N) & $E T^{*} L N^{2}$ & 3100 & 1340 & 1018 & 718 & 3100 & 1396 & 1197 & 1028 \\
\hline $\begin{array}{l}\text { Neck Flexion Moment } \\
(\mathrm{Nm})\end{array}$ & $E T^{*} \mathrm{LN}^{3}$ & 190 & 55 & 39 & 25 & 190 & 57 & 46 & 36 \\
\hline $\begin{array}{l}\text { Neck Extension Moment } \\
(\mathrm{Nm})\end{array}$ & $E T^{*} \mathrm{LN}^{3}$ & 57 & 17 & 12 & 8 & 57 & 17 & 14 & 11 \\
\hline Chest Acceleration (g) & $\mathrm{EB} / \mathrm{LC}$ & 60 & 73 & 58 & 43 & 60 & 109 & 123 & 135 \\
\hline
\end{tabular}


The neck of an infant consists of three different bones that grow together during the third year. However, the atlas (C1) and the axis (C2) (Figure 13) do not complete joining until the child is between the ages of 4 and 6 . In the early years of a child's development, the facet joints in the upper neck are almost horizontal which is not the case for adults. This formation allows for partial dislocation of the bones under small loads for children. In addition, the neck muscles in children are weaker than those of adults.

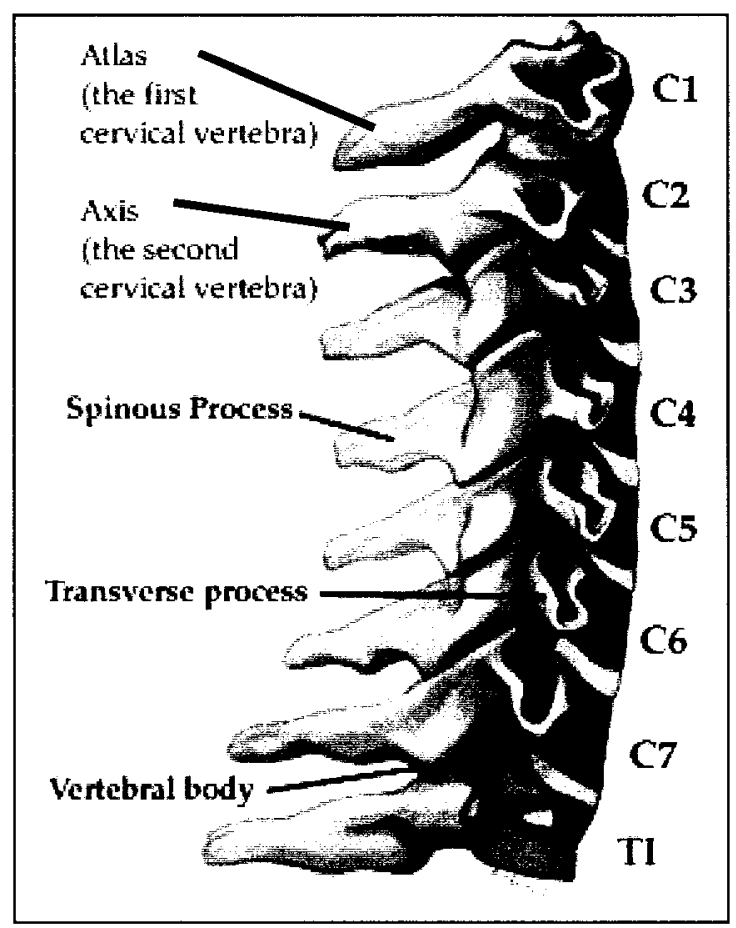

Figure 13. The adult cervical spine [35].

According to Desantis-Klinich et al. [34], if the necks of infants and toddlers are not properly supported, injuries are likely to occur in the case of a vehicle collision. Spinal cord stretch injuries are common for children due to the difference in neck structure. Because of the flexible vertebrae of children, the spinal cord is allowed to stretch without breaking the bones. This injury is rarely found in adults. The injury criteria and the protection reference values for the neck children and child dummies are scaled down. Figure 14 illustrates how the axial neck tension has been scaled down accordingly for the size of the dummy. 
In short, there are two opposing theories in child impact injury. On is that since children are smaller, they are likely more fragile and therefore the adult injury criteria and protection reference values should be scaled down. On the other hand, it can be said that children are more durable and elastic than adults and therefore, the criteria should be scaled upwards. The conclusion of this study is that the best solution to formulating injury criteria and/or PRV for children is to work between these two extremes.

An important finding that was stressed in the publication by Desantis-Klinich et al. [34] was that there is a relationship between the critical loads to cause injury sustained and the duration of time for which that force was sustained. This relationship is clear in Figure 14 where tensile neck force is plotted versus duration of loading. The lines represent the child dummy protection reference value line, above which, injury is to be sustained. Below that threshold, no severe injury occurs. It is clear that as time duration increases, the level of force that the child dummy can sustain decreases. This is a noteworthy finding as it implies that it is possible for a child to

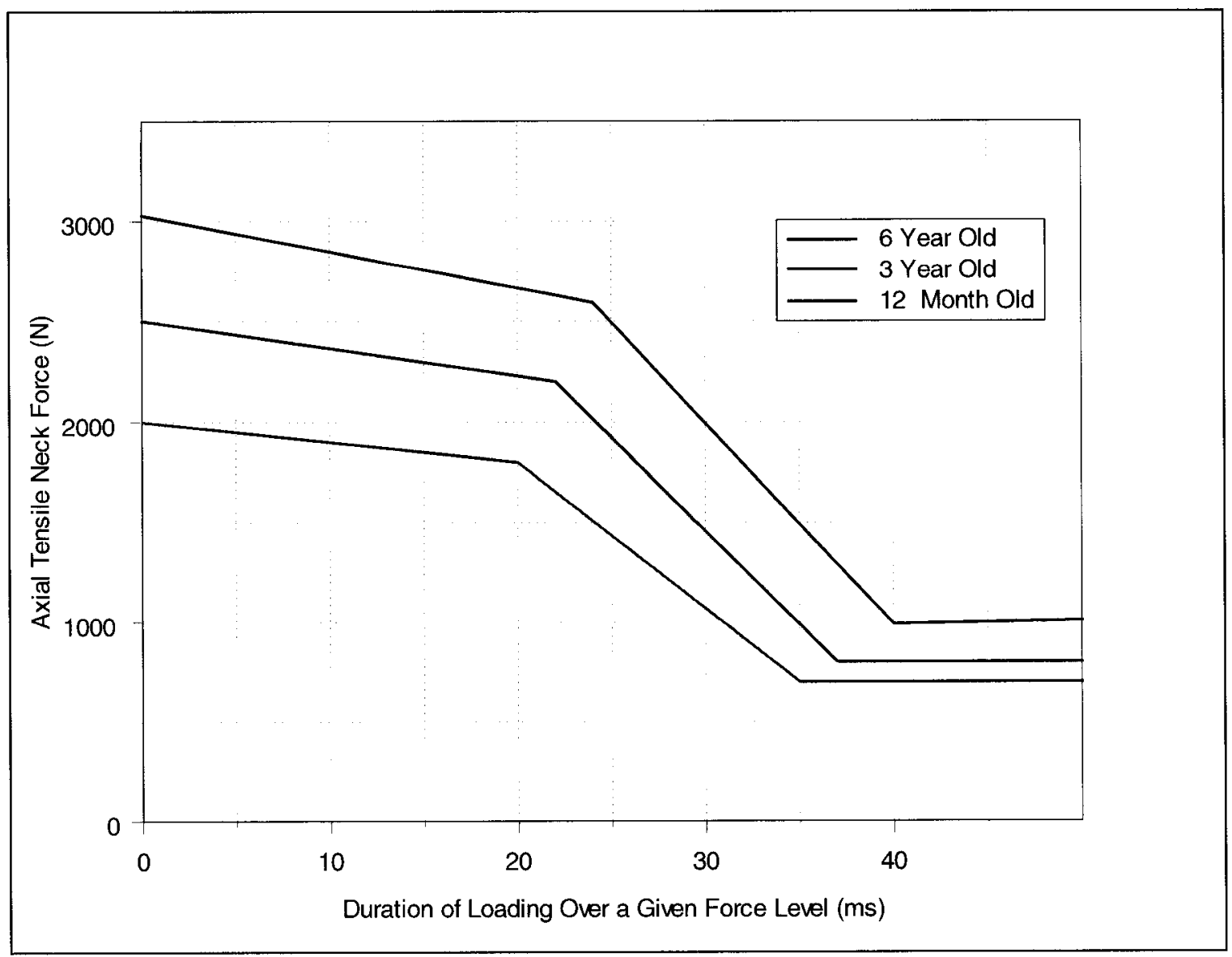

Figure 14. Axial neck tension - child dummy protection reference curves [34]. 
remain relatively unharmed even if the child sustains a high level of force for a short period of time. Conversely, if the child is victim to a critical load value for a long period of time, injury may result based on the duration of the force.

In a report by Macaulay [36], it was noted that "there is an overall tendency for the level of acceleration to rise as the pulse duration falls." Figure 15 illustrates a curve of adult head acceleration versus pulse duration. Figure 15 illustrates that for short pulse duration, one's head can withstand high values of rearward acceleration, whereas for longer pulse duration, the ability for the head to withstand high values of acceleration decreases.

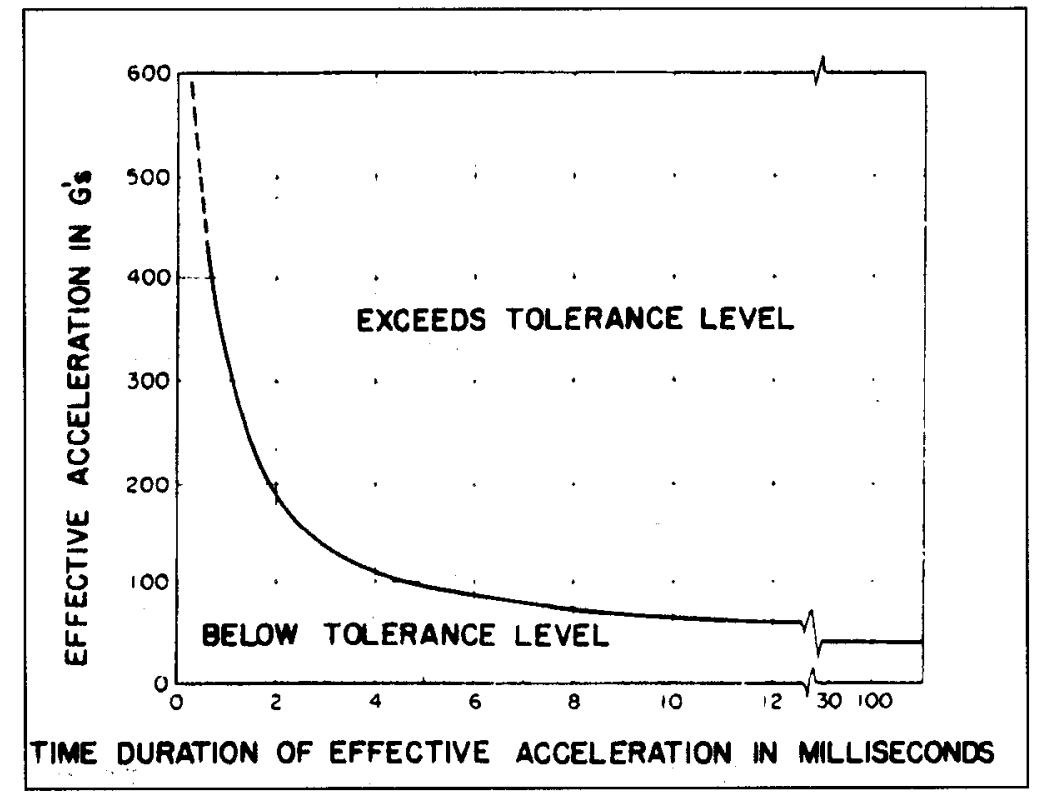

Figure 15. Impact tolerance for the human brain in forehead impacts against plane, unyielding surfaces [36].

Also in the publication by Macaulay [36], information was found relating the effect of time duration of whole body acceleration to injury potential. Figure 16 illustrates the downward sloping line indicating that for a longer duration of force, the less acceleration can be sustained for the whole body. 


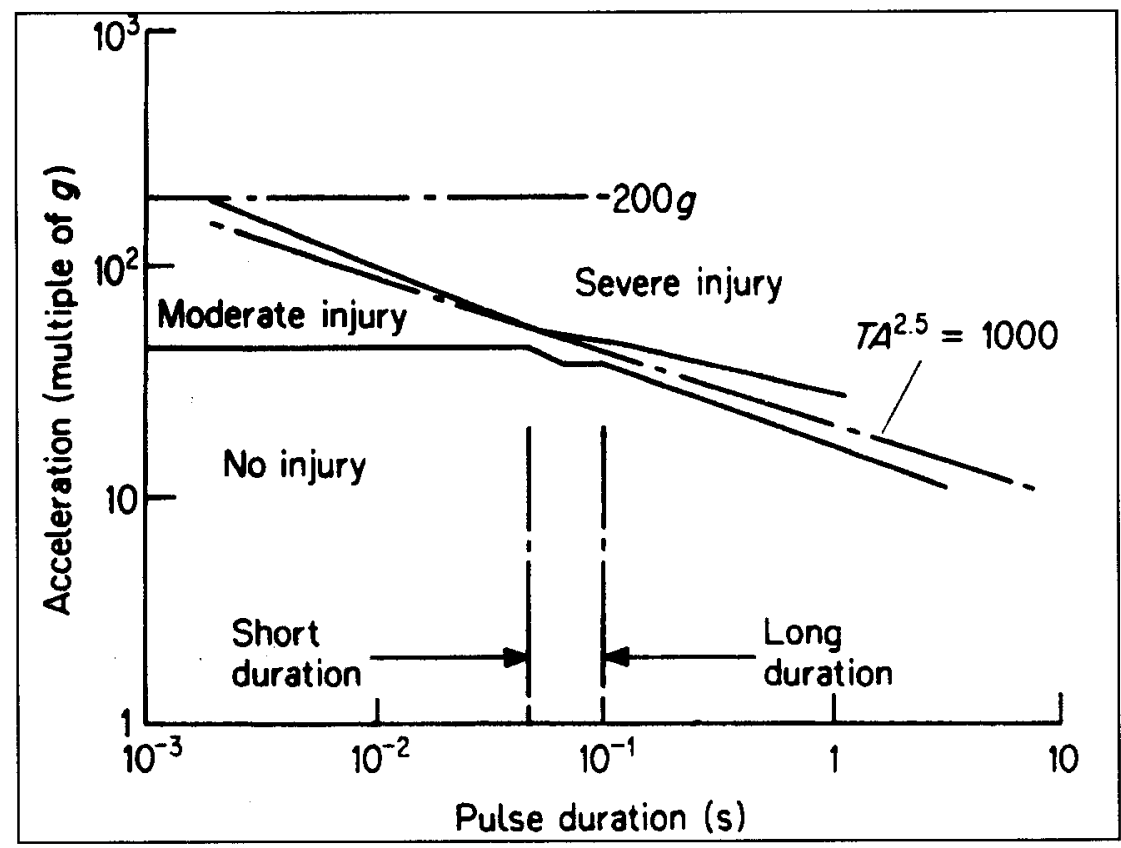

Figure 16. Whole body tolerance of rearward acceleration [36]. 


\subsection{Current standards in automotive crash for children}

\subsubsection{Federal Motor Vehicle Safety Standard 213 - child restraint systems}

This section emphasizes the procedures and standards from FMVSS 213 that describes the standards applicable to child restraint systems. The following are some of the points that apply to this study and were taken directly from the FMVSS 213 Standard [37], including the dynamic test procedure as well as injury calculations such as the head injury criteria and the neck injury criteria, unless otherwise noted.

\subsubsection{Most important aspects of FMVSS 213}

During an experimental sled test, no portion of the test dummy's head should extend further than $813 \mathrm{~mm}$ through a vertical transverse plane that is forward of point $\mathrm{Z}$ on the standard assembly and measured along the centre of the Seat Orientation Reference Line (SORL). Figure 17 illustrates the bench seat that is used in experimental crash tests and important geometrical

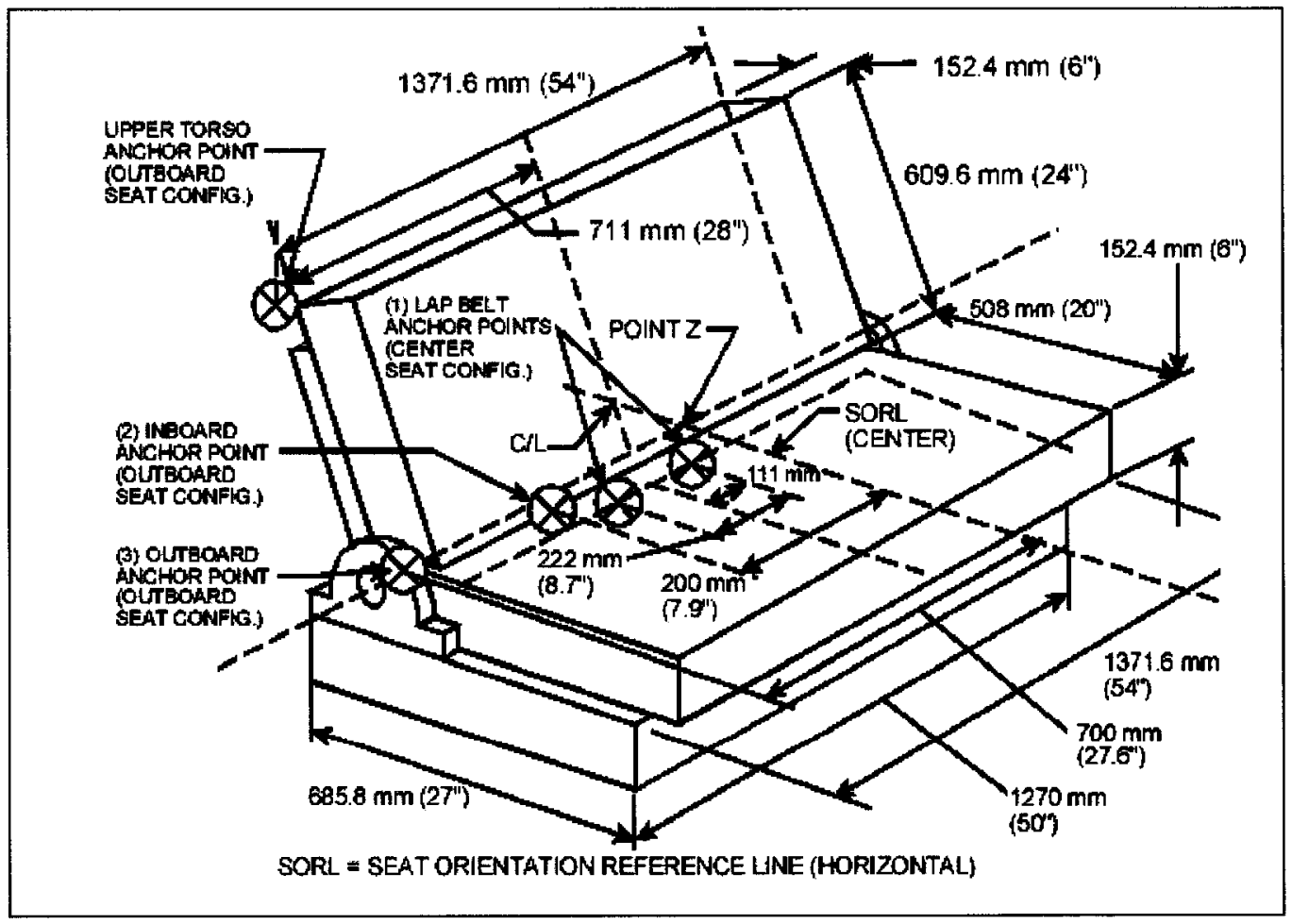

Figure 17. Bench seat used in FMVSS 213 crash testing [37]. 
locations associated with the seat and the testing standard. In addition, the knees cannot extend further than $914 \mathrm{~mm}$ through a vertical, transverse plane forward of point $\mathrm{Z}$ on the standard seat assembly, measured along the center SORL.

The child safety seat assembly should be mounted on a dynamic test platform so that the center of the SORL of the seat is parallel to the direction of the test platform travel and so that movement between the base of the assembly and the platform does not occur.

The platform should be mounted with an accelerometer and a data processing system and the axis of sensitivity of the accelerometer should be the axis parallel to the travel of the test platform.

\subsection{Dynamic test procedure}

The child safety seat is to be installed at the center seating position of the standard seat assembly in accordance with the manufacturer's instructions provided with the system. The seat assembly should be secured to the standard vehicle seat/bench using only the standard vehicle lap belt and shoulder belt. The belts should then be tightened at this time.

The Hybrid III 3-year-old dummy should then be placed in the child safety seat in accordance with the instructions of the manufacturer of the child safety seat while conforming to the following:

i Hold the torso of the dummy upright until it contacts the seat surface. The dummy's head dhould be coincident with the centre SORL of the standard seast/bench. lace the test dummy in the seated position within the system with the midsagittal plane of the test dummy head coincident with the center SORL of the standard seating assembly.

ii The arms of the dummy should be extended as far as possible in the upward vertical direction and the legs should be extended as far as possible in the forward horizontal direction

iii The dummy's limbs should then be rotated downwards until they contact a surface. 
The test seat/bench should then be accelerated to simulate frontal impact in accordance with an acceleration that falls between the upper and lower bounds of acceleration illustrated in Figure 48 . The velocity reaches $48 \mathrm{~km} / \mathrm{h}$.

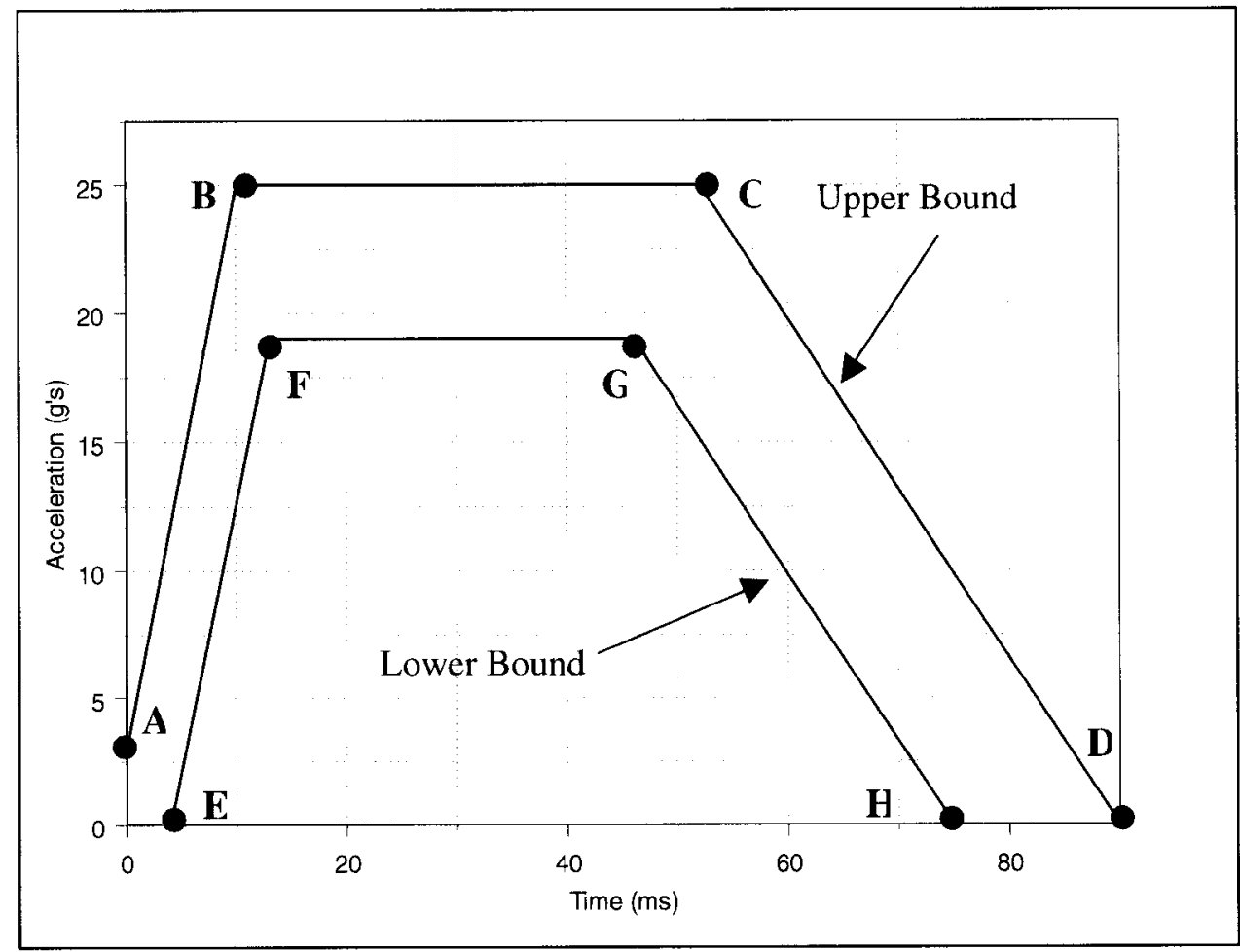

Figure 18. FMVSS 213 input acceleration upper and lower limit curves [37].

The lettered value points are listed in Table 8 .

Table 8. FMVSS 213 input acceleration upper and lower limit coordinates [37].

\begin{tabular}{|c|c|c||c|c|c|}
\hline \multicolumn{3}{|c||}{ Upper Bound } & \multicolumn{3}{c|}{ Lower Bound } \\
\hline Point & Time (ms) & Acceleration (g's) & Point & Time (ms) & Acceleration (g's) \\
\hline \hline A & 0 & 3 & E & 4 & 0 \\
\hline B & 10 & 25 & F & 13 & 19 \\
\hline C & 52 & 25 & G & 46 & 19 \\
\hline D & 90 & 0 & H & 75 & 0 \\
\hline
\end{tabular}




\subsection{Dressing the Hybrid III dummies}

When used in testing under this standard, the dummy is clothed in thermal knit waffle-weave polyester and cotton underwear, a size 4 long-sleeved shirt weighing $0.01 \mathrm{~kg}$, a size 4 pair of long pants weighing $0.01 \mathrm{~kg}$ and cut off just far enough above the knee to allow the knee target to be visible, and size $7 \mathrm{M}$ sneakers with rubber toe caps, uppers of dacron and cotton or nylon and a total weight of $0.495 \mathrm{~kg}$.

\subsubsection{Injury criteria}

\subsection{Head injury criteria}

The Head Injury Criteria (HIC) was determined to have a limit value of acceleration to the head of the crash test dummy, limiting the injury potential to the head. Currently, Equation 1 is used for the calculation of HIC and the window of time used is $36 \mathrm{~ms}$. That is, the difference between $t_{2}$ and $t_{1}$ is $36 \mathrm{~ms}$. The value of $\mathrm{HIC}_{36}$ is not to exceed 1000 .

$$
H I C=\left[\frac{1}{t_{2}-t_{1}} \int_{t_{1}}^{t_{2}} a \cdot d t\right]^{2.5} \cdot\left(t_{2}-t_{1}\right)
$$

NHSTA made suggestions made to change the time domain for the calculation of the HIC from $36 \mathrm{~ms}$ to $15 \mathrm{~ms}$, thereby limiting the value of HIC to 570 for a Hybrid III three-year-old child dummy, rather than 1000 [38]. 
NHTSA developed the curves in Figure 19 in order to better comprehend the injury associated with a specific value of $\mathrm{HIC}_{15}$ [38]. Each curve is associated with a specific Maximum Abbreviated Injury Scale (MAIS) value. The severity of injury increases as the MAIS increases.

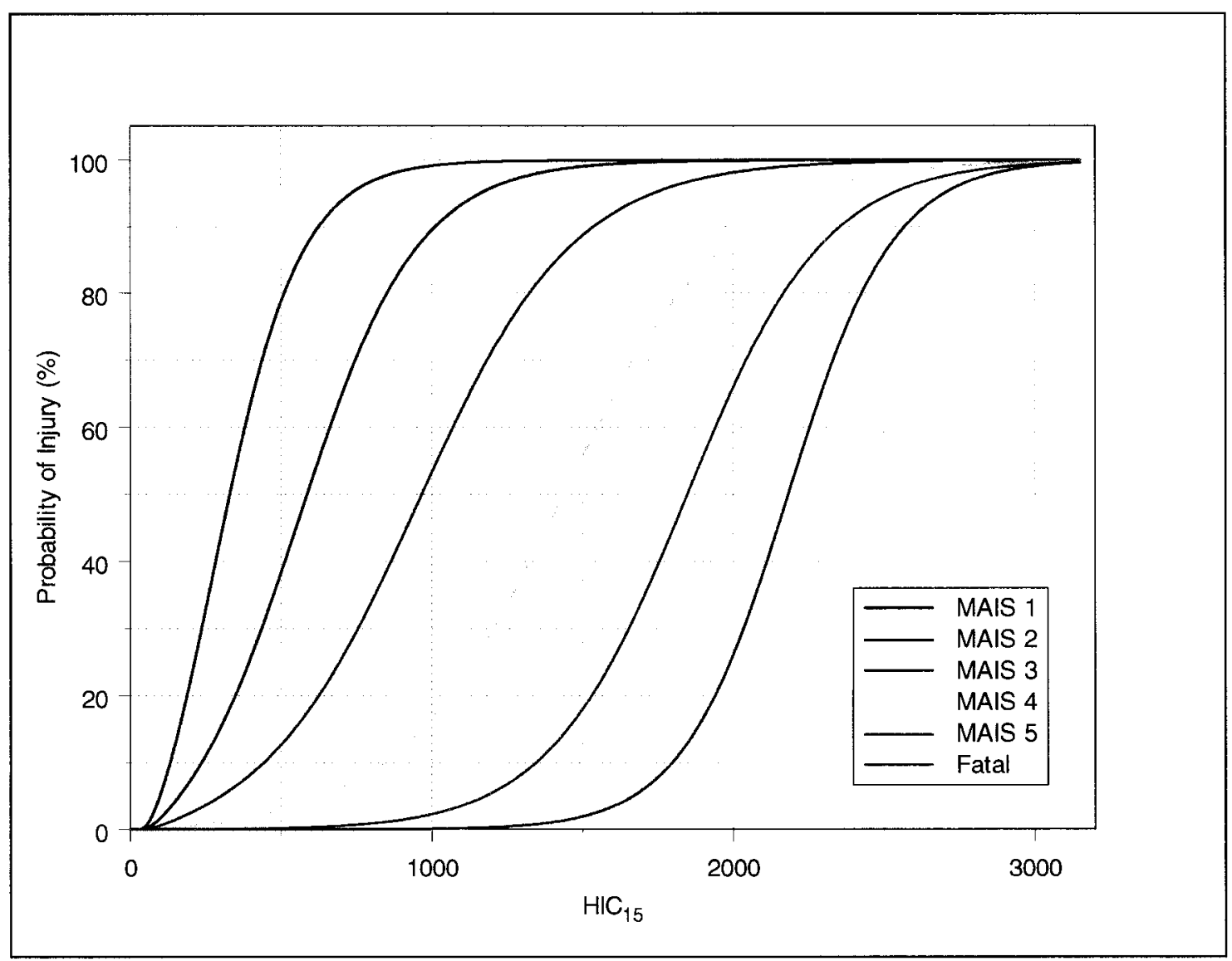

Figure 19. Probablity of injury versus head injury criteria [38].

Table 9 characterizes the values of a specific MAIS score into descriptive words that illustrate the severity of injury.

Table 9. MAIS score and associated injury [38].

\begin{tabular}{|c|c|}
\hline MAIS Score & Injury \\
\hline \hline 1 & Minor \\
\hline 2 & Moderate \\
\hline 3 & Serious \\
\hline 4 & Severe \\
\hline 5 & Critical \\
\hline 6 & Unsurvivable \\
\hline
\end{tabular}




\subsection{Neck injury criteria}

The normalized neck injury criterion $\left(\mathrm{N}_{\mathrm{ij}}\right)$ was developed to determine a combination of forces and moments subjected to the neck that would cause injury. According to Schmitt et al. [39], $\mathrm{N}_{\mathrm{ij}}$ was proposed to assess severe neck injuries in frontal impacts. The $\mathrm{N}_{\mathrm{ij}}$ was defined by NHTSA [38] as a linear combination of the normalized neck axial load (tension or compression) and normalized neck moment about the occipital condyle. In Figure 20 the occipital condyles are illustrated as two smooth surfaces protruding outward. The head sits on top of the atlas (the first vertebral bone) by these condyles. Figure 21 illustrates a side view of the base of the skull with the occipital condyles protruding downwards.

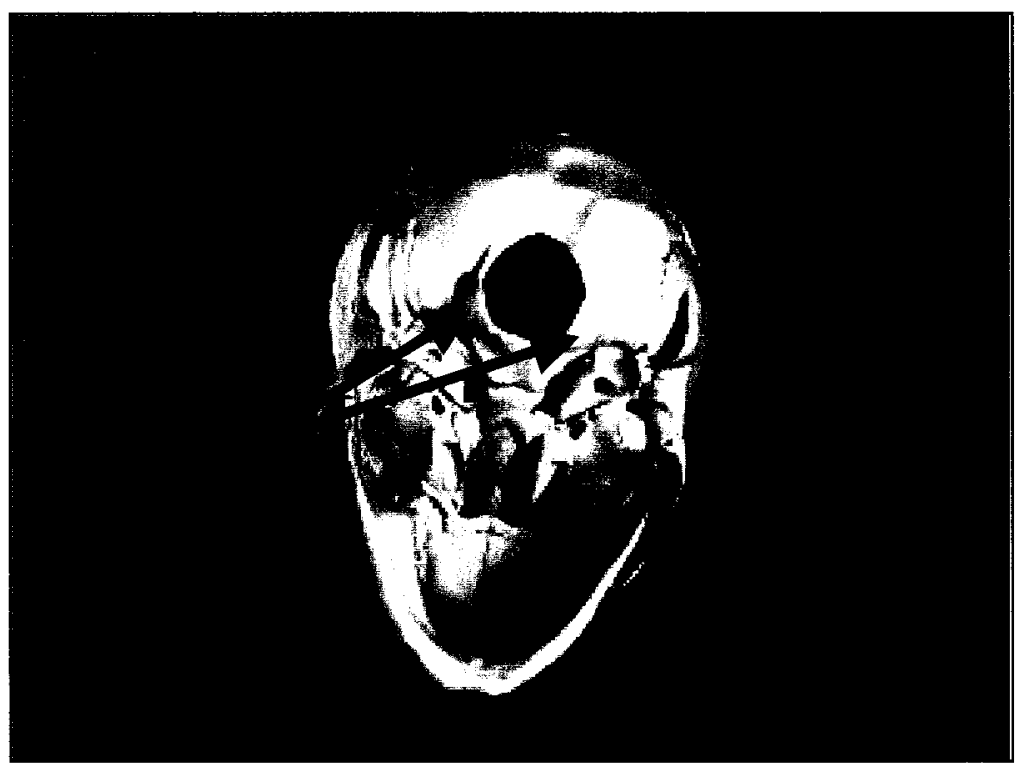

Figure 20. Bottom view of the skull illustrating occipital condyles [40].

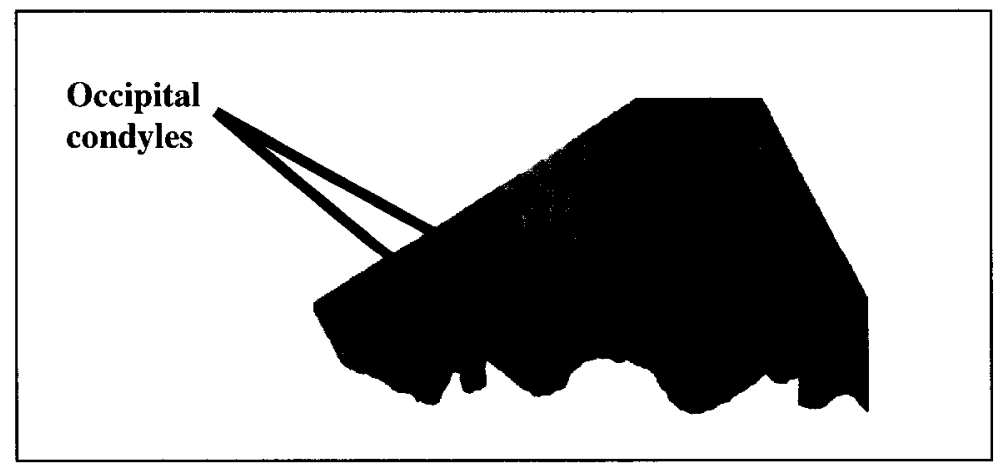

Figure 21. Side view of the base of the skull [41]. 
The equation used to determine this the $\mathrm{N}_{\mathrm{ij}}$ value is as follows:

$$
N_{i j}=\left(F_{Z} / F_{Z C}\right)+\left(M_{Y} / M_{Y C}\right)
$$

$\mathrm{F}_{\mathrm{ZC}}$ and $\mathrm{M}_{\mathrm{YC}}$ are the critical values of force and moment, respectively. They values used are selected based on the size dummy used in testing. Table 10 lists the values of the critical forces and moments used for the Hybrid III 3-year-old dummy. The value $\mathrm{N}_{\mathrm{ij}}=1.0$ applies to all dummy sizes. The Neck Injury Criteria value cannot exceed 1.0 at any time. The critical neck intercept values that are currently being proposed vary according to dummy type [38].

Table 10. Critical values for calculation of neck injury criteria of Hybrid III 3-year-old dummy [35].

\begin{tabular}{|c|c|c|}
\hline Item & Type of Force & Value \\
\hline \hline$F_{\mathrm{ZC}}$ & Tension & $2120 \mathrm{~N}$ \\
\hline $\mathrm{F}_{\mathrm{ZC}}$ & Compression & $2120 \mathrm{~N}$ \\
\hline $\mathrm{M}_{\mathrm{YC}}$ & Flexion & $68 \mathrm{Nm}$ \\
\hline $\mathrm{M}_{\mathrm{YC}}$ & Extension & $27 \mathrm{Nm}$ \\
\hline
\end{tabular}


NHTSA also published injury curves related to $\mathrm{N}_{\mathrm{ij}}[38]$ and are illustrated in Figure 22. Each curve is associated with a specific Abbreviated Injury Scale (AIS) value. The severity of injury increases as the AIS increases. The AIS 5+ curve and the Fatal Injury curve are the almost the exact same curve and therefore cannot be distinguished from one another.

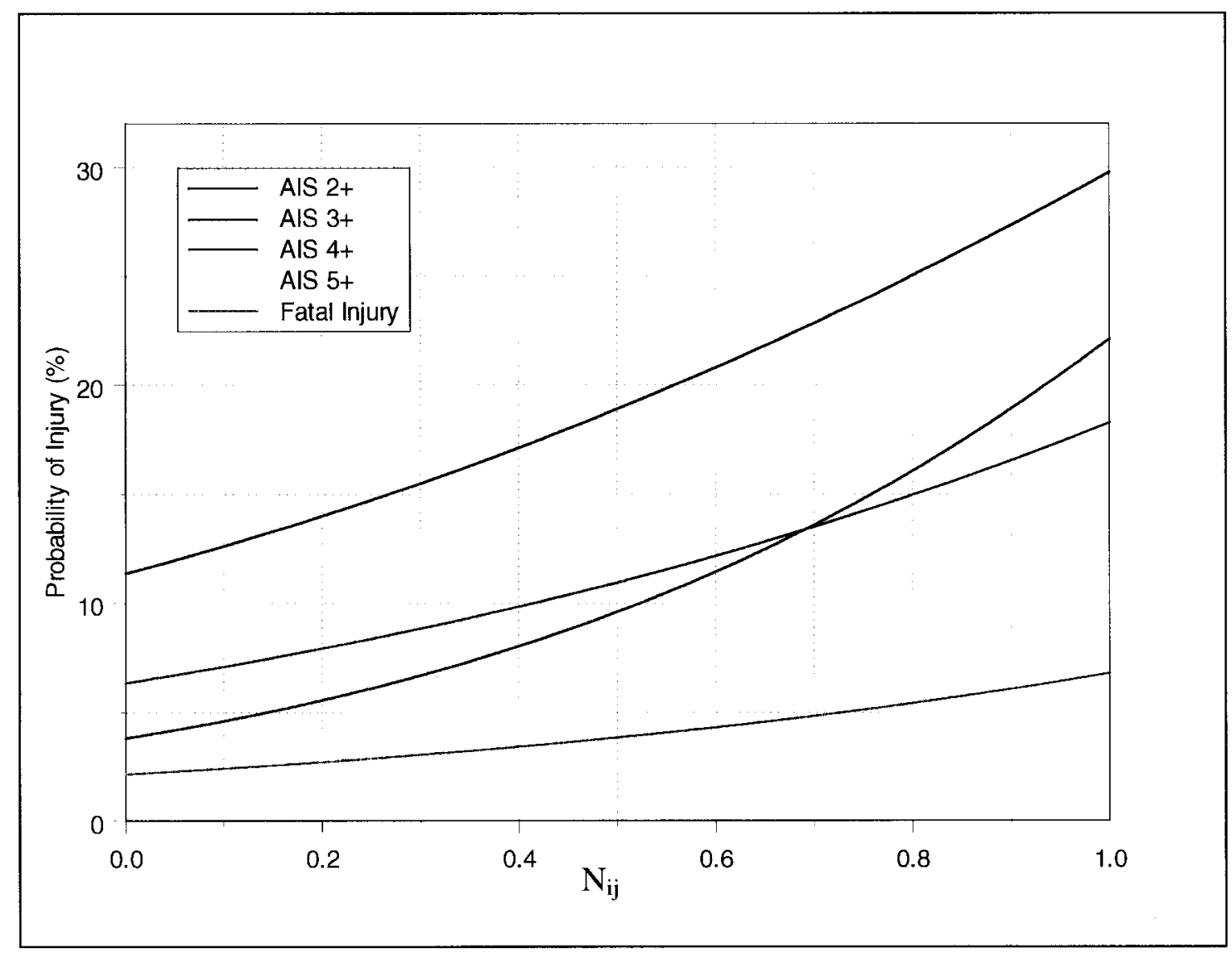

Figure 22. Probability of injury versus neck injury criteria [38].

One can apply the characterizations of Table 9 to this graph to obtain qualitative descriptions of the potential for injury knowing the $\mathrm{N}_{\mathrm{ij}}$.

\subsubsection{Canadian Motor Vehicle Safety Standard 213}

The Canadian Motor Vehicle Safety Standard No. 213 (CMVSS 213) is essentially the identical to its American counterpart, FMVSS 213. The only difference refers to the limits regarding excursion of the head. The Canadian standards states that when a forward-facing child restraint system is subjected to a dynamic test, no portion of the head of the test dummy must pass through 
the vertical transverse plane that is $720 \mathrm{~mm}$ forward of the $\mathrm{Z}$ point on the seat assembly measured along the centre of the SORL.

There has been an amendment to FMVSS 213 which states that the head excursion now cannot exceed $720 \mathrm{~mm}$. This standard is used when a top tether is used to restrain the child safety seat to the vehicle in addition to all other belts and straps. However, when a top tether is not present, the head excursion limit increases to $813 \mathrm{~mm}$.

Canada was the first to impose that an anchor be manufactured in the back seat of passenger vehicles in order to secure the top tether of a child safety seat. Because of this, all cars, both in Canada and the United States were manufactured with the possibility of including the anchor. It was not until June 24, 2003, that the United States changed the FMVSS 213 standard. Recently, the child restraint seats in the United States have been available with standard or add-on tethers for forward-facing use. This may have been inspired by the new head-excursion requirements in the United States [33].

\subsubsection{Motor vehicle standards in other parts of the world}

In Sweden, children remain rear facing until the ages of three and four. In fact, the rear facing car seats are designed very differently than those in North America. A study done by Skold [6] explains a Swedish system called ISOFIX which incorporates the child safety seat and anchorage points within the vehicle. The seats are larger and can be set up in such a way that there is sufficient leg room for a three or four year old toddler. A study that explored the current issues with the ISOFIX system determined that there are some design aspects that need to be changed, including the anchorage points since they are not easily visible and therefore hard to find. In addition, the system is not entirely ergonomic. The system was designed based on the in-car components, in that the anchors are strong enough to hold the seat in place. Also, modifications were made to offer the most possible legroom for the child. There is a high demand for rearward facing child seats due to their superior protection effect.

Although Sweden has made significant progress in their quest to better protect child passengers in vehicles, there still exists the issue of misuse of the child restraint system, giving less protection to the child. According to Skold [6], misuse originates from the child safety seat not being fit properly into the car as well as the child being incorrectly secured into the child seat. In addition, 
there still exists the problem that parents face their children that are younger than three years of age in a forward facing child safety seat. Skold's study [6] states that the previously stated practice is extremely unsafe and considers North America to have "less developed child protection strategies."

This study also stated that while restraint systems have been observed as an integrated part of the crashworthiness of an automobile, child safety seats are considered to be add-on systems made to fit in any car. The European regulations still adhere to this identification, however, more recently, the EURO-NCAP (the European crash safety rating system) has integrated the protection of children into the rating of a complete vehicle.

In a study by Fildes et al. [10], it was estimated that rearward facing restraints reduce the risk of serious injury by about $80-90 \%$. This publication makes reference to a study of a the Swedish Volvo crash database reported that the injury reducing effect of rearward facing child restraints could be as high as $96 \%$, whereas estimates of the capability of forward facing child restraints have been closer to $70 \%$. 


\subsection{Crash testing}

\subsubsection{Crash test dummies}

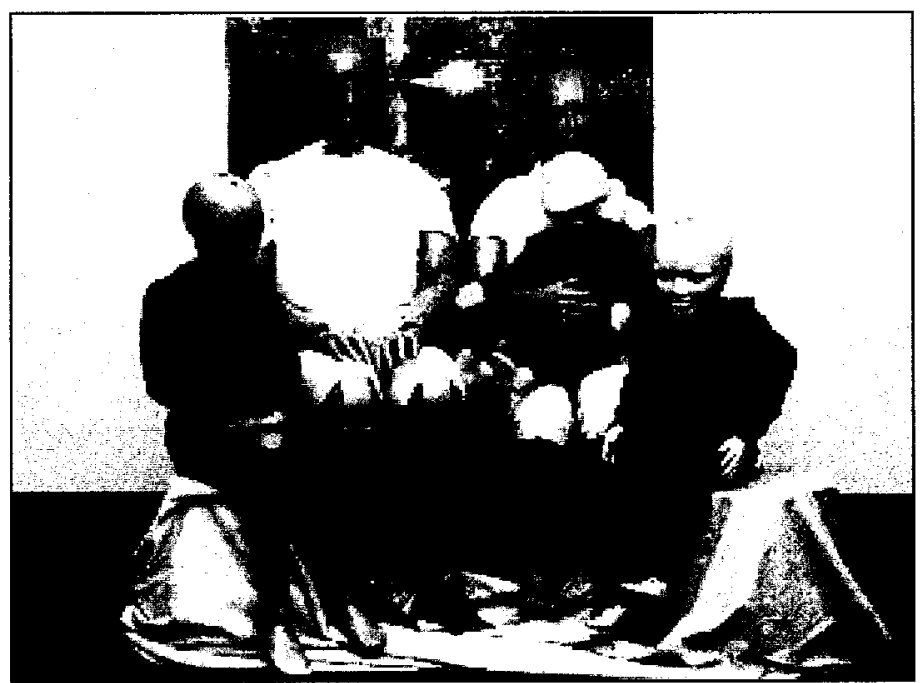

Figure 23. Hybrid III family of crash test dummies [42].

The literature describing crash test dummies was paraphrased from references [42 - 45] unless otherwise stated. A crash test dummy is used in measuring the risk of injury to which a person may be potentially exposed to during automotive crash. Exposure to extreme forces, one can make use of a crash dummy to estimate both the overall harm and the injuries sustained by specific regions of the body. The more realistic the dummy, the more reliable the information which the device can provide. Suitable crash test dummies reflect their respective human models in all possible components, so as to mirror both kinematics and kinetics of the respective vehicle collision situations. An anthropometric dummy defines one who's dimensions and mass realistically mirrors that of its respective human model. Crash test dummies attempt to replicate the human body's mechanical properties, particularly the range of motion of joints, thoracic stiffness, skin force deflection, and other mechanical characteristics.

\subsubsection{Hybrid III history and development}

Under contract with NHTSA, General Motors (GM) constructed the first of what was to be many Hybrid crash test dummies. The current series of Hybrid dummies is the Hybrid III. The dummies range from a $5^{\text {th }}$ percentile adult female to a $50^{\text {th }}$ percentile adult male and a $95^{\text {th }}$ percentile large adult male. The CRABI is a Hybrid III dummy that represents a typical 12 month 
old infant. Also, there are Hybrid III dummies that represent three, six, and ten year old children. To date, the Hybrid III crash test dummy family is the only recognized device used in crash testing, both in the United States and European frontal impact restraint regulations, such as imposed by their respective governments. The Hybrid III was designed for frontal impact situations. Regardless of the original intended application of the Hybrid III child dummy, Lau et al [30] determined that it is being utilized in a variety of impact environments (e.g., side and rear) due to the lack of viable alternatives.

The Hybrid III series of dummies has an extensive history that begins in the field of aviation. Crash test dummies in general have evolved from mannequin-like figures to extensively instrumented human-like devices that are highly accurate.

In the 1940s, the first dummies were developed to test jet ejection seats for the United States military. In year 1956, GM was the first company to begin looking at crash test dummies for the purpose of testing automobiles. GM attended an Air Force conference where Col. John Paul Stapp, a military researcher shared his knowledge about the dummies used in testing the ejection seats. Col. Stapp was also an Air Force doctor who volunteered to sit on a rocket sled traveling up to $1017 \mathrm{kph}$ and he suffered through extreme decelerations. In doing so, Col. Stapp was able to gather the first measurements of the effect of crash forces on human beings.

Ten years later, in 1966, the United States Congress enacted the Motor Vehicle Safety Act. This act regulated the automotive industry and established vehicle safety standards. At this time, GM was searching for ways to improve on the existing dummies and they developed a method for determining the extent of injury when measuring impact forces on crash test dummies during laboratory tests.

In 1971, GM created its own crash test dummy, the Hybrid I. This dummy was created using the most desirable components from dummies of two manufacturers' dummies (Alderson Research and Sierra Engineering), hence the name "Hybrid." This dummy was only used internally. One year later, GM improves upon the Hybrid I, thereby creating the Hybrid II crash test dummy. The improvements made the dummy made the dummy durable and repeatable. The United States government made the GM Hybrid II dummy standard for frontal crash testing to comply with regulations regarding restraint systems. General Motors begins to work on improvements to develop a third generation of crash test dummies. The dummy that was developed had a new head and improved joint characteristics and it was named the GM ATD 502. 
Later, in 1976, from more refining and upgrading, evolved the Hybrid III dummy. One year later, the Hybrid III is made commercially available and GM creates a child dummy for air bag testing. In 1980, Dr. Harold Mertz began leading GM's dummy development projects. Dr. Mertz is an internationally recognized engineer specializing in dummy development, injury assessment criteria and occupant restraint system development.

GM petitioned NHTSA to use the Hybrid III crash test dummy for government compliance and in 1986, NHTSA agreed to use the dummy for compliance.

By 1987, a family of Hybrid III dummies were being developed by a committee under the supervision of Dr. Mertz. The family would include a 3-year-old, 6-year-old, 10-year-old, small adult female, and a large adult male.

The Hybrid III dummy is an human-like test device used in crashworthiness testing to assess the extent of occupant protection provided by the vehicle structure and its restraint systems in the event of a collision [34]. Although the dummy geometry is based on human measurements and the physical response of its components closely resemble that of a human cadaver, it doesn't necessarily behave like a human. For instance, the skeleton of the dummy is typically made of steel and aluminum and do not simulate exact bone mechanical characteristics. The reason for the choice of these materials is so that the dummy can be used in several crash tests and the results would remain repeatable.

The head of the Hybrid III dummy consists of a hollow cast aluminum shell of uniform thickness. The occipital portion of the aluminum shell is removable to allow for mounting and servicing of the accelerometer located in the center of gravity of the head. This accelerometer monitors the head's three-dimensional translational acceleration response. The aluminum shell is covered with a vinyl covering, simulating skin. The physical properties of the skin were made such that it has a similar impact response on a rigid surface with cadaver experiments.

The Hybrid III dummy's neck is comprised of four polymeric discs as demonstrated in Figure 24 The neck contains a slit in the back thereby providing appropriate flexion and extension responses. In between the polymeric discs are aluminum discs used to provide structural stiffness. Inserted along the neck is a steel cable to provide tensile strength. The top plate of the neck is connected to the head by a pin joint, simulating rotation through the occipital condyles. The occipital condyle is the area about which the Neck Injury Criterion $\left(\mathrm{N}_{\mathrm{ij}}\right)$ is based. The lower neck is attached to the spine box using an adjustable joint. 


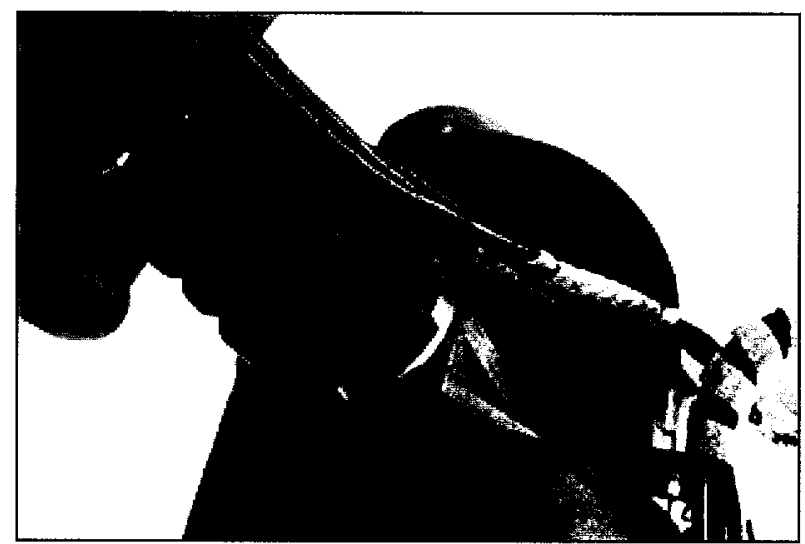

Figure 24. Neck of the Hybrid III dummy [44].

The shoulders of the dummy are comprised of cast aluminum links between the spine and the upper arms. To allow for flexibility and to prevent metal-to-metal contact there are rubber blocks, pivots and bushings inserted in this area. The shoulders are built in order to allow for a good shoulder-to-belt fit, providing a realistic setting for a three-point restraint system.

The thorax is an assembly that contains six steel ribs, as partially shown in Figure 25 . These ribs are covered with a material that provides a damping response. The ribs are connected at the back by a "spine" made from welded steel plates. At the front, the ribs are attached to a plexiglass plate, simulating a sternum. The entire assembly is covered in a removable vinyl jacket. There is also a foam pad at the sternum plate. Within the thoracic spine exists a triaxial accelerometer. It is placed at the thorax assembly's center of gravity. There is also a displacement transducer mounted between the sternum and the thoracic spine to measure chest compression. 


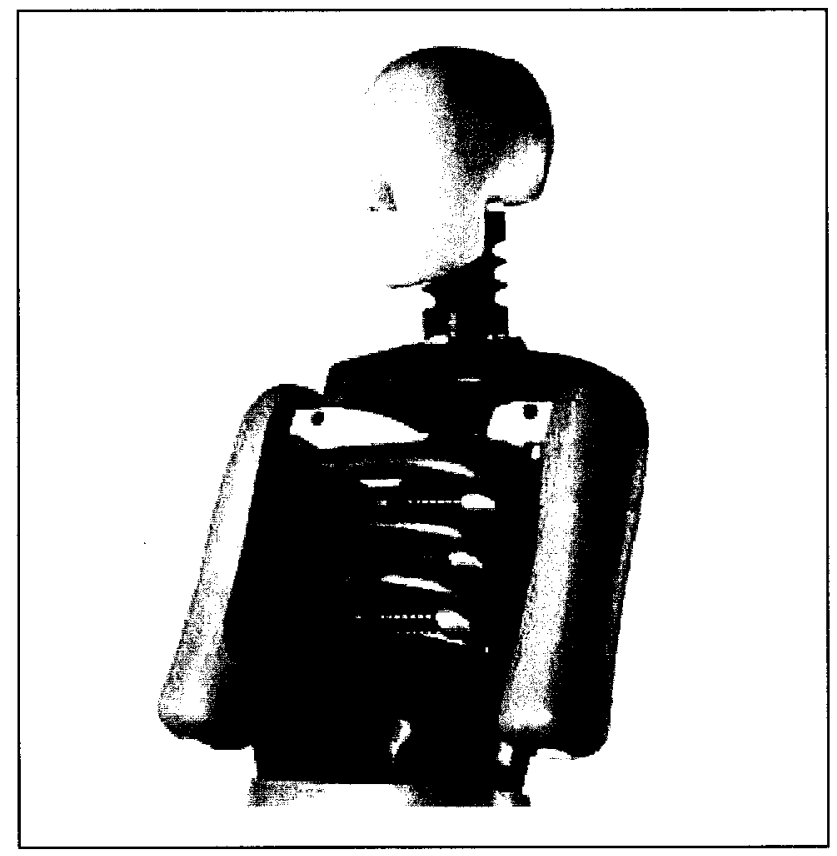

Figure 25. Chest/rib area of the Hybrid III dummy [44].

In 1991, the International Organization of Standardization (ISO) recommended the use of GM's Hybrid III dummy in restraint system testing. In addition, The Insurance Institute for Highway Safety (IIHS) chose to use the Hybrid III dummy. Furthermore, in 1997, NHTSA announced that the Hybrid III dummy would be the only official frontal impact test dummy for occupant restraint compliance testing, finally replacing the Hybrid II dummy. Europe accepted the Hybrid III dummy as the official test device for frontal impact restraint testing in 1998. Later, in 2000, NHTSA adds the 3-year-old and 6-year-old child dummies into its regulations. 


\subsubsection{Development of the finite element model of the Hybrid III dummy}

Khalil and Lin [46] published a study with GM regarding the simulation of the Hybrid III dummy response to impact by nonlinear finite element analysis. Essentially, finite element models of the Hybrid III dummy segments were developed and subjected to impact testing. The results of the finite element simulations were then compared to impact testing conducted on the specific portions of the dummy. The component finite element models represented the dummy sections as closely as possible. They were modeled with the appropriate material models and the response of the individual components was determined by explicit integration finite element analysis. Once the finite element models of the components were verified to be accurate, they were assembled using the appropriate joint characteristics and subjected to a ballistic pendulum impact on the thorax and compared to the response of a real Hybrid III dummy and the response of human cadavers. Figure 26 illustrates the components of a Hybrid III $50^{\text {th }}$ percentile male dummy and dummy finite element (FE) model.

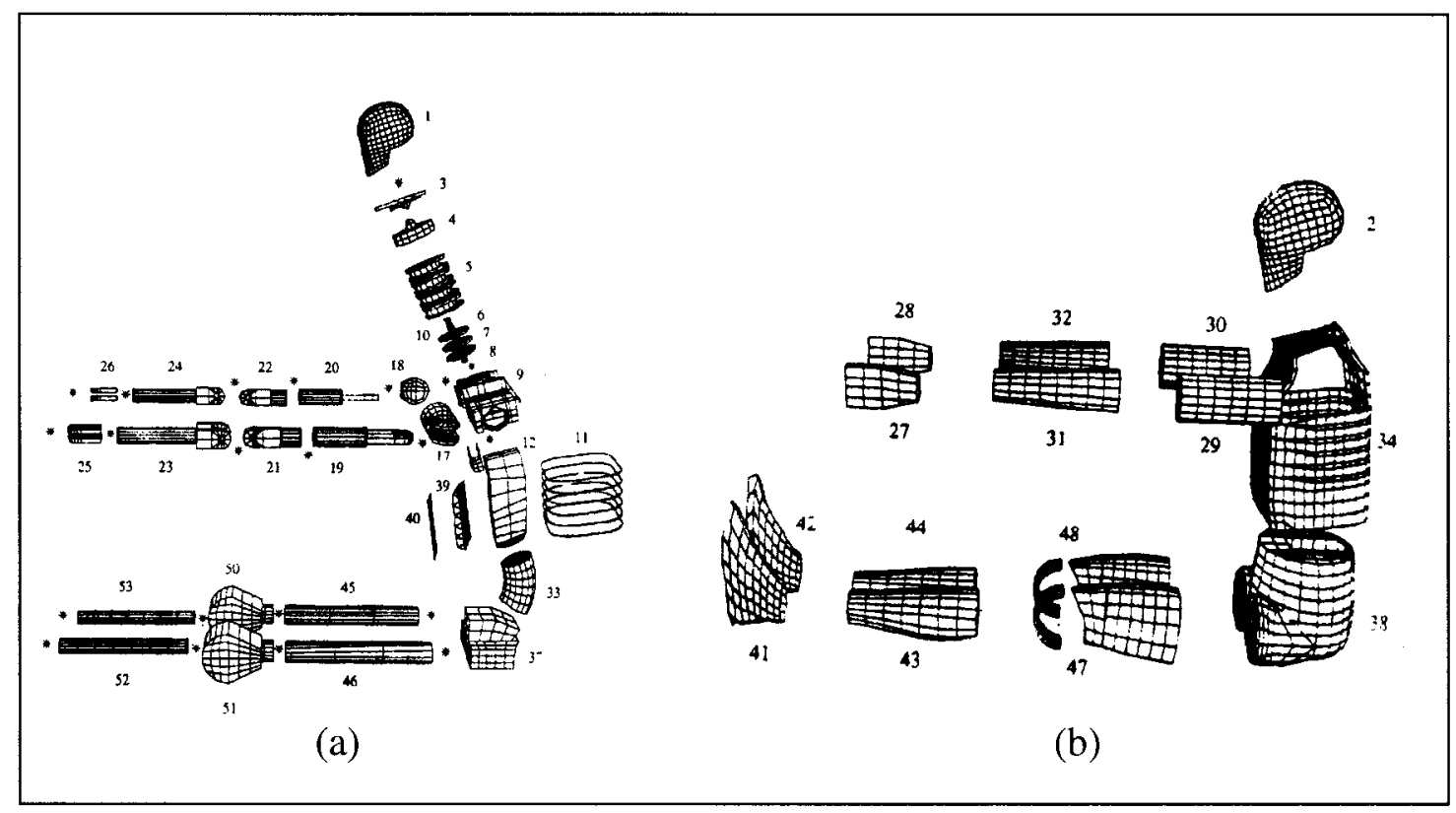

Figure 26. FE models of the interior components (a) and the polyvinyl exterior components (b) of the Hybrid III dummy [46]. 
The nonlinear finite element code DYNA3D was used to calculate the impact response of the dummy components. Each component was validated in an impact test. The head, for instance was subjected to two separate drop tests from a height of $376 \mathrm{~mm}$ and $889 \mathrm{~mm}$. The impact test was conducted in such a way that the forehead would impact the plate. The head acceleration was between 225 and $275 \mathrm{~g}$ 's. The finite element representation of the head impact (drop) test is demonstrated in Figure 27.

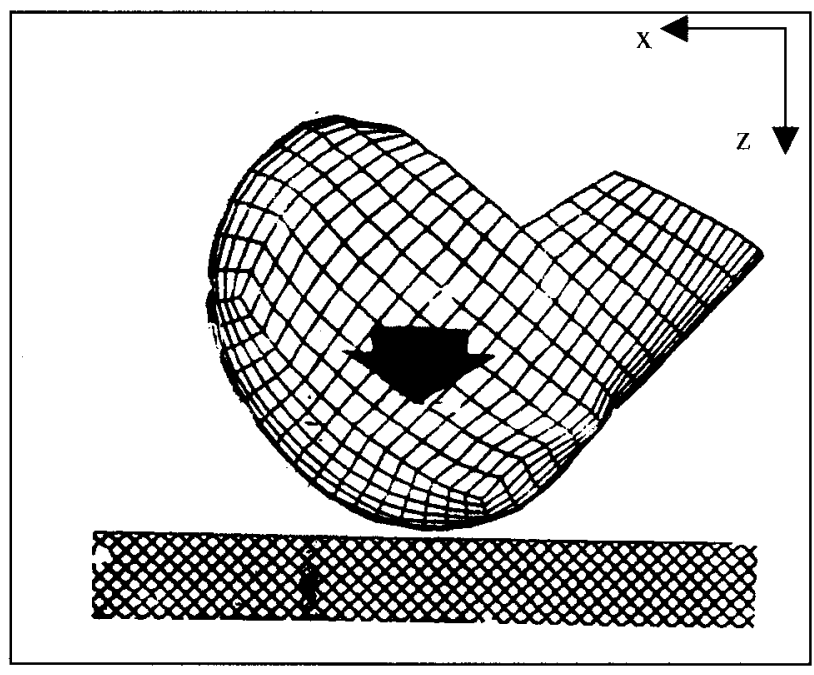

Figure 27. Finite element representation of head impact (drop) test [46].

The acceleration versus time was plotted for both the experimental and numerical data obtained and the results correlated well. The curves for the experimental drop test and the numerically simulated drop test show the similar patterns and similar peak acceleration values. Khalil and Lin [46] performed similar types of tests for all dummy components and then verified their finite element models by comparing their reaction to impact forces.

\subsubsection{Crash test dummy models and their use in computer simulations}

Computer crash simulations provide an efficient and economical approach to extending safety testing to include children and a far greater number of crash scenarios. Crash test dummy models have been used as standard, validated tools by vehicle and restraint manufacturers to evaluate the safety of new designs for vehicle occupants [47]. 
Crash test dummy models are capable of measuring accelerations, forces, and moments encountered in a collision, which can be related to risk of injury. For instance, the Hybrid III 3 year-old dummy model is equipped with 8 triaxial accelerometers and 5 load cells dispersed throughout their bodies that measure the accelerations and forces sustained by the particular regions of the dummy's body. The triaxial accelerometers are located in the head, chest, plevis, C7 bone, upper sternum, lower sternum, T12 bone, and the lower spine. The load cells are located at the upper neck, lower neck, pelvis, left acetabulum, and the right acetabulum. Each load cell can output three forces and three moments.

With computer crash simulations, the forces and accelerations experienced by occupants during different crash scenarios can be measured. Through recognized mathematical relationships that were determined through extensive biomechanical testing, these engineering measurements have been translated into a predicted risk of biological and structural injuries for distinct body regions of either children or adults in most part by Mertz and Prasad [38].

\subsubsection{Other dummies available in industry}

The Hybrid III family of dummies have been designed and used primarily for frontal impact tests of automotive restraint systems. Furthermore, the 3-year-old, 6-year-old, small female, and midsized male are used for frontal impact compliance testing by NHTSA. However, as previously mentioned, it is being utilized in a variety of impact environments due to the lack of viable alternatives [30].

\subsubsection{Side Impact Dummies}

The Side Impact Dummy (SID) was developed in the late 1970s and is used officially for side impact testing of new cars. The SID is used particularly by NHSTA for side impact head airbag compliance. The EuroSID and EuroSID-2 were developed by the European Experimental Vehicles Committee as their form of the North American SID. A more intricate torso was designed for the BioSID dummy. Essentially, the BioSID was designed to be more human-like and assesses the risk of injury to the head, neck, shoulders, abdomen, pelvis and legs. Although 
the BioSID is more sophisticated, it has not yet been authorized for side impact compliance in the United States. Another side impact dummy, SID II, was created by the Occupant Safety Research Partnership of USCAR, a group of United States vehicle manufacturers. The SID II represents a small female and is a scaled down version of the BioSID. In an effort to create a side impact dummy to be used world wide, ISO created the WorldSID.

\subsubsection{CRABI}

CRABI is short for Child Restraint Air Bag Interaction dummy. As its name suggests, this dummy is used to evaluate the exposure of airbags to infants restrained in a child restraint system. CRABIs come in three sizes including a six-month-old, 12-month-old, and 18-month old. CRABI is based on an infant's shape, scaled down from an adult dummy's general make.

\subsubsection{Rear Impact Dummies}

The BioRID and the RID-2 were developed in Europe in order to assess the potential for whiplash injuries. They are mid-sized male dummies and they measure the risk of minor neck injuries in low-speed rear-end collisions. 


\section{FOCUS OF RESEARCH}

Throughout the literature, it was determined that children in forward facing CRS face a high risk of head and neck injuries in a frontal crash. One argument is that the relatively large weight of a child's head with respect to the rest of the body causes high stresses and strains in the neck as the head accelerates during a frontal crash. Furthermore, for a child in a forward facing CRS, there is no mechanism to inhibit forward motion/rotation of the head. The rear of the rearward facing CRS does inhibit forward motion/rotation of the head.

There is no evidence to suggest that children placed in rearward facing CRS are at risk for head and neck injuries during a frontal crash. Convertible CRS are capable of facing children up to the ages of three and four in a rearward facing configuration but are typically faced forward for children older than 12 months.

There has been no complete study conducted comparing injury potential for young children in forward and rearward facing configurations.

This study is multifaceted in that it uses both experimental testing and numerical simulations to examine the potential of injury to children of three years of age. Through the requirements of FMVSS 213, experimental sled tests were performed on a Hybrid III 3-year-old dummy in both forward and rearward facing configurations. A numerical model of the forward facing configuration was developed and simulated using the same testing conditions. Verification of the finite element model allowed for a numerical comparison of forward and rearward facing configurations. Specifically, the purposes of this investigation are

1) To investigate the risk of injury to the head and neck that 3-year-old children are subjected to in a frontal crash according to FMVSS 213 in both forward and rearward facing configuration of CRS.

2) To propose a solution capable of reducing the load exerted on the neck of a child in a situation of a frontal collision, thereby reducing the injury imposed on the child. 


\section{EXPERIMENTAL PROCEDURE}

Further research was conducted to determine the potential of injury for the forward versus rearward facing children in child restraint systems. Experimental work was conducted through sled testing using a Hybrid III 3-year-old dummy restrained in a five-point restraint child seat according to standards outlined in FMVSS 213. These results were then compared against numerical simulations using the same set-up and testing procedure.

\subsection{Experimental crash testing - FMVSS 213 sled test}

Testing equipment and facilities were provided by Graco Corporation where the manufacture of several varieties of child restraint seats takes place. The testing facility has the capability to conduct experimental sled testing in accordance to FMVSS 213.

The runway is $30.48 \mathrm{~m}$ long and the sled is powered pneumatically by a $1.06 \mathrm{~m}^{3}$ pressure vessel with $6.89 \mathrm{kPa}$ of compressed air. Beneath the crash barrier at the end of the runway exists 60 tonnes of reinforced concrete measuring $1.83 \times 2.44 \times 1.52 \mathrm{~m}$ underground and continues above ground level for $0.61 \mathrm{~m}$. Figure 28 illustrates the Hybrid III 3-year-old dummy is seated on the sled with the $30.48 \mathrm{~m}$ foot length track on which the sled is guided. At the very front of the image is the reinforced concrete block into which the sled crashes. On either side of the sled there are two high-speed video cameras. This equipment is illustrated in Figure 28. 


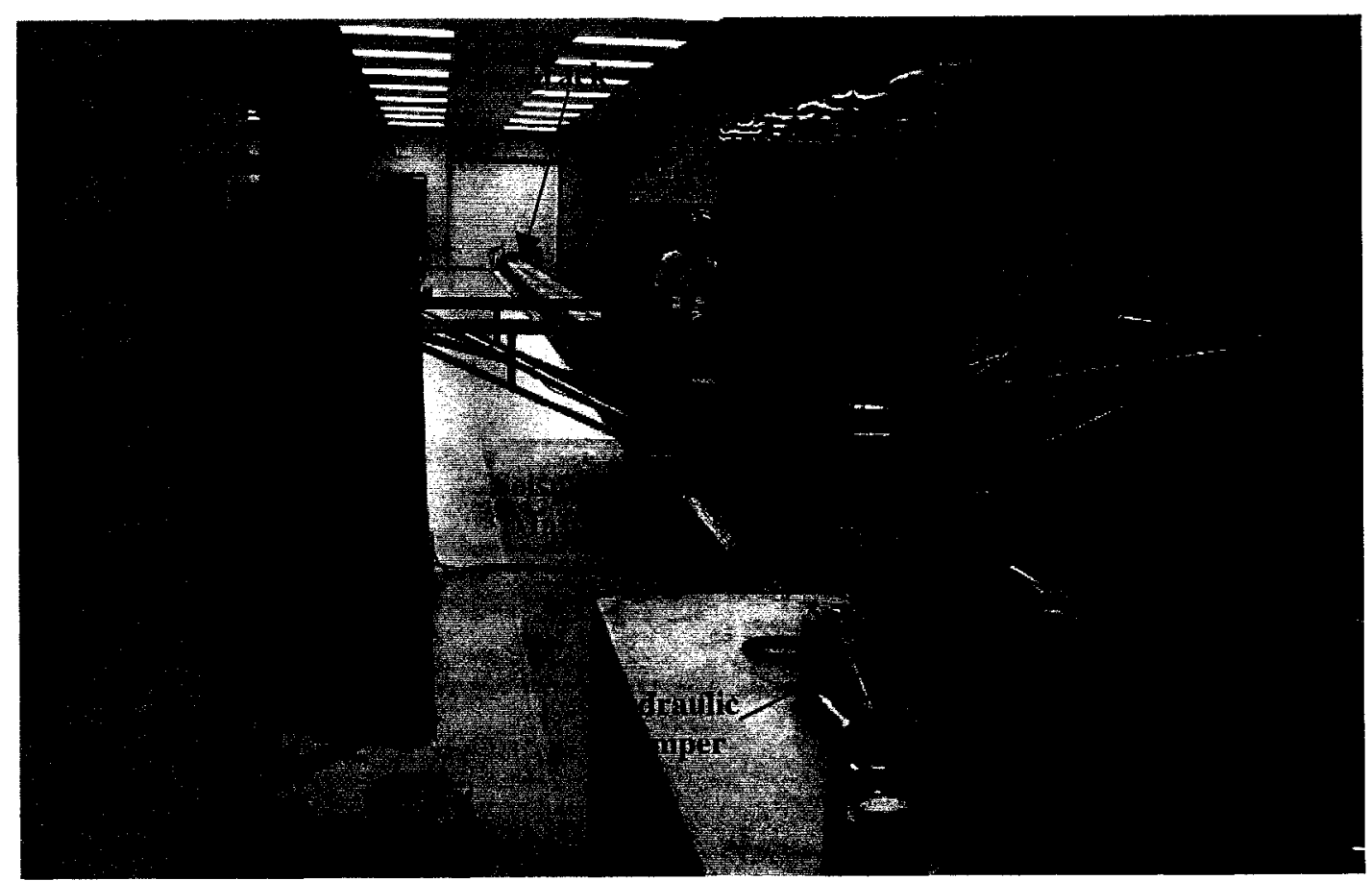

Figure 28. Pneumatically powered sled test device.

A Hybrid III 3-year-old dummy, acquired from Denton ATD, Inc. was used in the sled tests. The dummy contained three uniaxial accelerometers in both the head and the chest. Figure 29 (a) shows the three uniaxial accelerometers in the head and Figure 29 (b) illustrates the chest area of the dummy. The steel ribs hide the uniaxial accelerometers' exact position. However, the black thread-covered wires leading to the accelerometer can easily be seen.

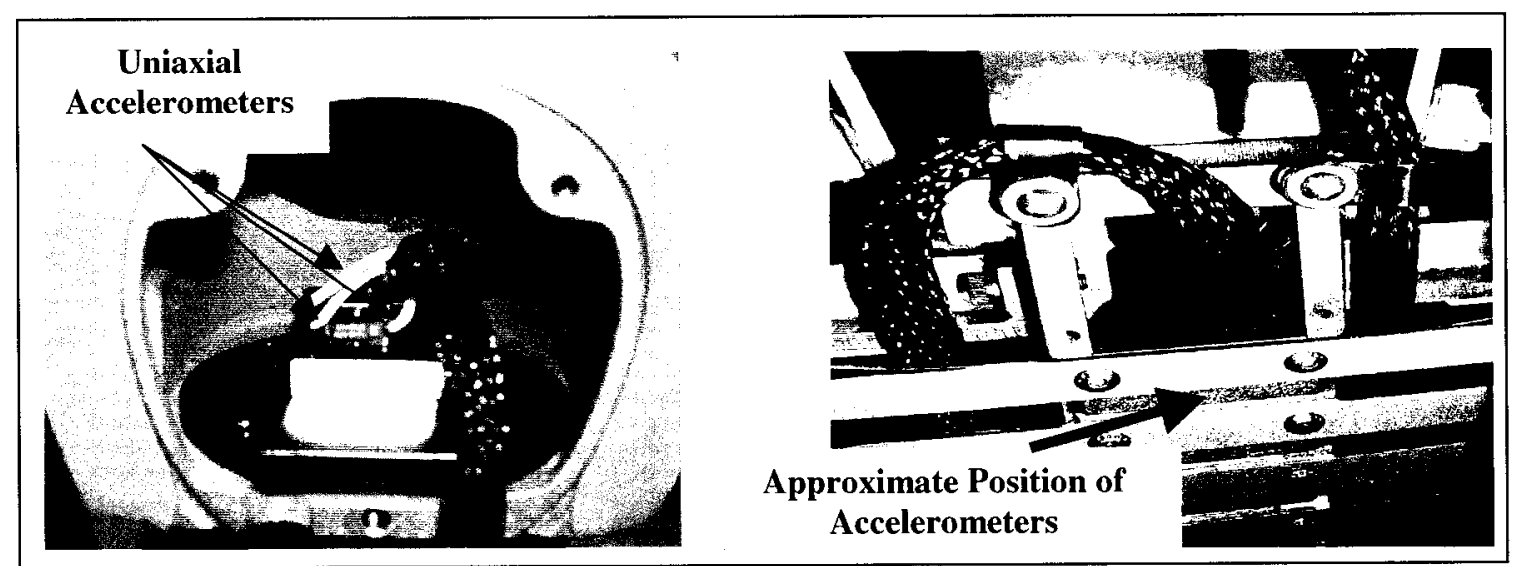

Figure 29. Hybrid III 3-year-old dummy uniaxial accelerometers in (a) the head and (b) the chest. 
The uniaxial accelerometers were set up in such a way that they acquire data in the $x, y$, and $z$ local coordinate system with each direction perpendicular from the other. The accelerometers were rated for a capacity of $2000 \mathrm{~g}$ 's.

\subsubsection{Forward facing sled test}

The first sled test completed using the Hybrid III 3-year-old dummy restrained in a five-point child seat facing the forward direction. Figure 30 shows how the dummy was restrained in a forward facing child safety seat using a five-point restraint and then further restrained to the sled seat. The child is naturally reclined to an angle equaling around 20 degrees due to the angle of the seat backing. The accelerometers were attached to the appropriate receptors so that acceleration readings would be read into the computerized analysis system. The system was then subjected to an acceleration pulse that is shown in Figure 31.

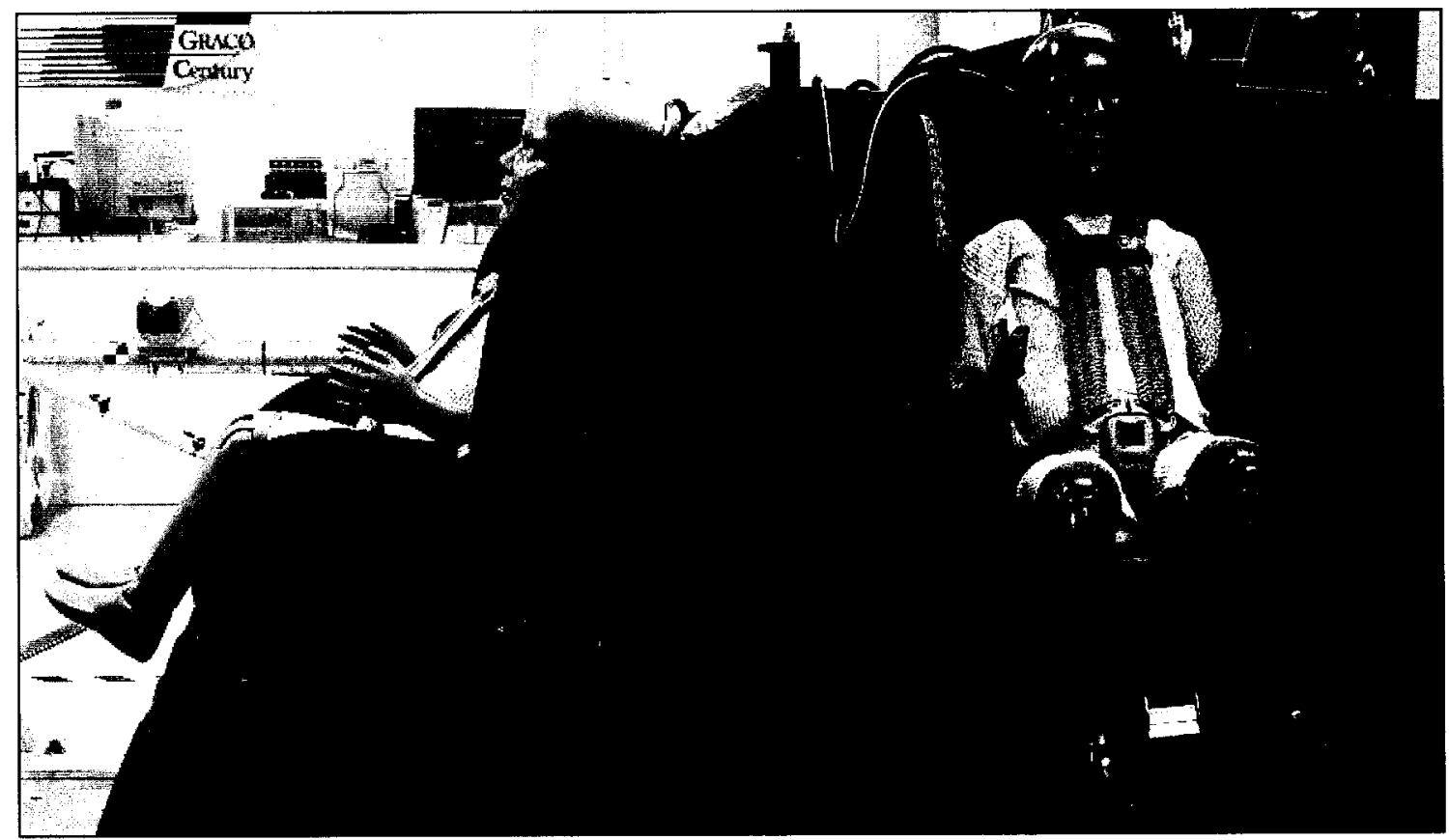

Figure 30. Side and front view of the Hybrid III 3-year-old dummy restrained in the five-point restraint child seat at the Graco crash test facility. 


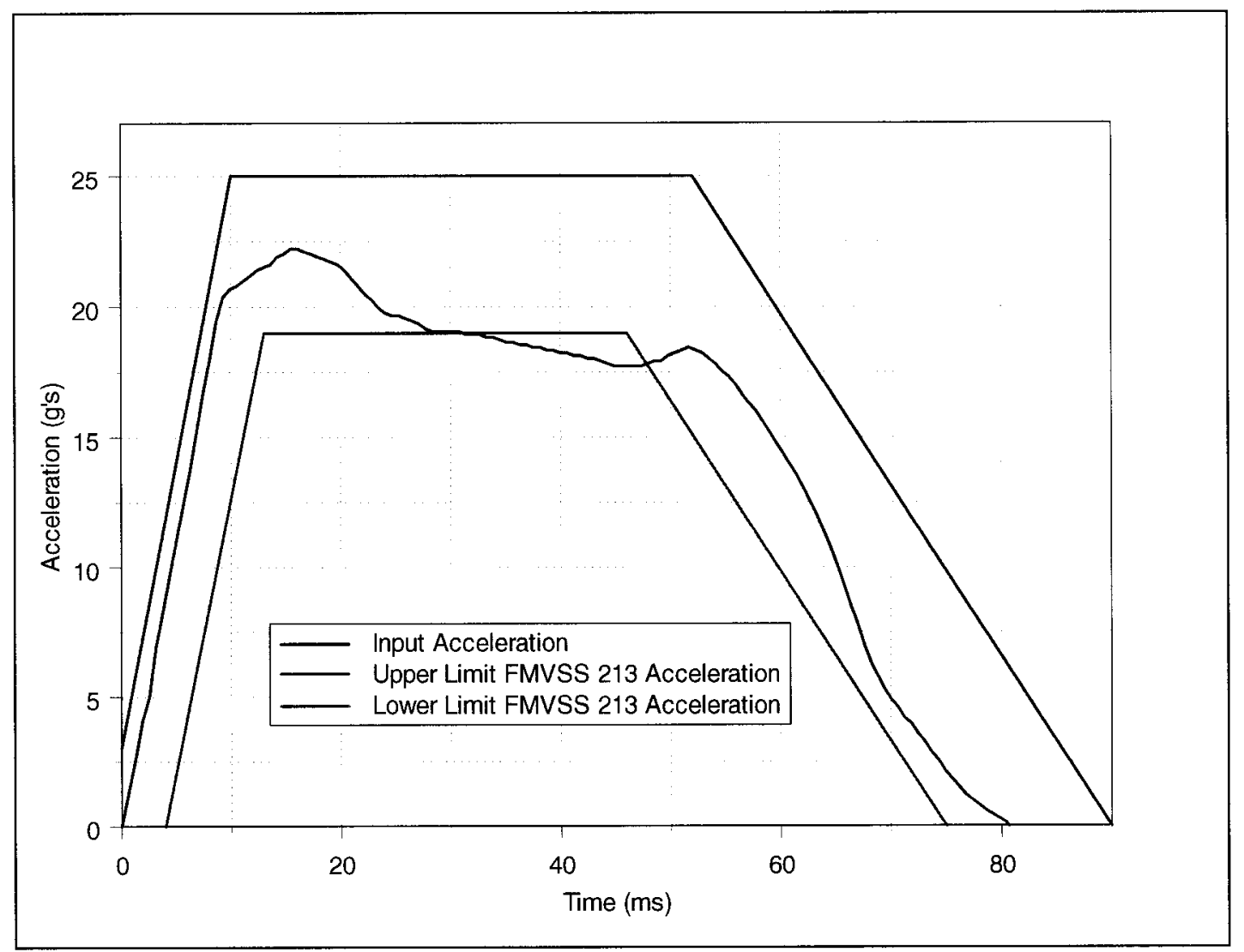

Figure 31. FMVSS 213 standard input acceleration versus time curve.

The manner in which the acceleration pulse was administered to the bench seat was through a hydraulic damper on a seismic mass. The length of the damper was $1.22 \mathrm{~m}$ and it was covered with small orifices. A piston penetrated the damper and a coolant fluid (consisting of water and soluble oil) exited the orifices. The plugging up of the holes controlled the acceleration pulse.

The output of the tests that were run include sled, head, and chest accelerations. The sled acceleration, illustrated in Figure 31 was obtained through one uniaxial acceleromter lying in the direction of the sled's travel. The head and chest uniaxial accelerometers were in three mutually perpendicular directions, acquiring data in the local $\mathrm{x}, \mathrm{y}$, and $\mathrm{z}$ coordinates. In addition, high-speed camera techology allowed for pictures demonstrating the motions of the Hybrid III 3-year-old child in the forward facing position. In total, there were three high-speed cameras, one on either side of the sled seat, as well as an overhead camera. The cameras acquired photos as a rate of 1000 frames/second. 


\subsubsection{Rearward facing sled test}

The Hybrid III 3-year-old child dummy was also placed in a rearward facing position seated in the same five-point child saftey seat. Figure 32 illustrates that the sled used is not designed for a child of three years of age to sit in the rearward facing position. The legs do not bend down at the knees. Instead, the are forced to be placed above chest level, hyperextended on the back of the sled seat, which does not mimic reality. The same conditions would be seen in the back seat of a passenger car. Ergonomically, it is not possible to face a three-year-old child in the rear facing position.

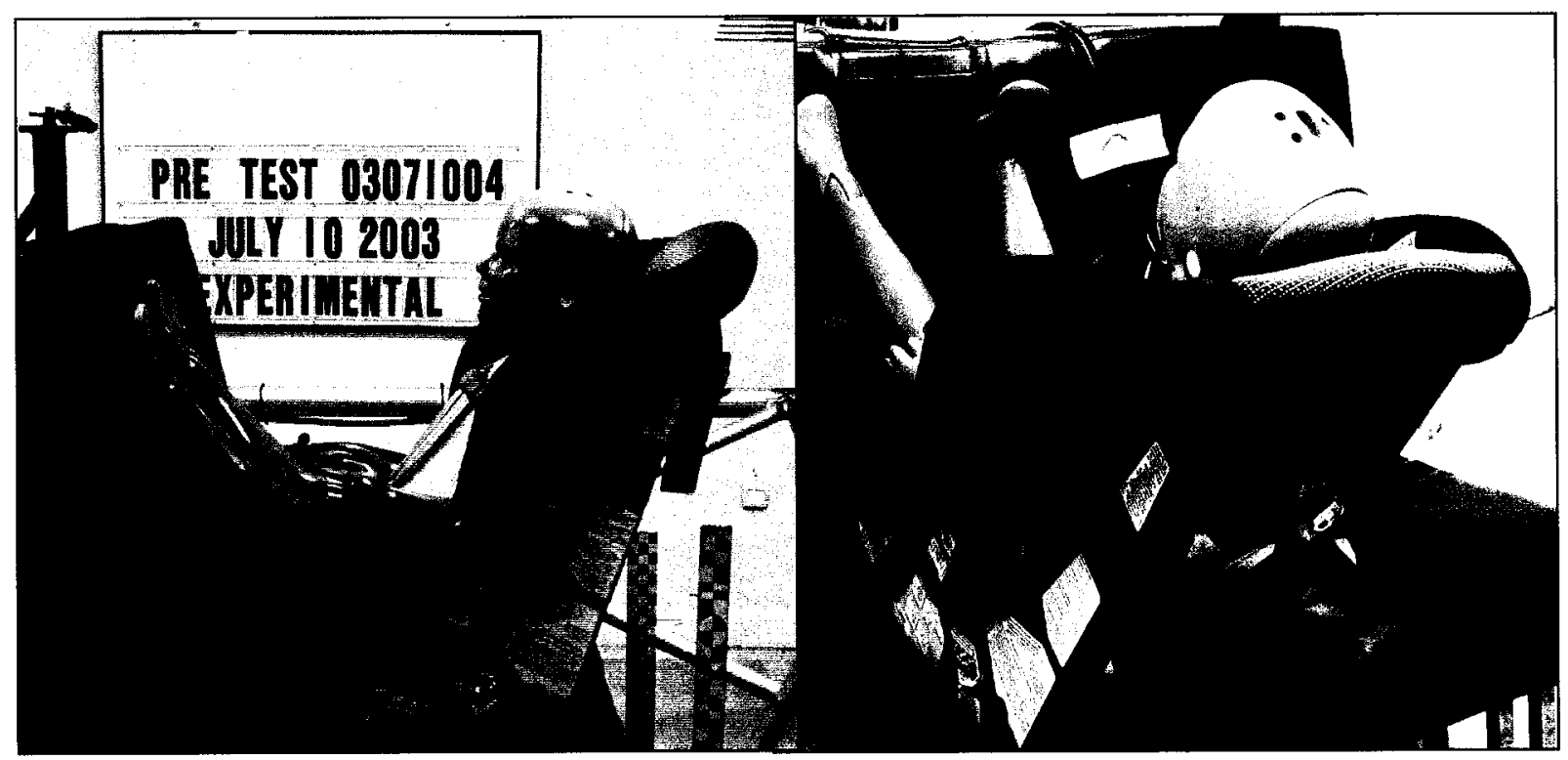

Figure 32. Side and back view of the Hybrid III 3-year-old dummy restrained in the five-point restraint child seat in the rearward facing position.

Due to the awkward position of the child dummy in the child seat, the experimental results of the sled tests proved to be insignificant and unrealistic as they did not provide a realistic portrayal of the configuration. Instead, excessive backward rotations of the child safety seat were observed. The sled test was performed and only qualitative observations were presented in the results. 


\subsubsection{Data acquisition}

The data acquired included head and chest accelerations. No digital data was acquired. Instead, hard copies of the $\mathrm{x}, \mathrm{y}$, and $\mathrm{z}$ acceleration versus time curves for the head and chest were obtained. These hard copies of the graphs were scanned and digitized using UN-SCAN software. This made the digital data available for future calculations and comparisons to numerical simulation results. 


\subsection{Numerical simulations}

\subsubsection{Preprocessing}

The Hybrid III dummy is extensively used in crash testing and is especially important for frontal crash test situations. In this study, a Hybrid III three-year-old dummy model is used, which is a scaled down version of the $50^{\text {th }}$ percentile adult male Hybrid III dummy model. Donated by First Technology Safety Systems (FTSS), the dummy model is comprised of 12,172 elements and 11,698 nodes. There are zero-length beam elements and nodes located in specific areas of the body used to provide numerical observations similar to the experimental load cells and accelerometers. The zero-length beam elements are modeled using material Type 66 (linear elastic discrete beam) and they act as stiff translational and rotational springs. The stiffness in the translational and rotational direction are specified in the material model. These tools are essential in the determination of forces and accelerations in the head and neck area of the child. The Hybrid III three-year-old dummy model is completely deformable and is complex combination of various material characteristics, joint stiffnesses, masses, and element formulations. In addition, some internal organs and other structures are modeled, some of which can be seen in Figure 33(b). The meshed model is shown in Figure 33(a). The dummy model itself was not manipulated other than changing its position to correctly place it into the child seat.

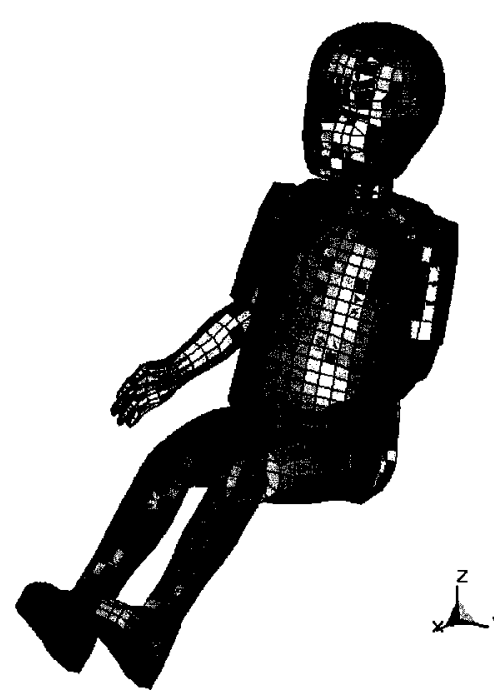

(a)

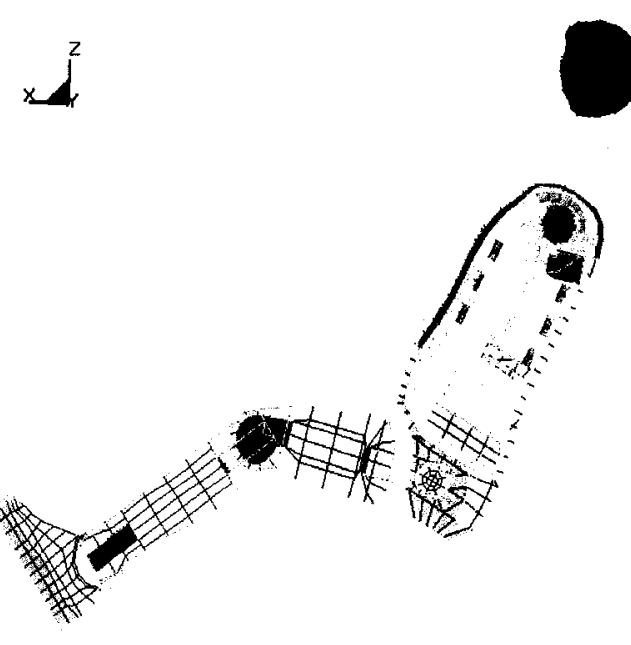

(b)

Figure 33. (a) Meshed view and (b) side view of Hybrid III 3-year-old dummy model. 


\subsubsection{Contact for the Hybrid III 3-year-old dummy model}

In general, a dummy model consists of two types of contact algorithms - internal contact surfaces and additional contact surfaces [48]. The internal contact surfaces are the permanent and necessary for the dummy model. The additional contact surfaces are defined by the user and they would vary depending on the analysis. Table 11 lists the types of internal contact algorithms used.

Table 11. Types of internal contact algorithms used in Hybrid III 3-year-old dummy model [48].

\begin{tabular}{|c||c|}
\hline \multicolumn{1}{|c||}{ Contact Type } & Contact Keyword \\
\hline \hline Type 3 & ${ }^{*}$ CONTACT_SURFACE_TO_SURFACE_TITLE \\
\hline Type 4 & ${ }^{*}$ CONTACT_SINGLE_SURFACE_TITLE \\
\hline Type 5 & ${ }^{*}$ CONTACT_NODES_TO_SURFACE_TITLE \\
\hline Type 13 & ${ }^{*}$ CONTACT_AUTOMATIC_SINGLE_SURFACE_TITLE \\
\hline Type 26 & ${ }^{*}$ CONTACT_AUTOMATIC_GENERAL_TITLE \\
\hline
\end{tabular}

There are a total of 13 internal contact algorithms used within the Hybrid III 3-year-old dummy model and they are all listed in Appendix B.

\subsubsection{Joint characteristics}

The manner in which the dummies limbs are able to move depend on the default joint characteristics set by FTSS within the Hybrid III 3-year-old dummy model. According the FTSS Hybrid III 3-year-old dummy model user manual [48], two joints are defined for each physical joint. In the case that the physical joint is a ball joint, such as the knee joint, a spherical joint is used. In the case that the physical joint acts as a hinge, such as the elbow joint, a revolute joint is used. The joint characteristics, such as stiffness and damping, can be changed in the LS-DYNA input file. In this study, the joint characteristics were left at the default values set by FTSS. Table 12 lists the joints located within the dummy model as well as the parts they joint together. 
Table 12. Hybrid III 3-year-old dummy model joint location and parts joined [48].

\begin{tabular}{|c||c||c|}
\hline \multirow{2}{*}{ Location of Joint } & \multicolumn{2}{|c|}{ Parts Joined } \\
\cline { 2 - 3 } & Part A & Part B \\
\hline \hline Left Shoulder & Spine Box & Left Shoulder Bracket \\
\hline Right Shoulder & Spine Box & Right Shoulder Brackt \\
\hline Right Elbow & Right Upper Arm & Right Lower Arm \\
\hline Left Elbow & Left Upper Arm & Left Lower Arm \\
\hline Left Knee & Left Femur Skeleton & Left Tibia Skeleton \\
\hline Left Ankle & Left Tibia Skeleton & Left Foot Skeleton \\
\hline Right Knee & Right Femur Skeleton & Right Tibia Skeleton \\
\hline Right Ankle & Right Tibia Skeleton & Right Foot Skeleton \\
\hline Right Yoke & Right Shoulder Damper & Left Upper Arm \\
\hline Left Yoke & Left Shoulder Damper & Right Upper Arm \\
\hline Right Hip & Right Hip Joint Bracket & Right Femur Skeleton \\
\hline Left Hip & Left Hip Joint Bracket & Left Femur Skeleton \\
\hline Fake Neck Joint & Neck Loadcell Beams & Neck Fake Joint Beam \\
\hline
\end{tabular}

\subsubsection{Modeling of the child safety seat}

FEMB was used in the meshing of the child seat. The computer aided drawing (CAD) data for the five-point CRS was donated by Graco Corporation. The seat was modeled using a rigid material model. Half of the seat was meshed in FEMB and then it was mirrored in its line of symmetry to obtain the full seat. The CAD data of the seat was quite complex, showing many intricate details of the plastic mold. For the purposes of this research, only the pertinent surfaces were considered when meshing the seat since it was modeled using a rigid material model. The rigid material model, Type 20 in LS-DYNA, makes it easy to convert one or more parts into a rigid entity [49]. This method is sometimes desirable when modeling. In this case, it was used because the seat, which is modeled as rigid, is not being analyzed. The stresses and strains that potentially occur in a seat during a crash are not of interest for this research.

The inertial properties of parts of the rigid material type can be defined by default or they can be defined by the user. By default, the inertial properties are arrived at by the geometry of the rigid body's elements and the density of the part. When defined, the user input the inertial properties and the initial velocities [49]. 
The rigid material type required the user to enter such values as Young's Modulus, E, and Poisson's ratio, $v$ and these are used in determining sliding interface energy in the case of contact between the rigid body and other parts [50]. Even though the body is defined as rigid, realistic values should be used because unrealistic values could contribute to problems with contact. The values used for the material properties were of typical polypropylene properties.

Figure 34 (a) illustrates the fully meshed child safety seat. The seat was comprised of 12002 nodes and 11990 quadratic and triangular shell elements. The element formulation employed was the Belytschko-Lin-Tsay formulation. This formulation defines a 4-noded element with both bending and membrane capabilities. The element has 6 degrees of freedom at each node. The Belytschko-Lin-Tsay shell element was developed in 1981 as "computationally efficient alternative" to the Hughes-Liu shell element [51]. Both shell elements have five integration points through the thickness, but the Belytschko-Lin-Tsay shell elements require 725 floating point operations per cycle compared to 4,066 operations per cycle for the under integrated Hughes-Liu elements and 35,367 operations per cycle for the selectively reduced integration formulation. Clearly, the Belytschko-Lin-Tsay is the element of choice to reduce computation time. The seat was constrained to move in one direction. The seat was prescribed to follow the input acceleration in Figure 31 in one direction, the x-direction. Figure 34 (b) illustrates the seat belt slots available in the CRS. Typically, the top slots on the back of the CRS are used for an older/larger child. 


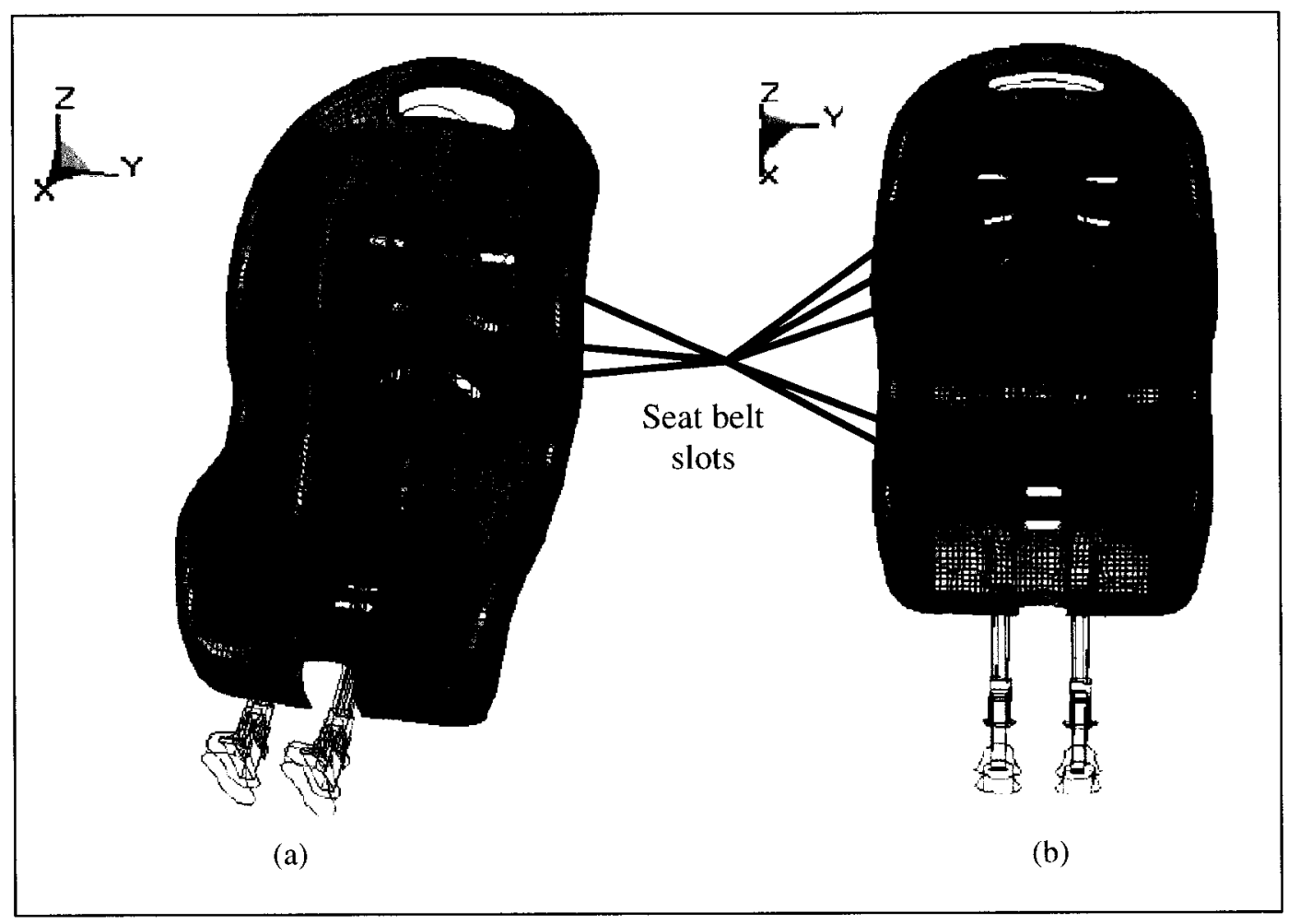

Figure 34. Meshed model of child safety seat illustrating (a) isometric and (b) top views.

\subsubsection{Modeling of the seat belt}

The seat belt was designed to fit properly around the Hybrid III 3-year-old dummy and to fit through the top slots of the child seat. Further, the seat belt was meshed using FEMB and the material properties given to the belt system were obtained from Quality Safety Systems (QSS) [49], a manufacturer of seat belts in Windsor, Ontario, Canada. The seat belt was created and meshed in the same way as the seat in that half of it was created and mirrored in its line of symmetry. The seat belt was modeled using a fabric model and consisted of 1,102 nodes and 929 4-noded shell elements. The seat belt was modeled using fully integrated Belytschko-Lin-Tsay shell elements. The belt and the clasps are demonstrated in Figure 35 . The last two rows of nodes at the end of the belts were constrained to follow the motion of the seat in the $\mathrm{x}$-direction. The input acceleration that was prescribed to the seat was also prescribed to the 
nodes on the belt. The material model used was *MAT_FABRIC, Material 34. According to the LS-DYNA theoretical manual [51], the fabric material model is strongly recommended for airbags and seatbelts. This model employs a special membrane element formulation that is better suited for the large deformations experienced by fabrics.

\subsubsection{Modeling of the clasps}

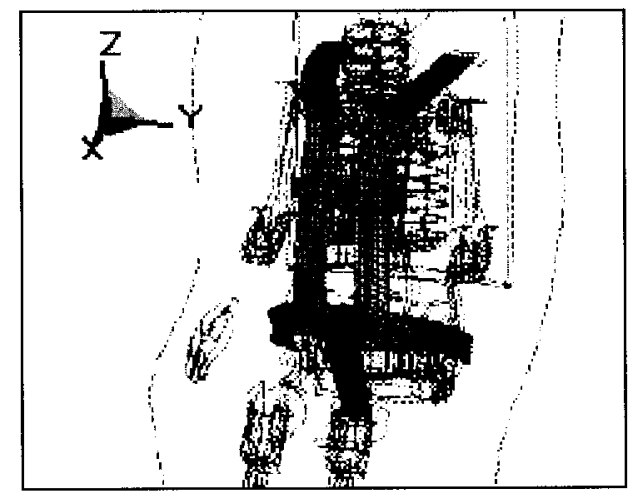

Figure 35. Meshed seat belt and clasps model.

The clasps were modeled as rigid entities and using the same polypropylene mechanical characteristics as used for the child seat model. The clasps consisted of 313 nodes and 257 4-noded shell elements. The clasps were modeled using a Belytschko-Lin-Tsay element formulation.

\subsubsection{Modeling of the foam insert}

A part of the child safety seat that was not apparent in the CAD data but is clearly apparent in the actual child seat is a foam insert. This serves to further protect the child as well as to provide some comfort against the plastic seat. This material was modeled as low-density foam. The low-density urethane foam material model, Material Type 57, is used to model highly compressible foams such as those used in seat cushions. In tension, it is assumed that the material behaves linearly until it tears. In compression, there exist various modes of behaviour. Figure 36 illustrates a typical foam load versus deflection curve. First, there is a linear region, 
which exists in all elastic materials. This is followed by a region called the plateau region, which is another linear region beyond the yield point. The next region is called densification where the foam requires a large increase in load to compress the foam by a very small amount. Lastly, the hysteretic unloading region takes place. In LS-DYNA, this material model uses tabulated input for the loading curve. The loading curve includes the first three regions of behaviour; the linear region, the plateau region, and the densification region. By using input shape factor controls a hysteresis unloading factor (HU), a decay constant ( $\beta$, BETA), and a shape factor for unloading (SHAPE) the observed unloading behavior of foams can be closely approximated [49].

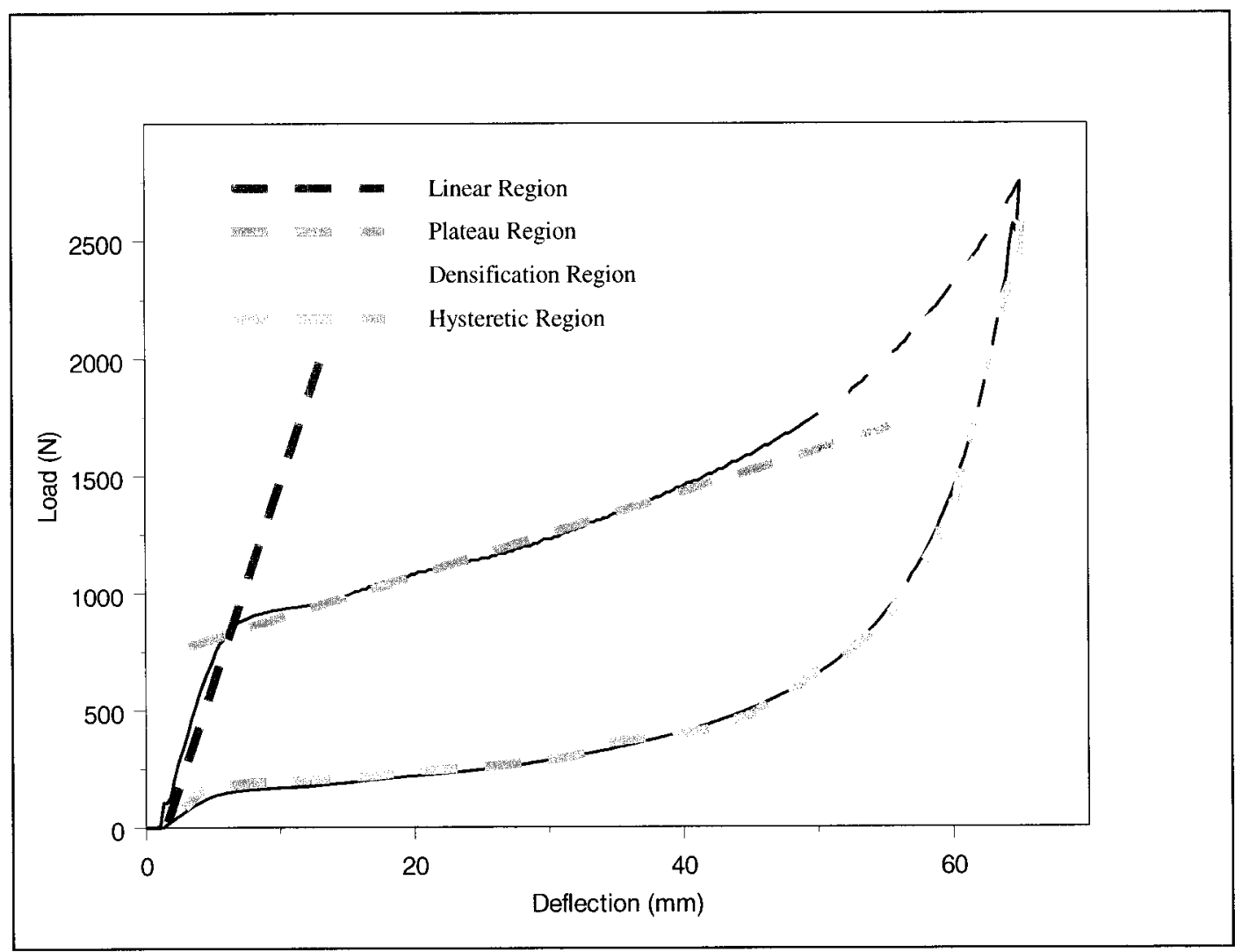

Figure 36. Typical load-deflection curve for urethane foams illustrating the linear, plateau, densification, and hysteretic regions.

Several foam samples were subjected to compressive testing to achieve the proper loading and unloading characteristics of the actual foam insert. Several samples of that was characteristic of the foam insert used in the actual child safety seat were subjected to compressive testing. In LS-DYNA, the low-density foam material model requires on only to input the loading curve. The 
unloading curve is characterized by two main inputs; or the hysteretic unloading factor (HU), and the shape factor (SHAPE). These values are attained by a trial and error method. Table 13 lists the values of HU and SHAPE that were used in the trial and error numerical simulations. Ten simulations were carried out to mimic the experimental compressive test, each simulation with varied hysteretic unloading and shape factors. The load-deflection data was plotted and compared to the experimental curve. The curve that most closely resembled the experimental curve was chosen to represent the foam in the child safety seat. Figure 37 illustrates the experimental load-deflection curve in addition to all simulation trials that were carried out.

Table 13. Trial HU and SHAPE values used in foam study.

\begin{tabular}{|c||c||c|}
\hline Trial & HU & SHAPE \\
\hline \hline 1 & 0.1 & 5 \\
\hline 2 & 0.1 & 4.5 \\
\hline 3 & 0.1 & 6.5 \\
\hline 4 & 0.05 & 7.5 \\
\hline 5 & 0.1 & 7.5 \\
\hline 6 & 0.05 & 7.5 \\
\hline 7 & 0.06 & 7.5 \\
\hline 8 & 0.15 & 6 \\
\hline 9 & 0.07 & 6.5 \\
\hline 10 & 0.1 & 8.5 \\
\hline
\end{tabular}




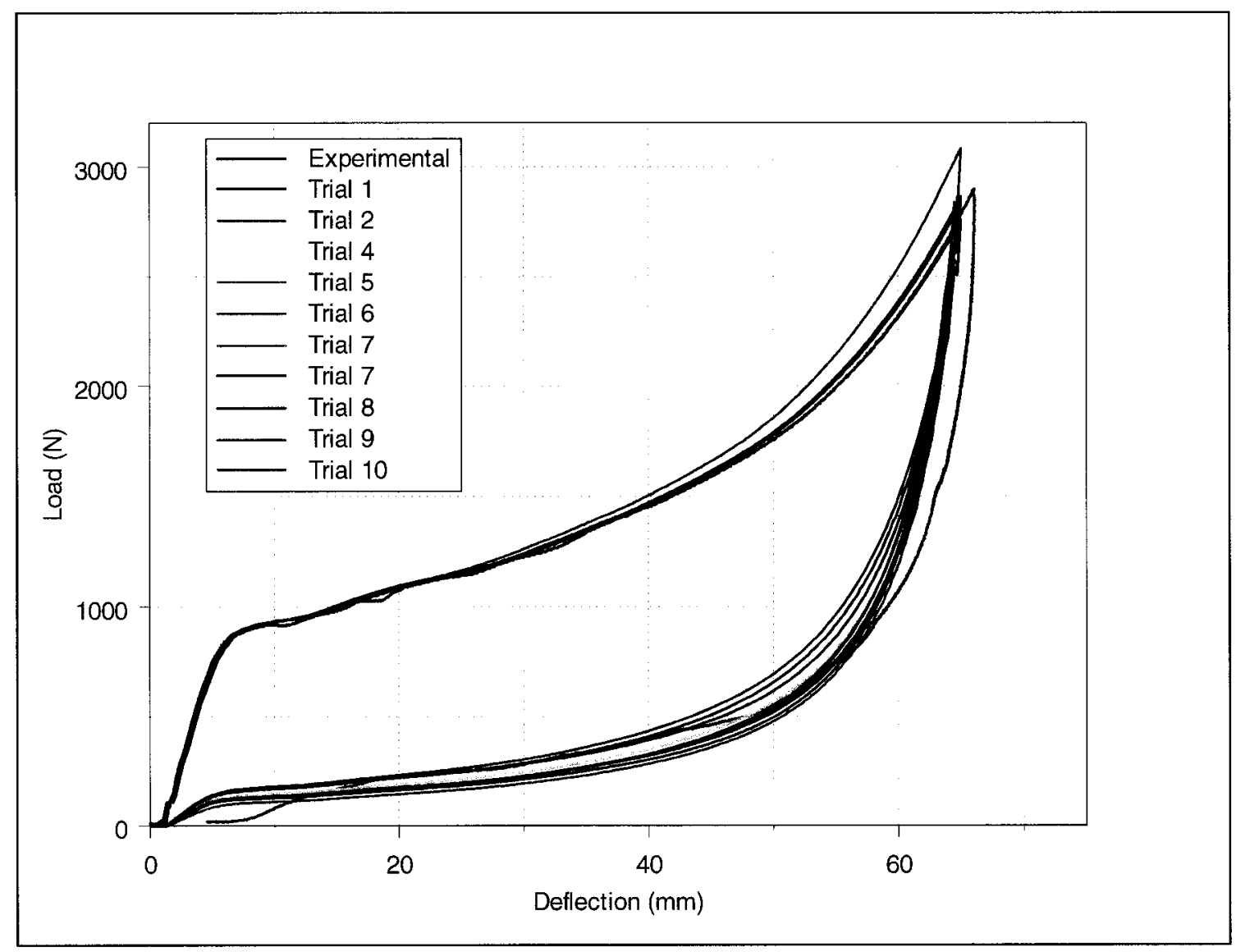

Figure 37. Load versus deflection for trial numerical simulations of urethane foams. 
Once the values that most closely characterized the actual foam were found, the model was created and it was used in the simulations. The values of HU and SHAPE of the first trial were found to create a load deflection curve that fit the experimental the best. Figure 38 illustrates the

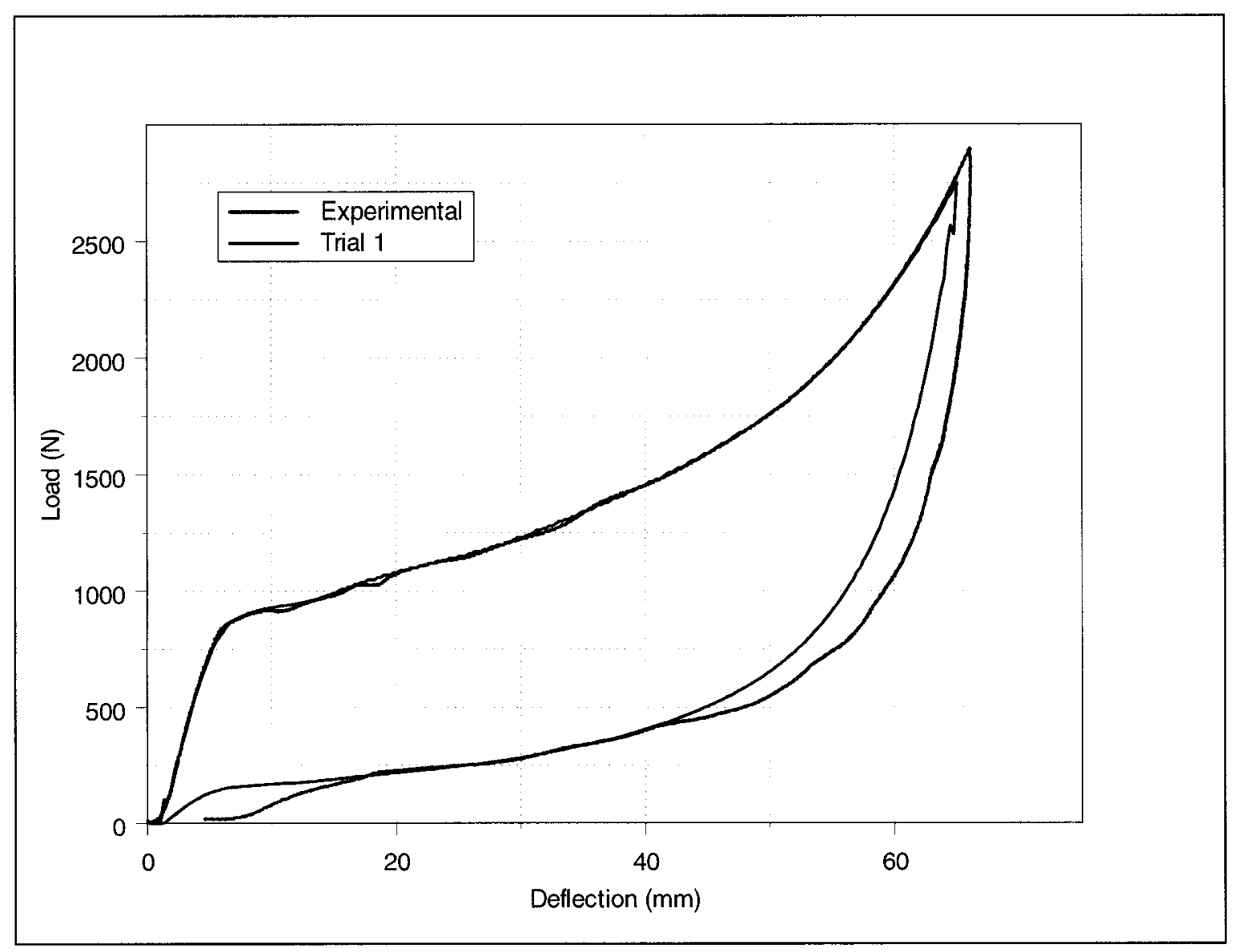

Figure 38 Experimental curve and numerical curve for foam model verification.

load deflection curve of the first trial that was used in the LS-DYNA input file to define the material characteristics of the foam. However, it was found that the negative volumes in the foam insert were obtained and the simulation ended with errors. Many simulations were completed to determine the effect of stiffening the foam. Comparisons were made between the simulations and it was found that stiffening the foam by a factor of 25 did not adversely affect any results because the force at which the dummy model comes into contact with the seat far surpasses the strength of the foam material. 
Figure 39 illustrates the foam insert, which consisted of 1,953 nodes and 1,200 solid elements. The element formulation used was the selectively reduced solid element formulation which uses three quadrature points in the normal direction and one quadrature point in the shear direction.

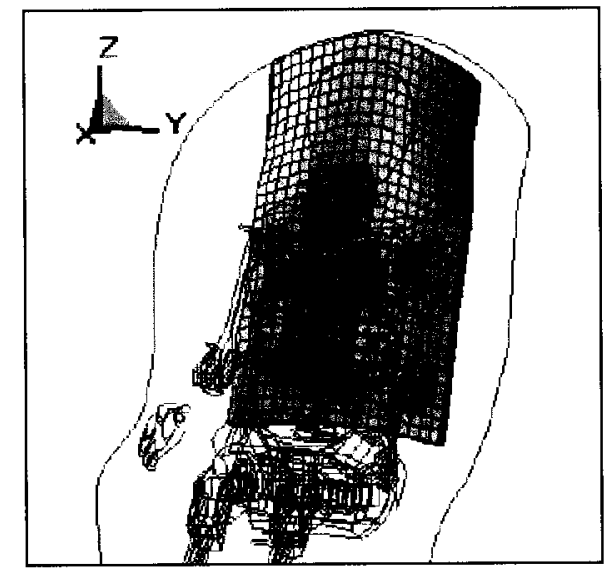

Figure 39. Meshed model of foam insert.

\subsubsection{General set-up of the system}

The positioning of the dummy model into the child seat was accomplished using EASiCrash Dyna. The simulations were run using the double precision version of LS-DYNA (release 3711) on a personal computer with dual $2.0 \mathrm{GHz}$ AMD Athalon processors with $500 \mathrm{MB}$ of DRAM.

The contact between the individual parts of the dummy model were not modeled by the user. These algorithms are included in the dummy file although changes can be made if the user finds it appropriate. In this study, no changes were made to any contact algorithms that were dummy-specific. Contact between the child safety seat, the seat belt system, the foam insert, and the child were modeled using an *AUTOMATIC_SURFACE_TO_SURFACE algorithm. The foam insert placed in between the dummy model and the plastic seat used the contact algorithm *CONSTRAINED_EXTRA_NODES_SET, where a node set was created using the nodes of the back of the foam insert and constraining them to the back of the polypropylene seat. 
The general set-up of the problem included a Hybrid III 3-year-old dummy model seated in an upright position in the child safety seat and buckled in using a typical five-point restraint. The FMVSS 213 acceleration pulse was input into the simulation. The child seat system was subjected to this pulse at angle of 20 degrees to the vertical in the forward position, and 45 degrees in the rearward position. These angles are the angles at which the experimental testing was carried out. Figure 40 illustrates the meshed setup of the system.

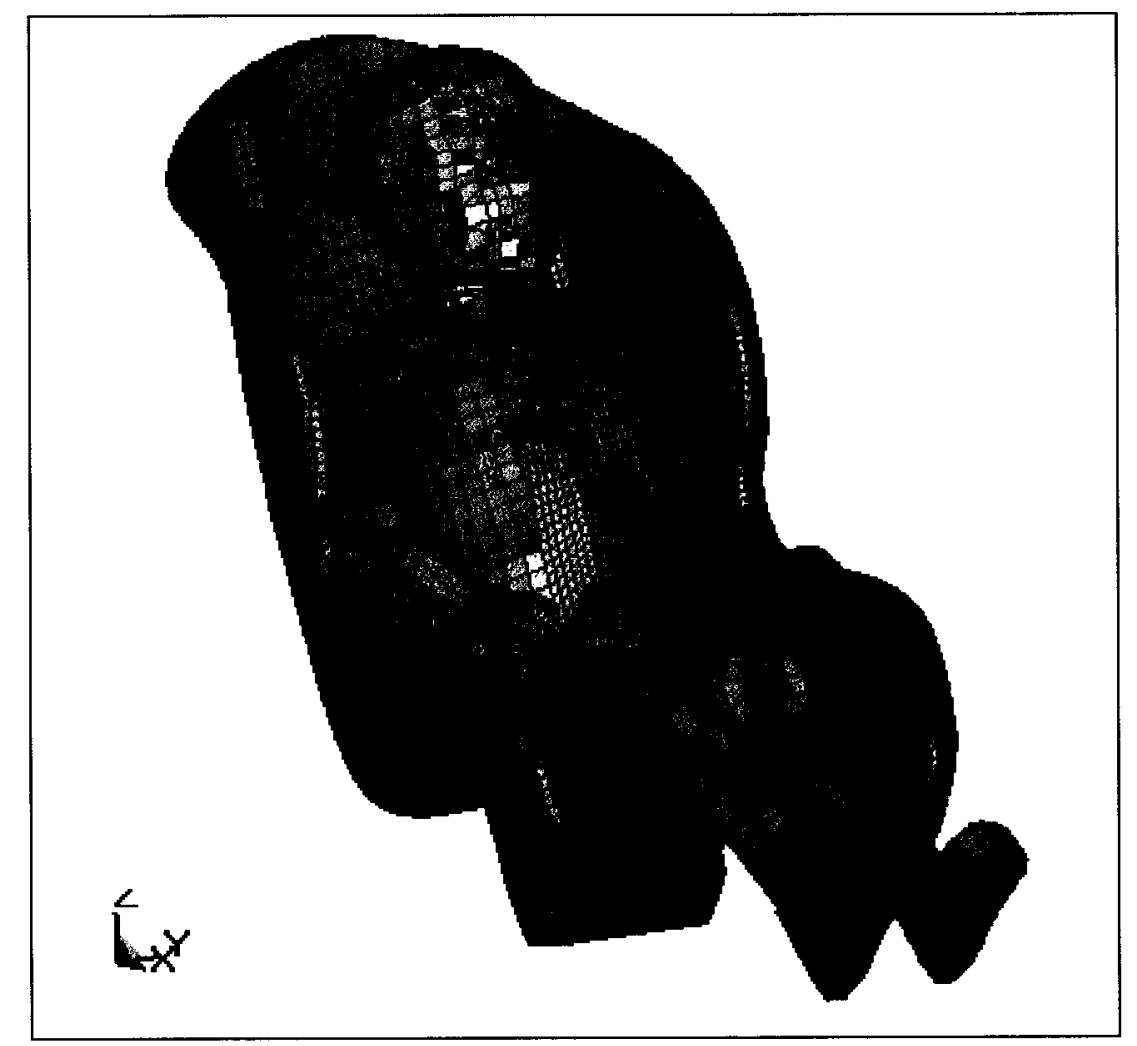

Figure 40. Hybrid III 3-year-old dummy model restrained in a five-point restraint in a forward facing position.

The verification of the model was accomplished by comparing the head and chest accelerations of the model and the experimental sled test results of the forward facing condition. The raw data results for both numerical and experimental tests were first filtered using the appropriate SAE J211 $2^{\text {nd }}$ order butterworth filters. Appendix C illustrates the numerical algorithm for this filter. 


\subsubsection{Extraction of injury data from Hybrid III 3-year old dummy model}

\subsubsection{Head and chest accelerations}

The determination of head and chest accelerations was accomplished through nodes that represented accelerometers in the dummy models. The notes acquired acceleration data in three local directions, $\mathrm{X}, \mathrm{Y}$, and $\mathrm{Z}$ as illustrated in Figure 41. The positive directions are shown with arrowheads. There are specifications that need to be applied to the data extracted from the nodes in the head and chest. In particular the data needs to be run through a specific SAE J211 $2^{\text {nd }}$ order butterworth filter [48]. Table 14 shows the specific filter for each dummy accelerometer and load cell. Figure 42 illustrates the location of the head and chest accelerometers within the Hybrid III 3-year-old dummy model.

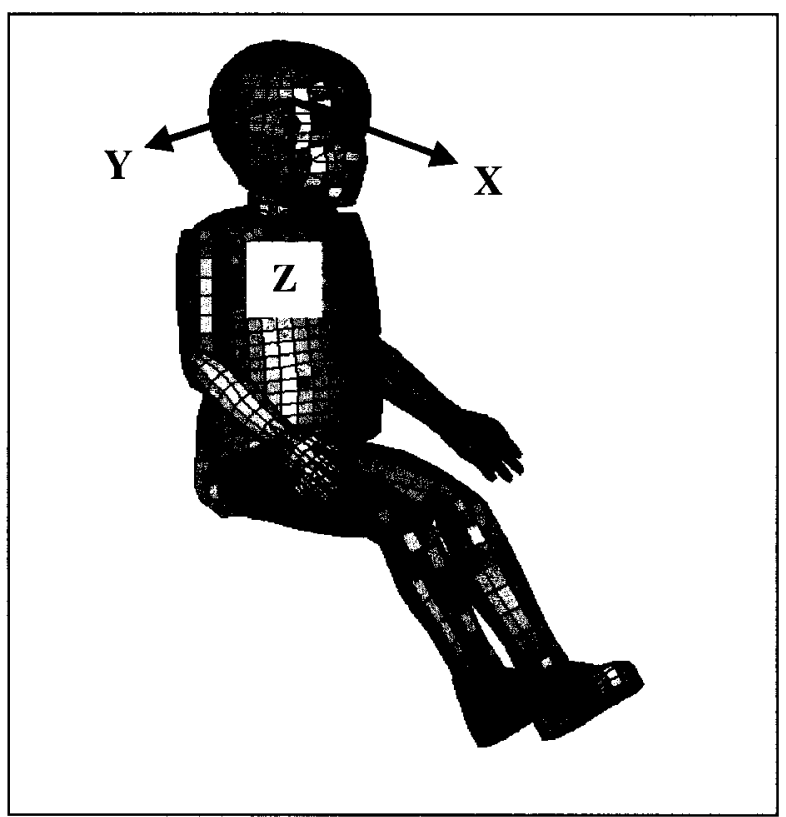

Figure 41. Hybrid III 3-year-old dummy model demonstrating the directions in which the accelerations are measured. 


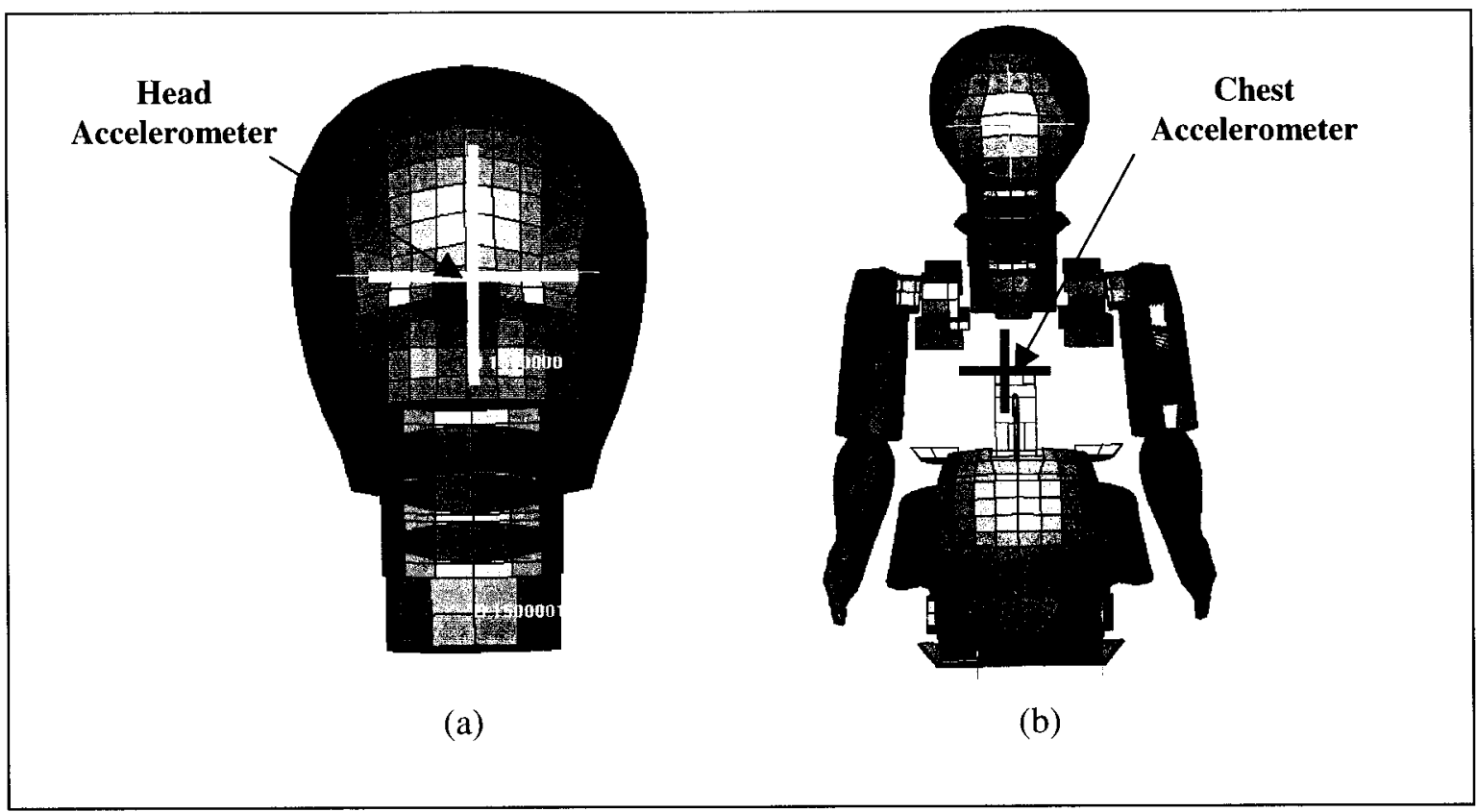

Figure 42. Accelerometer locations in the (a) head and (b) chest of the Hybrid III 3-year-old dummy model.

Table 14. SAE J211 filters for Hybrid III dummy accelerometers and load cells

\begin{tabular}{|c|c|}
\hline Item & SAE J211 Filter \\
\hline \hline Head Acceleration & Class 1000 \\
\hline Neck Force & Class 1000 \\
\hline Neck Moment & Class 600 \\
\hline Chest Acceleration & Class 180 \\
\hline
\end{tabular}




\subsubsection{Upper and lower neck forces and moments}

This research examined the forces and moments in the upper and lower neck region. These values were collected through the use of zero length beam elements that acted as load cells. These element locations are illustrated in Figure 43.

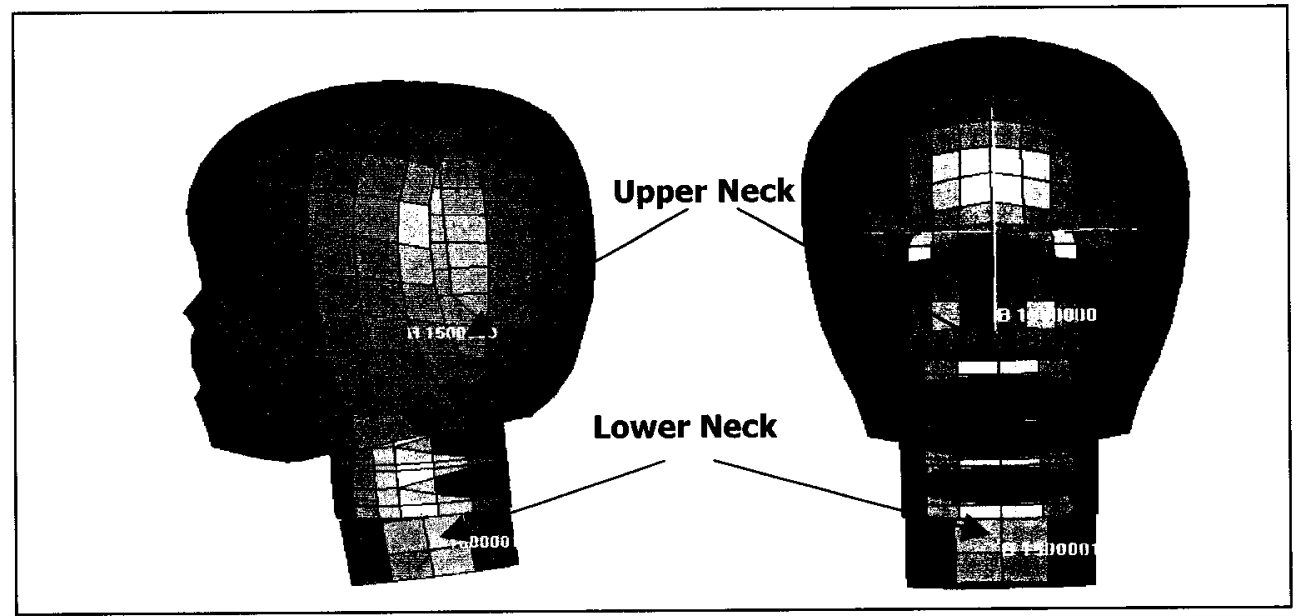

Figure 43. Upper and lower neck areas of the Hybrid III 3-year-old finite element dummy model.

Again, the forces and moments were collected about the axes of the local coordinate system shown in Figure 41. The data was filtered with the appropriate SAE J211 $2^{\text {nd }}$ order butterworth filters specified in Table 14.

\subsubsection{Analysis of forces and moments of the upper and lower neck}

The forces and moments endured in the upper and lower neck regions of the child dummy model were then analyzed by determining resultant forces and resultant moments through Equations 3 and 4.

$$
\begin{gathered}
F_{\text {resultant }}=\sqrt{F_{\mathrm{x}}^{2}+F_{y}^{2}+F_{z}^{2}} \\
M_{\text {resultant }}=\sqrt{M_{\mathrm{x}}^{2}+M_{y}^{2}+M_{z}^{2}}
\end{gathered}
$$


The resultant forces and moments (in the upper and lower neck) in both rearward and forward facing configurations were analyzed and compared.

\subsubsection{Head injury criteria}

Equation 1 was used in determining the head injury criteria for the three-year-old Hybrid III dummy model. It will be shown here again for clarity of the explanation that follows.

$$
H I C=\left[\frac{1}{t_{2}-t_{1}} \int_{t_{1}}^{t_{2}} a \cdot d t\right]^{2.5} \cdot\left(t_{2}-t_{1}\right)
$$

The HIC was analyzed using a $36 \mathrm{~ms}$ sampling window as well as a $15 \mathrm{~ms}$ sampling window. The reason for the analysis in the $15 \mathrm{~ms}$ window is due to proposed changes that may take place to the determination of head injury criteria for Hybrid III dummies [38]. The proposed maximum allowable HIC value for a 3-year-old Hybrid III dummy is 570, which was scaled down from the $50^{\text {th }}$ percentile Hybrid III dummy.

\subsubsection{Neck injury criteria}

Equation 2 was used in determining the neck injury criteria for the Hybrid III 3-year-old dummy model. It is shown again here for clarity of the explanation that follows below.

$$
N_{i j}=\left(F_{Z} / F_{Z C}\right)+\left(M_{Y} / M_{Y C}\right)
$$

The Neck Injury Criteria, $\mathrm{N}_{\mathrm{ij}}$, is a linear combination of the normalized neck axial load (tension or compression) and normalized neck moment about the occipital condyle. $F_{7}$ is the force in the $\mathrm{z}$ - direction in the neck. This would be defined as an axial force pulling the head away from the shoulders, or oppositely, compressing the neck. The $\mathrm{F}_{\mathrm{ZC}}$ is defined as the critical force for that area. $M_{Y}$ is the moment about the $y$-axis. This can be defined as the tendency for the head and neck to bend towards the chest (flexion) and/or toward the back (extension). Flexion and extension are illustrated in Figure 44. The neck injury criterion was determined based on a value 
of $2120 \mathrm{~N}$ for $\mathrm{F}_{\mathrm{ZC}}$ in both tension and compression. The value of $\mathrm{M}_{\mathrm{YC}}$ a value of $68 \mathrm{~N} \cdot \mathrm{m}$ in flexion and $27 \mathrm{~N} \cdot \mathrm{m}$ in extension is used for analysis [38]. The maximum $\mathrm{N}_{\mathrm{ij}}$ value allowed is 1.0 , regardless of dummy size.

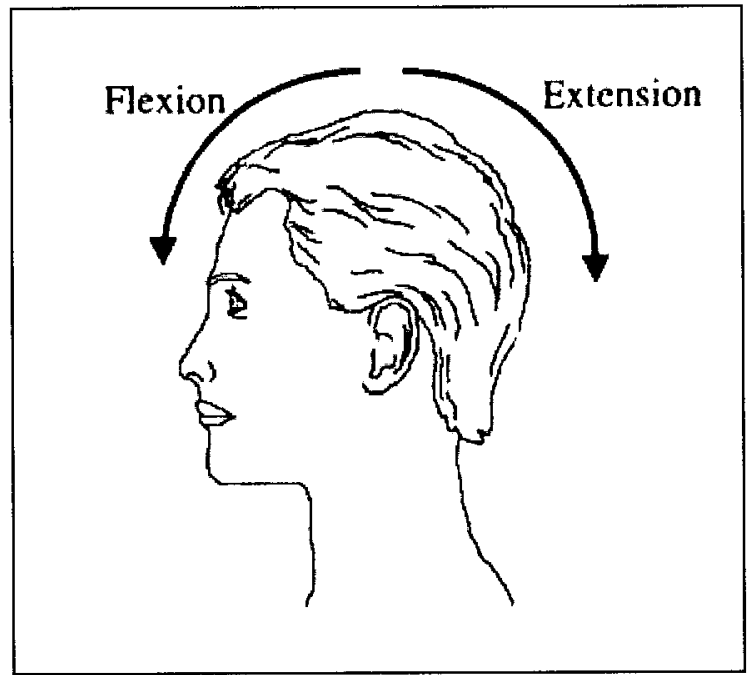

Figure 44. Illustration of flexion and extension in the neck [15].

\subsubsection{Head, neck, and chest average accelerations}

The average accelerations of the head, neck, and chest were determined over specific time intervals. Equation 5 was used to calculate the average accelerations over the time interval $t_{1}$ to $t_{2}$. The calculation utilized the trapezoidal rule to determine the integral.

$$
a_{a v e_{t_{1} \rightarrow t_{2}}}=\frac{1}{t_{j}-t_{i}} \cdot \sum_{m=i+1}^{n=j} \frac{1}{2} \cdot\left(a_{m}-a_{m-1}\right) \cdot\left(t_{m}-t_{m-1}\right)
$$

In equation $5, i$ and $j$ are the indices for $t_{1}$ and $t_{2}$, respectively. The acceleration averages of the head, neck, and chest were determined in order to compare the forward and rearward configurations in terms of their performance against time duration. Children are more susceptible to injury for a larger duration of time spent at a particular acceleration level [35, 37]. 


\section{RESULTS AND DISCUSSION}

\subsection{Finite element model verification}

To verify the numerical simulations that were completed, a comparison was made between experimental data from the forward facing sled tests and the forward facing numerical simulation. The comparison was based upon observations for the head and chest accelerations. Furthermore, an energy balance was completed for the $\mathrm{FE}$ simulations to provide an indication of the validity of the simulations.

\subsubsection{Head accelerations}

Figure 45 illustrates the experimental and numerical values of the local $x$-component of the head acceleration as a function of time after filtering with the recommended SAE J211 $2^{\text {nd }}$ order butterworth filter.

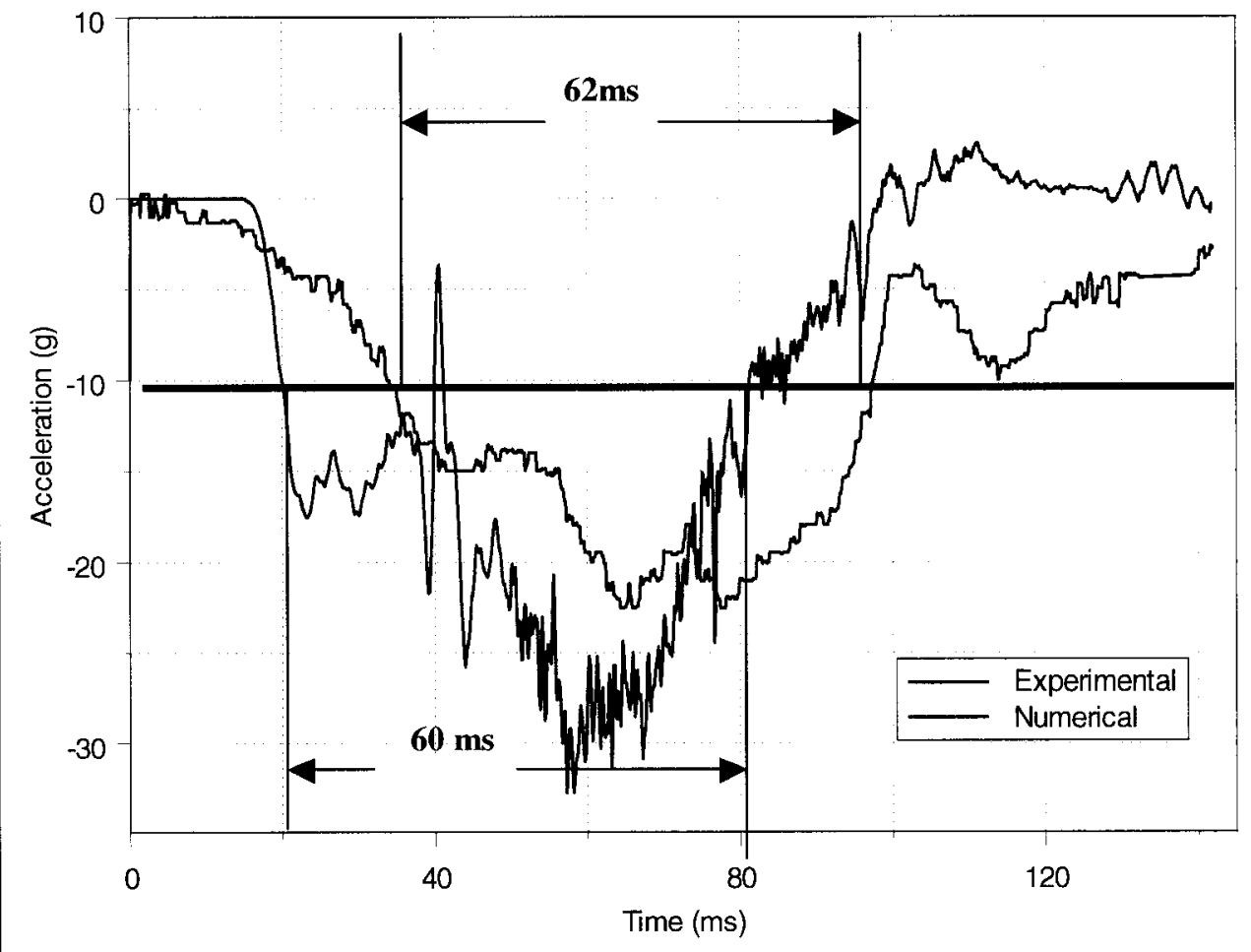

Figure 45. Experimental versus numerical local head accelerations in the x-direction. 
It was observed that the experimental results closely correlate to the numerical findings. There appeared to be a slight shift in time in the data, otherwise, the general patterns of acceleration were similar. The durations of the experimental and numerical responses were not perfectly synchronized. This was accounted for in two ways. Firstly, it was not known exactly at what time the data acquisition system begins acquiring information. However, the difference between the numerical simulation and the experimental crash test was believed to be no more than $10 \mathrm{~ms}$. Secondly, there were assumptions made in the numerical simulations which included the rigid child safety seat and the limited length of the webbing of the seat belt. In reality, the child safety seat and the seat belt were deformable. In the numerical simulations, this was not taken into consideration.

The peak acceleration values for the numerical simulations and the experimental crash test were $-34 \mathrm{~g}$ 's and $-24 \mathrm{~g}$ 's, respectively. The peak acceleration for the numerical simulation occurred when the head reached its highest displacement. At that time, the deceleration was maximum as the body was being pulled back by a seat belt of limited length. It is possible that the deceleration of the head in the experimental crash test did not reach the same peak value of the numerical simulation because of the slack in the seat belts.

The time to reach the peak value of acceleration for the numerical simulation and the experimental crash test were $59 \mathrm{~ms}$ and $78 \mathrm{~ms}$, respectively. To compare the acceleration curves in another manner, a critical acceleration was selected and the duration of time that the acceleration remained above or below curves were compared. Essentially, this compared the duration of the acceleration peak (maximum or minimum). For the local head accelerations in the $\mathrm{x}$-direction illustrated in Figure 45, a critical acceleration of $-10 \mathrm{~g}$ 's was chosen. The duration of the acceleration pulse was $60 \mathrm{~ms}$ for the numerical curve and $62 \mathrm{~ms}$ for the experimental curve. These time durations are illustrated in Figure 45. Hence, the curves were similar in regards to the acceleration pulse experienced. 
Figure 46 illustrates the experimental and numerical values of the local y-component of the head acceleration as a function of time.

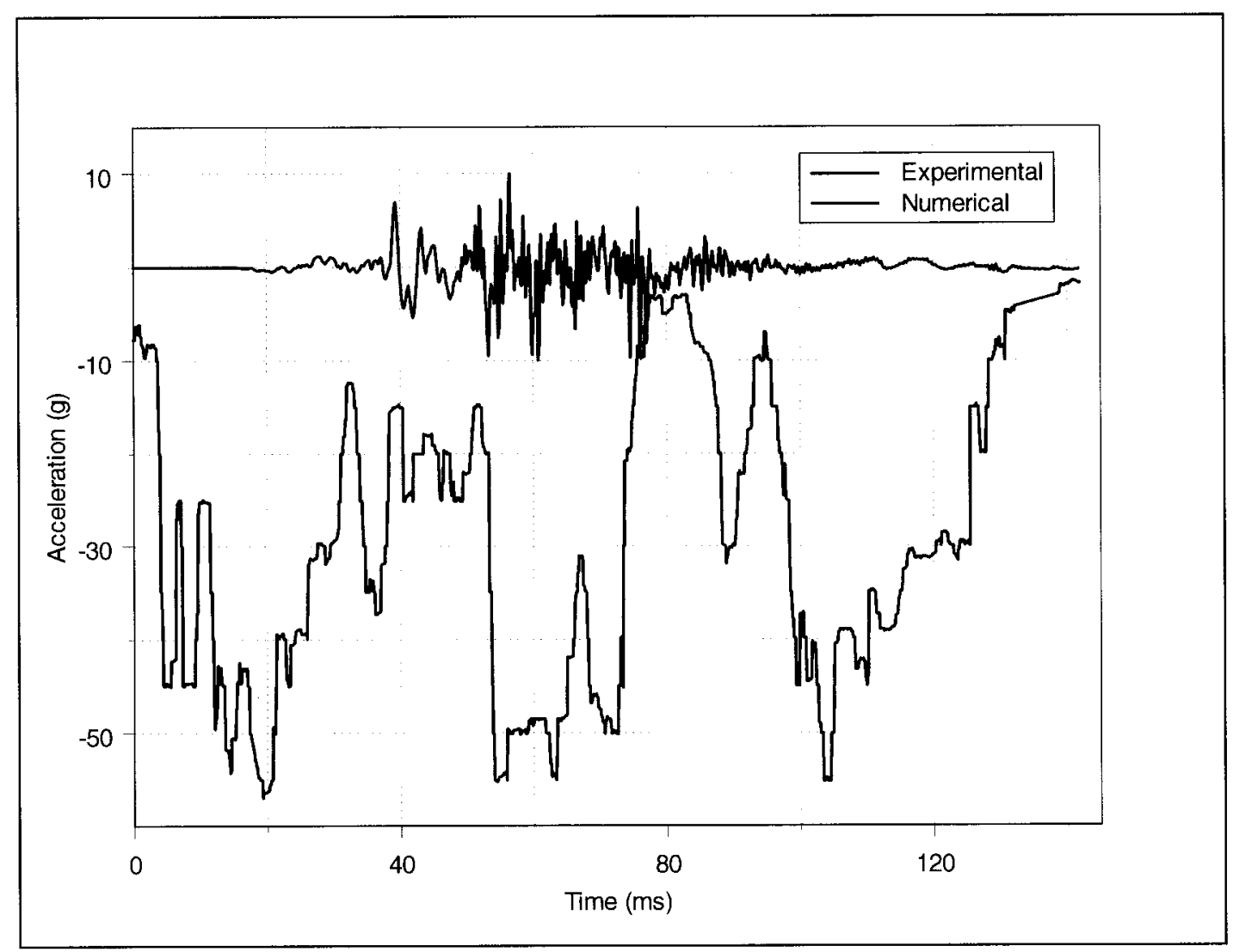

Figure 46. Experimental and numerical local head acceleration in the y-direction.

It was observed that little or no correlation between the experimental and numerical observations existed. It was believed that there might have been a sensitivity problem with the experimental accelerometer set-up causing the curve to be multiplied to a larger size than normal. However, it was not a certainty. Since the $y$-direction is perpendicular to the plane of motion, the head should not experience much acceleration in this direction. Therefore, it was believed that the numerical simulations are a better representation of reality. 
Figure 47 illustrates the experimental and numerical values of the local z-component of the head acceleration as a function of time.

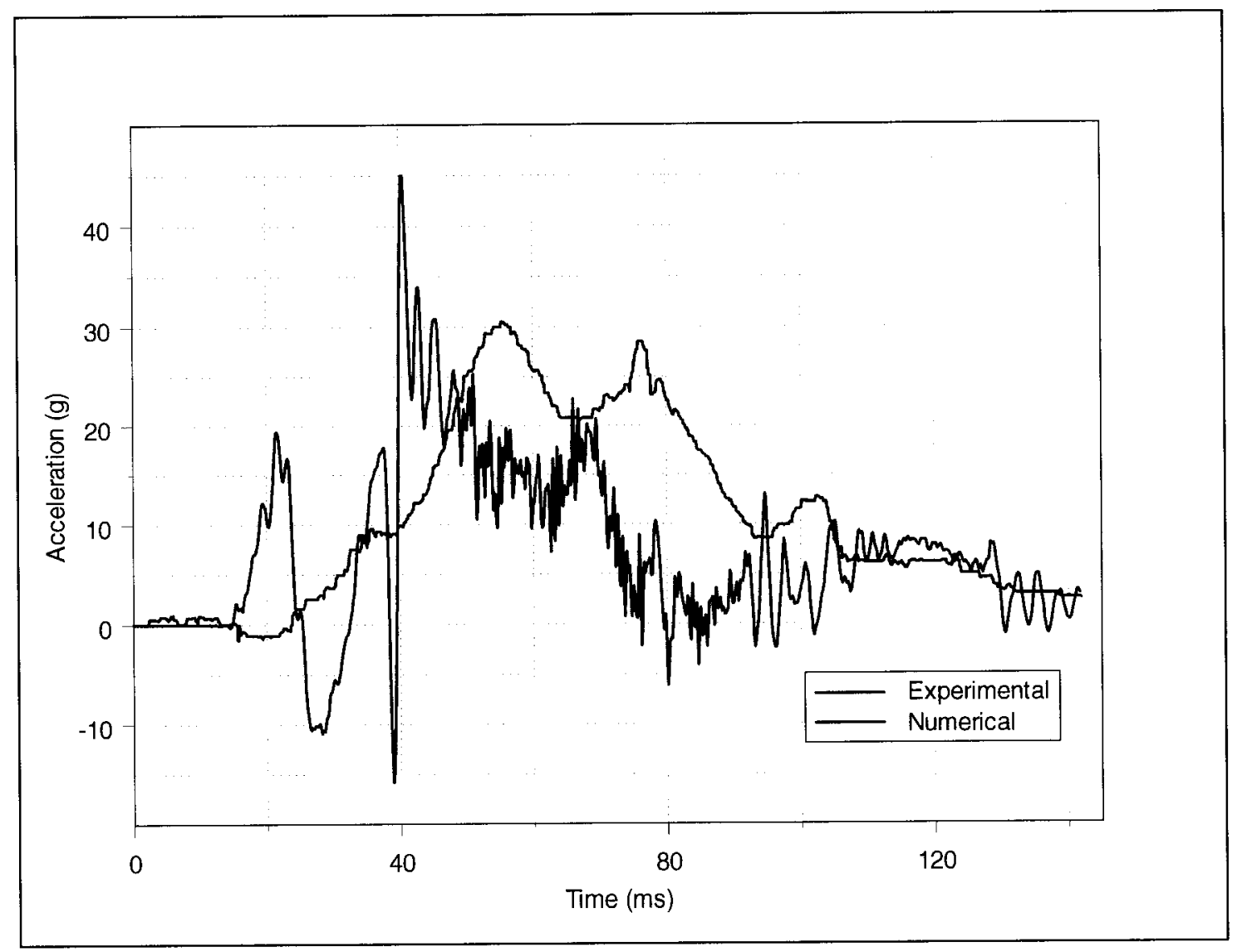

Figure 47. Experimental and numerical local head acceleration in the z-direction versus time.

The experimental and numerical curves of the local head acceleration in the z-direction were similar but had distinct differences in peak values and the time required to reach peak acceleration. The peak acceleration value for the numerical and the experimental curves were $45 \mathrm{~g}$ 's and $32 \mathrm{~g}$ 's, respectively. The peak acceleration of the numerical simulations occurred at a time of severe bending about the y-axis which explains the maximum deceleration quickly followed by the maximum acceleration. The time to reach the peak values for the numerical and experimental curves were $40 \mathrm{~ms}$ and $55 \mathrm{~ms}$, respectively. Both curves had a major and minor peak, in between which there was a small valley. Choosing a critical value of $0 \mathrm{~g}$ 's, the duration of the acceleration pulse for the numerical curve and the experimental curve were $80 \mathrm{~ms}$ and 100 ms, respectively. 


\subsubsection{Chest accelerations}

Figure 48 illustrates the experimental and numerical values of the local $x$-component of the chest acceleration as a function of time.

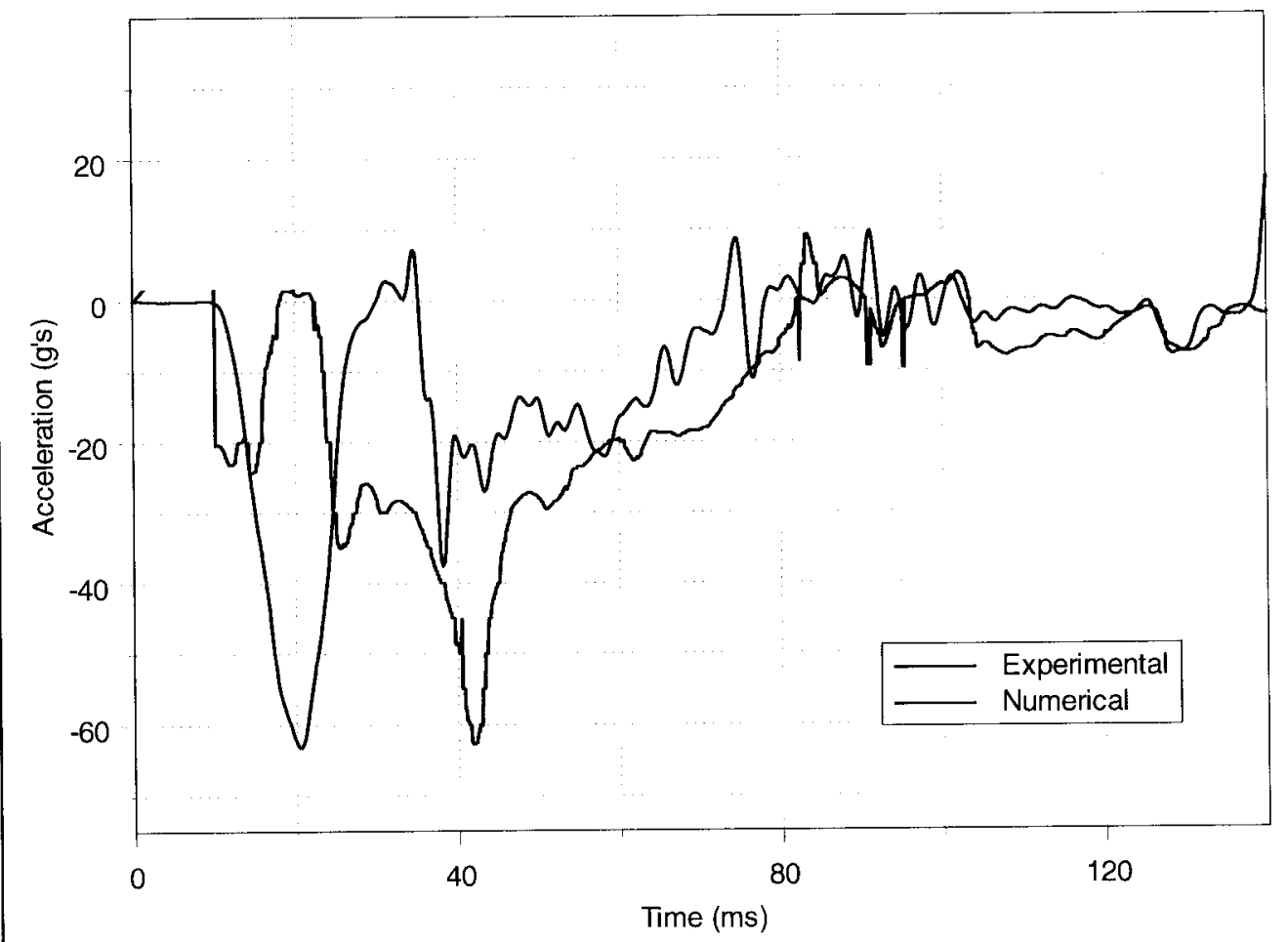

Figure 48. Experimental and numerical local chest acceleration in the $\mathrm{x}$-direction.

The experimental results correlated well with the numerical results although there were a couple of notable differences. Between 20 and $40 \mathrm{~ms}$, the peak chest accelerations occurred. The experimental curve il' ${ }_{A}$ strated a positive acceleration prior to the minimum peak value of the curve. This did n', agree with what should happen theoretically. Physically, the sled accelerates and it is possible that by the time it reaches the concrete block, the sled may slow down, causing the chest of the Hybrid III 3-year-old dummy to accelerate positively for a short time. This occurred until the barrier was reached and a sharp deceleration of the chest followed. The peak accelerations for the numerical and the experimental chest acceleration were $-63 \mathrm{~g}$ 's and $-64 \mathrm{~g}$ 's, respectively. The numerical chest acceleration remained at zero g's until $15 \mathrm{~ms}$, where a sharp 
deceleration began to occur. Once the peak value was reached, it was quickly followed by a positive acceleration up to just under $10 \mathrm{~g}$ 's. This acceleration may have occurred due to the limited length of the seat belt. This may have allowed for a limited forward displacement after which the body was forced to move backwards. The time to reach the peak acceleration for the numerical simulation and the experimental crash test were $25 \mathrm{~ms}$ and $35 \mathrm{~ms}$, respectively. A critical acceleration of $-10 \mathrm{~g}$ 's was chosen for comparison and both the numerical and experimental curves were found to be below that critical value for $50 \mathrm{~ms}$. After the main acceleration pulse, the curves followed each rather quite closely.

Figure 49 illustrates the experimental and numerical values of the local y-component of the chest acceleration as a function of time.

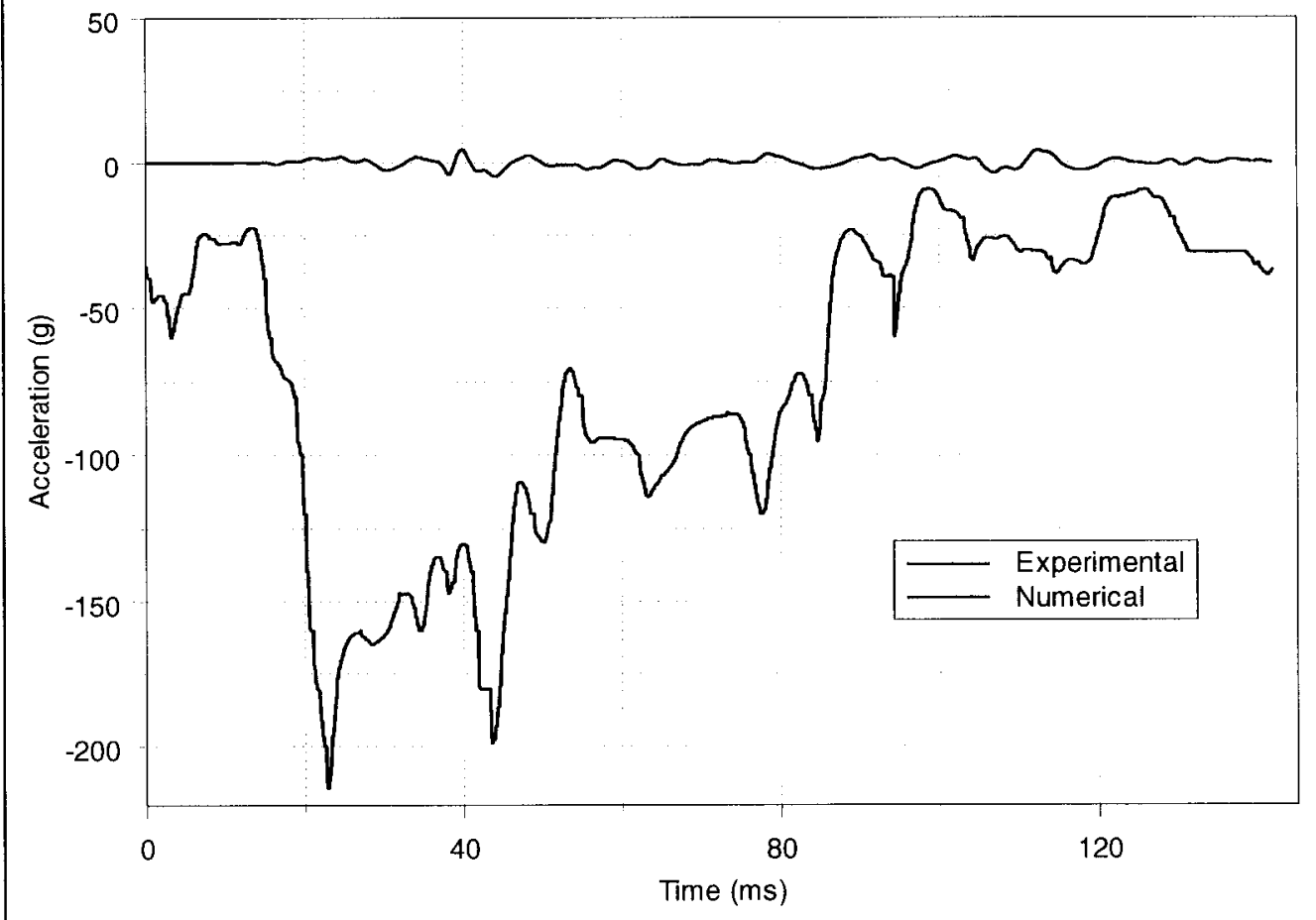

Figure 49. Experimental and numerical local chest acceleration in the y-direction. 
As in the case of the head accelerations in the y-direction, the experimental observations illustrated no correlation to the numerical findings. Again, since the y-direction was perpendicular to the plane of motion, one does not expect much more than a small oscillatory motion. The peak value of acceleration for the experimental curve reached a value below $-200 \mathrm{~g}$ 's which was $4-5$ times greater than the local chest accelerations in the $\mathrm{x}$ and $\mathrm{z}$-directions. This implied that there was an error in the reading or acquisition of the data in the y-direction and it was believed that the numerical results more realistically depicted the local acceleration of the chest in the y-direction.

Figure 50 illustrates the experimental and numerical values of the local z-component of the chest acceleration as a function of time.

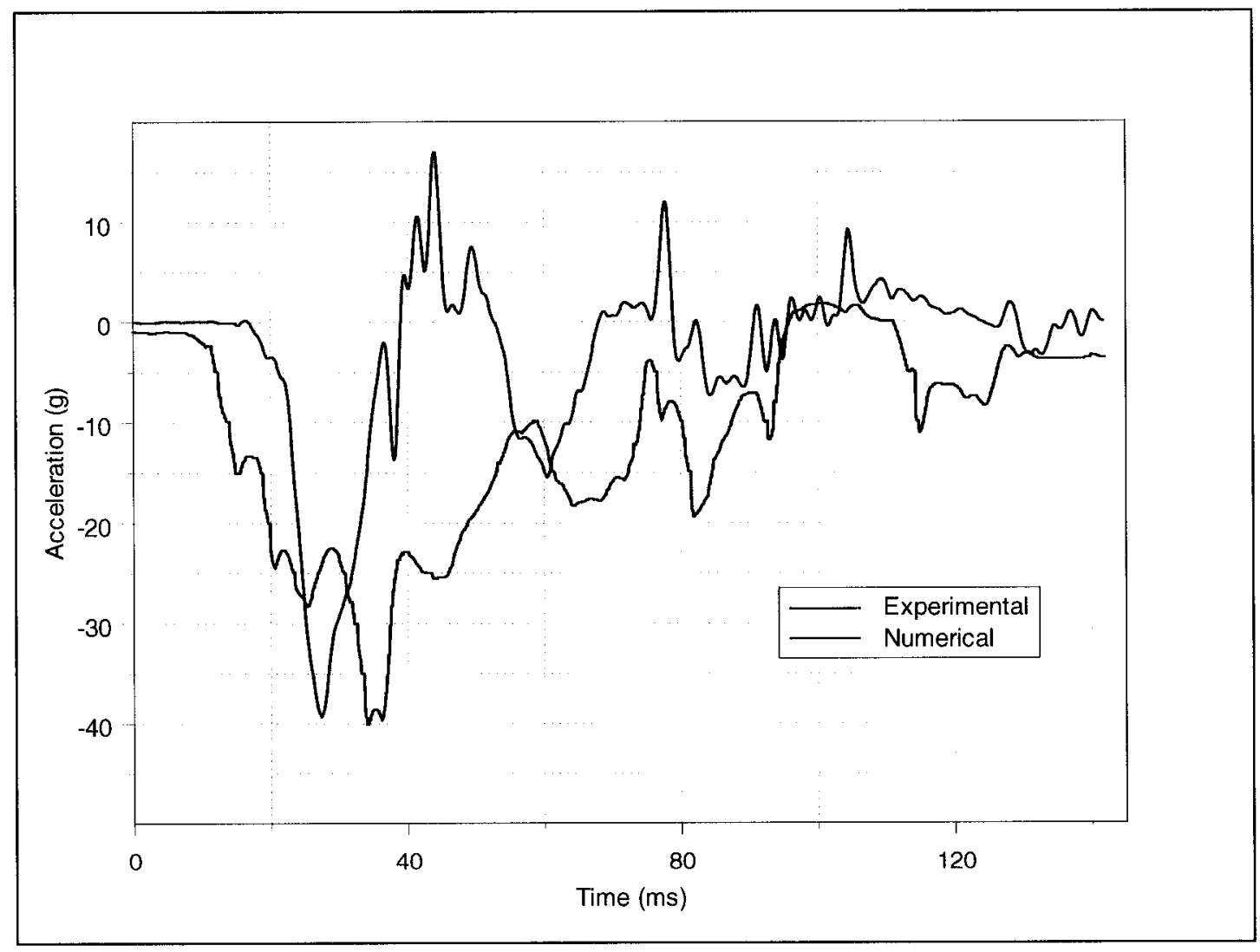

Figure 50. Experimental and numerical local chest acceleration in the z-direction. 
The numerical curve of the local chest acceleration in the z-direction had peak value of $-39 \mathrm{~g}$ 's which was followed by an acceleration to just over $10 \mathrm{~g}$ 's. This acceleration was believed to occur because once the dummy model hit the belt and decelerates, it began to move away from the belt and back into the seat, but the motion of the system was still in the positive $\mathrm{x}$-direction. Therefore, once there was no more resistance from the seat belt, the child dummy model accelerated forward. The peak value of the experimental curve was $-40 \mathrm{~g}$ 's. The times to reach these peak values for the numerical and the experimental curves were $29 \mathrm{~ms}$ and $35 \mathrm{~ms}$, respectively. Choosing a critical value of $0 \mathrm{~g}$ 's, the duration of the acceleration pulse of the experimental curve and the numerical curve was $85 \mathrm{~ms}$. Excluding the positive, short-lived peaks of the numerical curve, the duration of the acceleration pulses were the same for the numerical and the experimental curve.

A summary of the observed data from the experimental sled test and the numerical simulations are summarized in Table 15.

Table 15. Summary of peak acceleration, time to peak acceleration, and duration of acceleration pulse for experimental and numerical results.

\begin{tabular}{|c||c|c||c|c|}
\hline \multirow{2}{*}{ Direction of Acceleration } & \multicolumn{2}{|c||}{ Experimental Results } & \multicolumn{2}{c|}{ Numerical Results } \\
\cline { 2 - 5 } & head & chest & head & chest \\
\hline \hline $\begin{array}{c}\text { x-direction peak } \\
\text { acceleration (g's) }\end{array}$ & -24 & -64 & -34 & -63 \\
\hline time to peak (ms) & 78 & 35 & 59 & 25 \\
\hline $\begin{array}{c}\text { duration of acceleration } \\
\text { pulse (ms) }\end{array}$ & 62 & 50 & 60 & 50 \\
\hline \hline $\begin{array}{c}\text { z-direction peak } \\
\text { acceleration (g's) }\end{array}$ & 32 & -40 & 45 & -39 \\
\hline \begin{tabular}{c} 
time to peak (ms) \\
\cline { 2 - 5 }
\end{tabular} & 55 & 35 & 40 & 29 \\
\hline $\begin{array}{c}\text { duration of acceleration } \\
\text { pulse (ms) }\end{array}$ & 100 & 85 & 80 & 85 \\
\hline
\end{tabular}




\subsubsection{Qualitative comparison of numerical and experimental observations}

The Graco crash test facility was equipped with high-speed cameras allowing pictures to be taken at a frequency of 1000 frames per second. Figure 51 illustrates the numerical simulations and the experimental crash test at the same moments in time. This allowed for direct visual comparison to the numerical simulations. The seat of the numerical simulations was made to be transparent so one can see the entire body movements of the Hybrid III 3-year-old dummy model. 


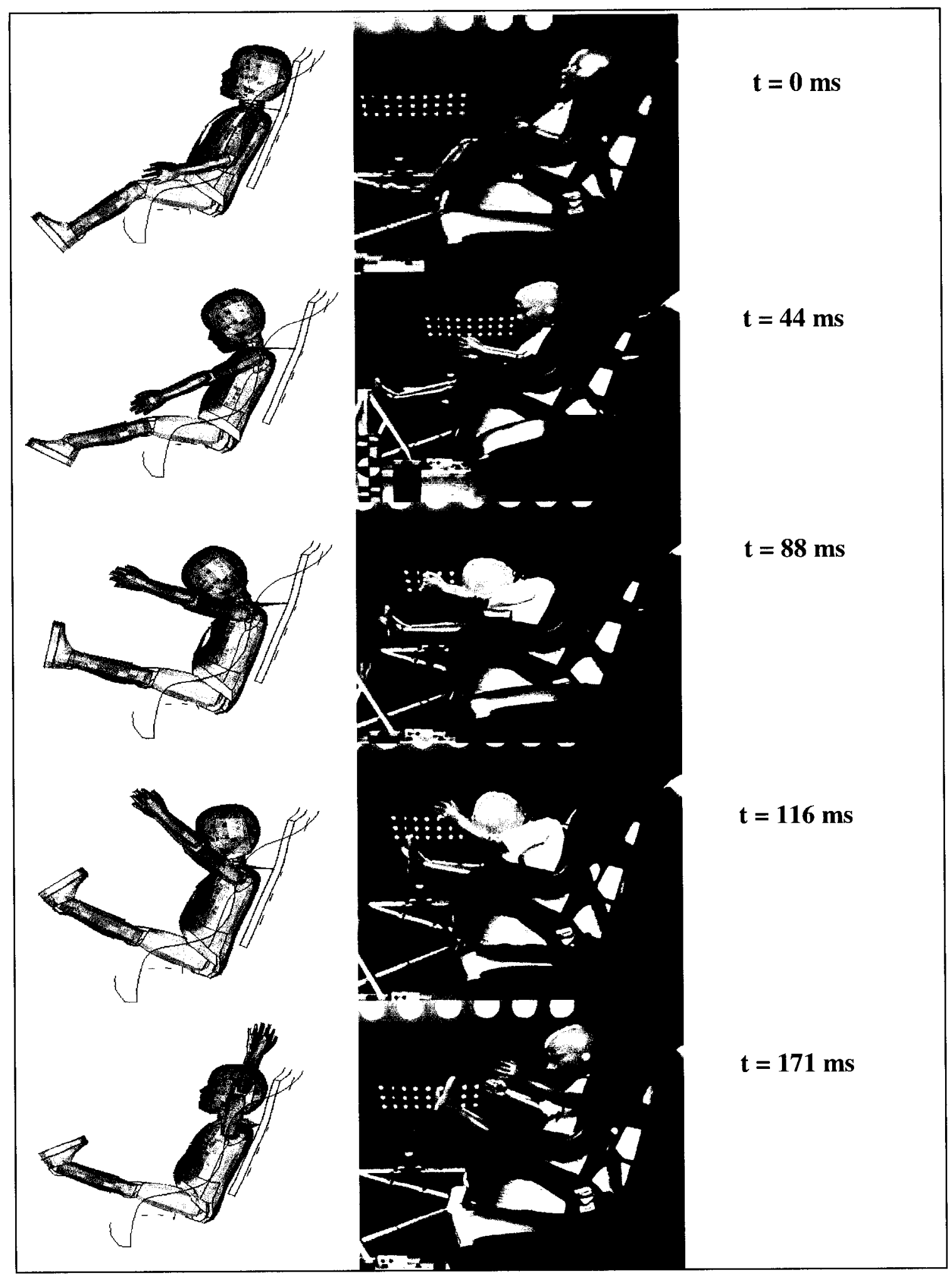

Figure 51. Numerical and experimental images at exact time increments. 
At a time of $0 \mathrm{~ms}$, the sled was just impacting the concrete barrier and the numerical simulation commenced. At time $44 \mathrm{~ms}$, the arms and legs of the Hybrid III 3-year old dummy began to extend outward. It is clear that the arms and legs of the dummy model in the numerical simulation extended further and straightened more than the experimental dummy at that time. There are several ways to justify this happening. Firstly, the joint characteristics of the joints in the arms and legs of the Hybrid III 3-year-old dummy and model were not believed to be identical. Moreover, in the experimental case, the arms were resting on the dummy's lap and also touching the side of the child safety seat. When they extended, the friction between the arms and the seat might have caused the arms not to extend as far. At time $88 \mathrm{~ms}$, all limbs and the bending of the neck appeared to be similar in both the experimental and the numerical simulation pictures. The arms were not fully extended in the experimental case and that was due to the factors mentioned above. At time $116 \mathrm{~ms}$, the bending of the neck was different. It appeared as though the dummy of the numerical simulation had been thrust into the seat, whereas the experimental dummy had yet not translated that far back. This might have been due to the rigidity of the child seat and the limited seat belt length in the numerical simulation. Because of these two factors, it was possible that the dummy model in the numerical simulation reached its maximum outward position, relative to the child safety seat, prior to the dummy in the experimental case. The experimental set up allowed for relative movement between the bench seat and the child safety seat. This was not taken into consideration in the numerical simulation. Correspondingly, the seat belt in the experimental case is allowed deformation and was not limited in length as was the seat belt in the numerical simulation case. Therefore, at time $171 \mathrm{~ms}$, there were obvious differences in body and limb positions between the two cases. The head of the dummy model in the numerical simulation was about to impact the back of the seat and this was not the state in the experimental case. The previous lag in movement of the experimental dummy due to the bench and seat belt differences were added to the fact that the arms came back into contact with the side of the child safety seat, thereby slowing the dummy down when it decelerated into the seat. Overall, the images of the experimental test and the numerical test were reasonably similar at the time increments shown. 


\subsubsection{Discussion of numerical and experimental results}

There was an acceptable correlation between the numerical and experimental sled test results and therefore it was concluded that the numerical simulations reasonably describe the real sled test conditions. Unfortunately, the experimental data of the y-axes in both the head and chest were determined to not acquire reliable data. It was concluded that the data acquisition of the $y$-axis in the numerical simulation better represented realistic values than the recorded experimental observations. Because the $y$-axis is perpendicular to the plane of motion, there was expected to be nothing more than small magnitudes of displacement, velocity, and acceleration. The $x$ and $z$ directions illustrated an acceptable correlation in the head and chest acceleration. Hence, one can make a reasonable comparison between numerical simulations of a forward facing and rearward facing child, thereby defining the potential for injury in each case. 


\subsection{Numerical simulations of forward and rearward facing configurations}

Numerical simulations were used to compare rearward versus forward facing Hybrid III 3-year old children subjected to the same acceleration pulse. The Hybrid III dummy was designed for frontal impact situations and technically is not acceptable to be used in the simulation of the rearward facing condition. However, Lau et al. [30] found that regardless of the intended application of the dummy, it is being utilized in a variety of impact environments due to the lack of viable alternatives. As mentioned in the experimental procedure, the rearward facing simulation was accomplished by reversing the direction of the acceleration pulse and rotating the child seat back to an angle of 45 degrees to the vertical. Figure 52 shows the configurations of both the forward and rearward facing configurations. The forward facing configuration was rotated at an angle of 20 degrees to the vertical. The simulations were run using double precision version of LS-DYNA and required approximately 14 hours to complete.

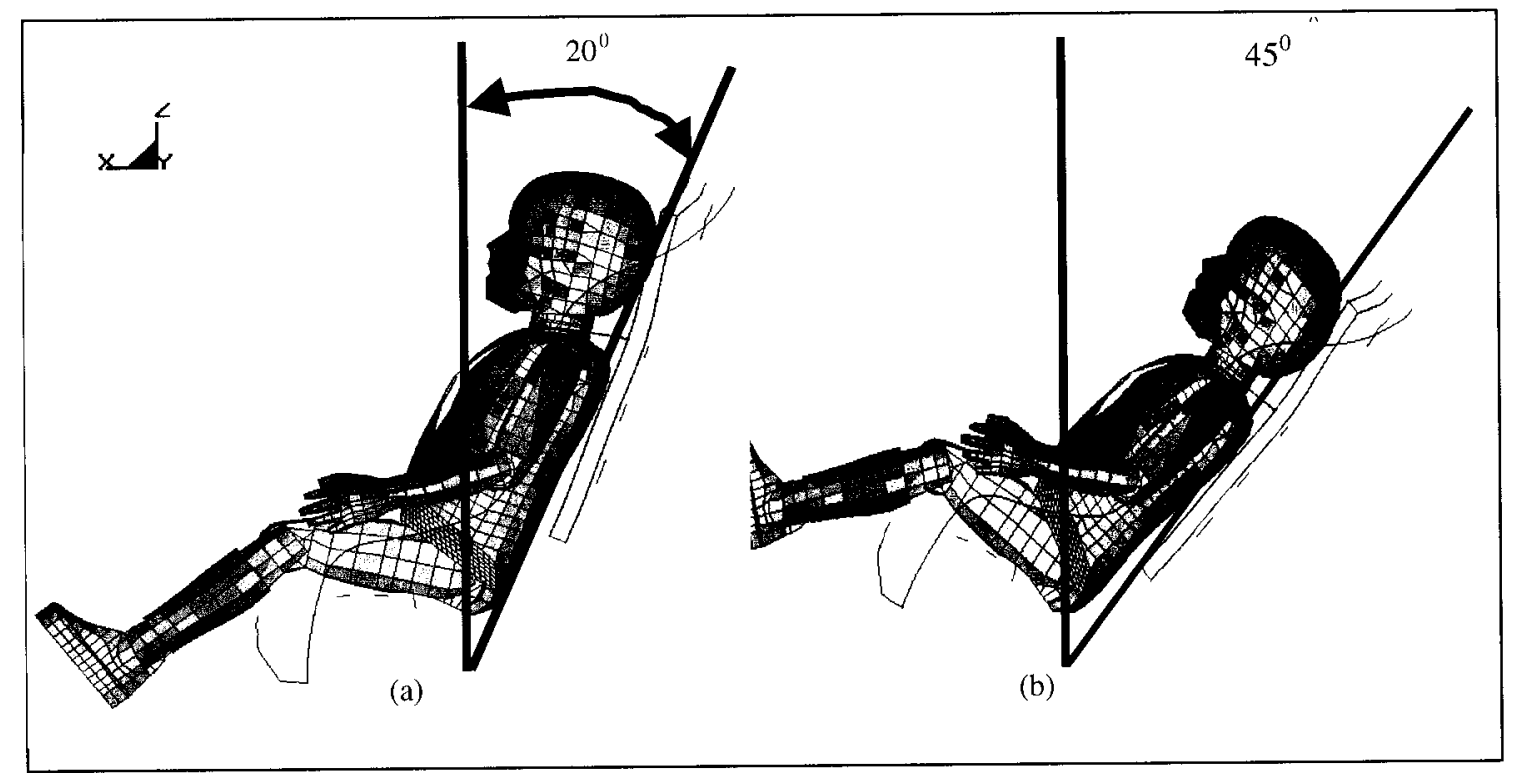

Figure 52. Hybrid III 3-year-old dummy model in (a) forward and (b) rearward configurations. 


\subsubsection{Global energy balance}

One method to ensure that the simulations were valid is to check the energy balance throughout the simulation. In LS-DYNA, there are five energies that are output including total energy, internal energy, kinetic energy, hourglass energy, and sliding interface energy.

\subsubsection{Hourglass energy}

Hourglassing is a phenomenon that occurs in under-integrated (single integration point) solid, shell, and thick shell elements. Hourglass modes can be defined as nonphysical, zero-energy modes of deformation that produce zero strain and no stress. Hourglass modes are nonphysical, zero-energy modes of deformation that produce zero strain and no stress under the occurrence of nodal motion. It is desirable to have no hourglass energy.
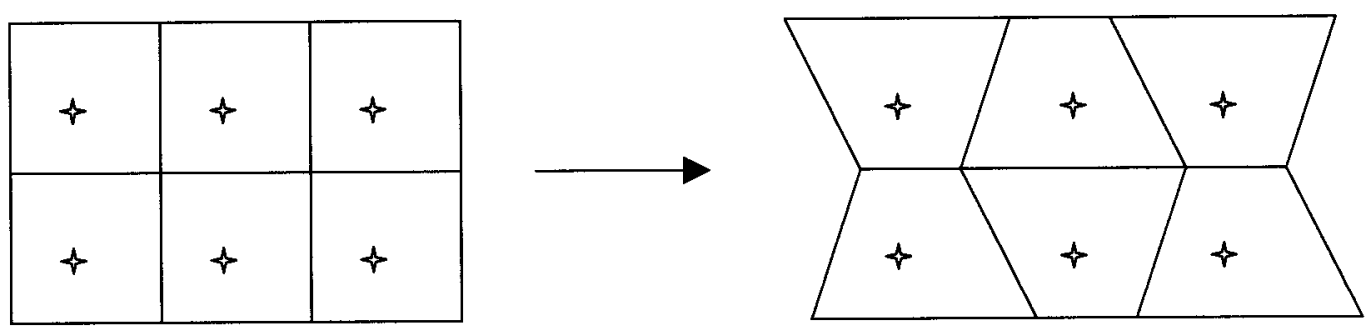

$\downarrow \quad$ Integration Point

Figure 55. Normally shaped shell elements (left) turn into distorted elements (right) through the hourglass effect.

\subsubsection{Sliding interface energy}

In absence of friction, sliding interface energy has a value of zero. Sliding interface energy is the energy that arises when nodal penetrations exist between parts within a system. If nodal penetrations exist, a negative sliding interface value will arise. Abrupt increases in sliding interface energy may be caused by undetected initial penetrations. Usually, if one defines the 
original geometry in such a way that there is an appropriate offset between parts, it will effectively stop or reduce sliding interface energy. Negative sliding interface energy sometimes is generated when parts slide relative to each other. This is not related to friction, rather it is referring to negative energy from normal contact forces and normal penetrations. When a penetrated node slides from its original master segment to an adjacent though unconnected master segment and a penetration is immediately detected, negative sliding interface energy results [49].

Figures 53 and 54 illustrate the global energy balance throughout the both the forward and rearward numerical simulations, respectively.

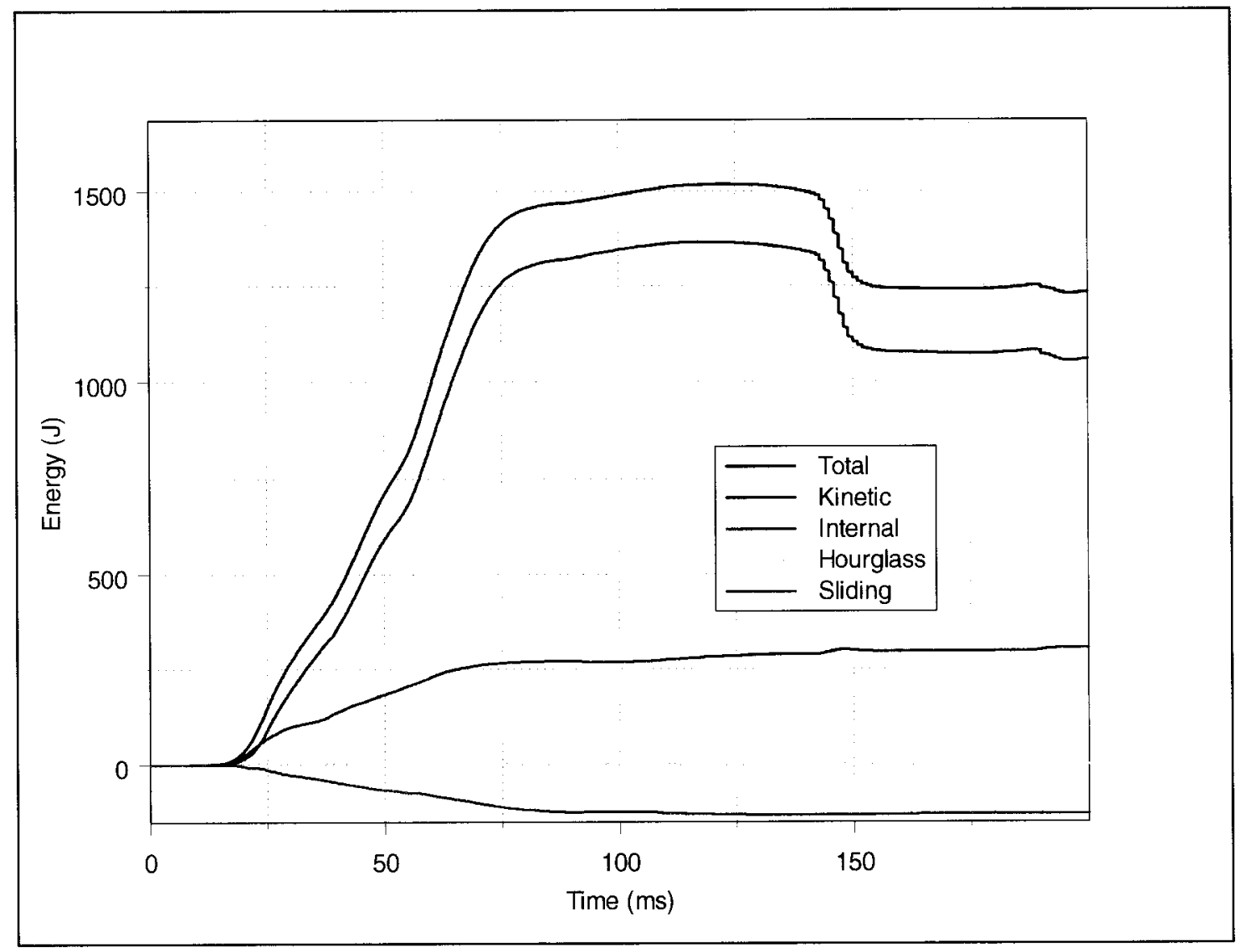

Figure 53. Total, kinetic, internal, hourglass, and sliding energies versus time for the forward facing simulation. 


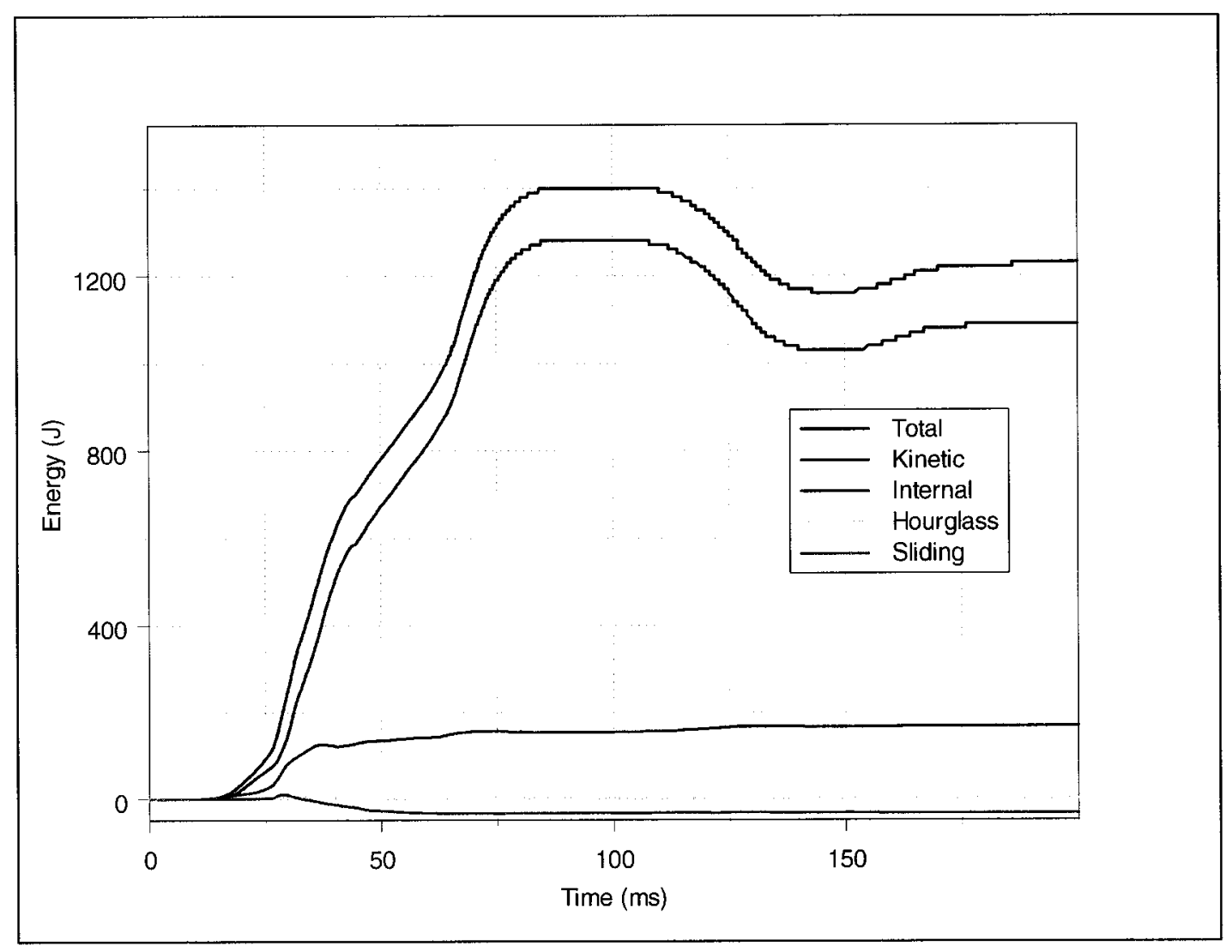

Figure 54. Total, kinetic, internal, hourglass, and sliding energies versus time for the rearward facing simulation.

\subsubsection{Total, internal and external energies}

The energy balance is perfect if the ratio of the total energy to the sum of the internal energy and the external work is equal to unity. In this case, the total energy of the simulation was the sum of the kinetic and internal energy. In both Figures 53 and 54, the graphs illustrated an equal distance between the total energy curve and the kinetic energy curve. The internal energy curve reached a plateau at the same instant as the total energy curve. Fortunately, Figures 53 and 54 illustrated that the hourglass energy and the sliding interface energy were very small compared to the total and internal energy. In fact, the hourglass energy is zero. Therefore, in both simulations, the total energy balance was acceptable. Both the forward and rearward simulations experienced negative sliding interface energy. This might have been due to some initial penetrations between 
the seat and the foam, the seat and the dummy, and the dummy and the seat belt. In both cases, the sliding interface energy was less than $10 \%$ of the total energy and was considered acceptable.

The energy balance of the forward and rearward simulations provided proof towards reasonable output results. The following sections compare forces and moments of the upper and lower neck of the Hybrid III 3-year-old dummy model in both forward and rearward configurations. In addition, the head and neck injury criteria were evaluated. 


\subsubsection{Comparison of the forces and moments observed in the upper and lower neck}

This section analyzes forces and moments that resulted in the upper and lower neck. The manner in which the data was analyzed and necessary calculations were discussed in the experimental procedure.

\subsubsection{Forward and rearward facing resultant upper neck forces}

Figure 56 illustrates the resultant upper neck forces versus time for the forward and rearward facing Hybrid III 3-year-old dummy model.

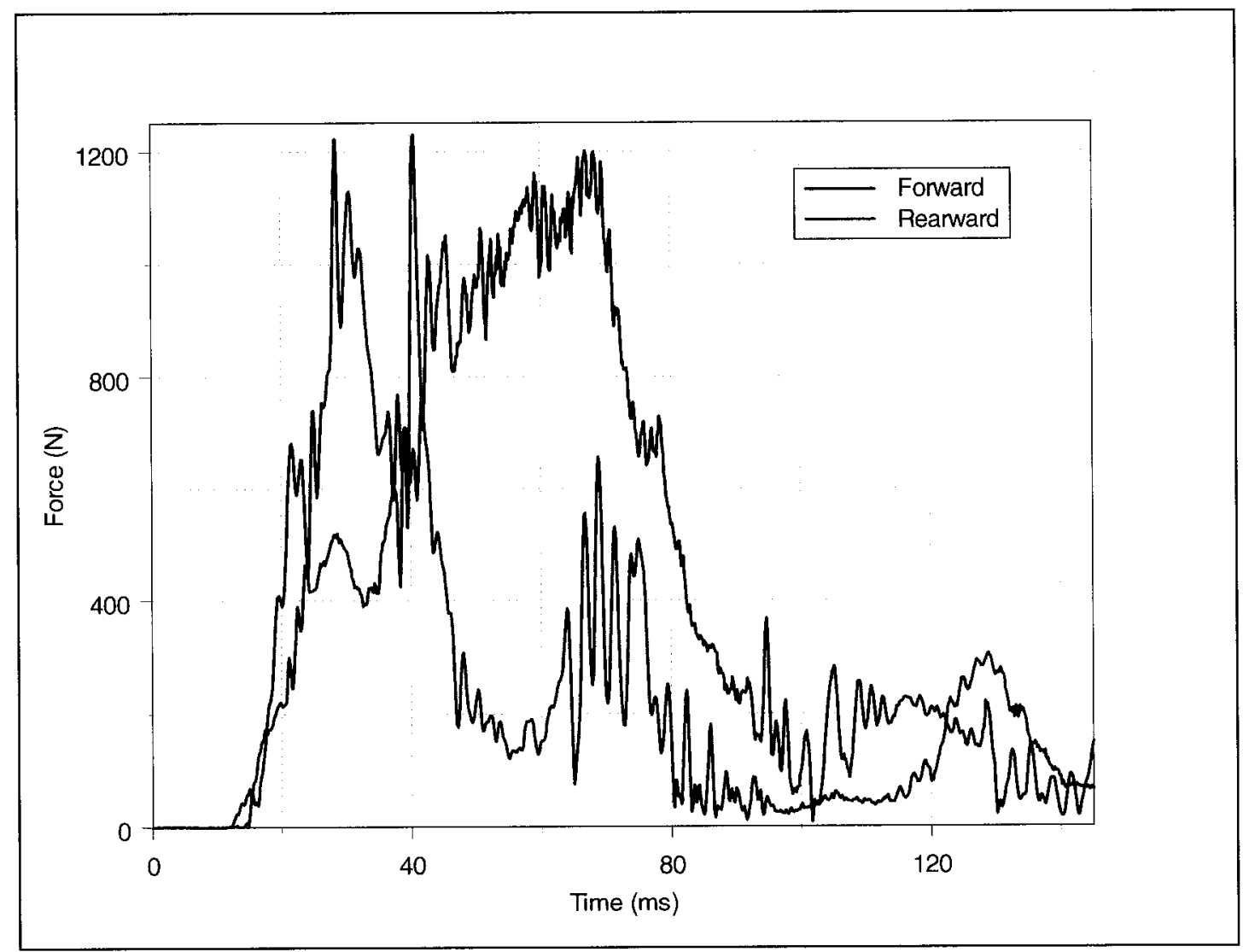

Figure 56. Resultant upper neck forces for forward and rearward facing simulations. 
The force subjected to the Hybrid III 3-year old dummy's upper neck was at a peak at a value of $1200 \mathrm{~N}$ in both the forward and rearward facing curves. However, the forward facing child was subjected to a relatively high value of force in the upper neck region for at least twice the duration of the rearward configuration. This is noteworthy considering that there is a greater potential for damaging injuries the longer one is subjected to a force. In a study released by NHTSA and written by Desantis-Klinich et al. [34], it was concluded that the duration of the acceleration sustained is an important factor in determining the potential injury incurred by a child or child dummy.

Figure 7 illustrates that for short pulse duration, the body can withstand high values of acceleration, whereas for longer pulse duration, the ability for a body to withstand high values of acceleration decreases. Therefore, a 3-year-old child would potentially sustain less injury in the upper neck area if restrained in a rearward facing CRS rather than a forward facing one. This is due to the longer duration of the time that the force sustained by the child in the forward facing child safety seat. The rearward facing car seat would most likely render less potential for injury to the 3-year-old child in the upper neck region. 


\subsubsection{Forward and rearward facing resultant lower neck forces}

Figure 57 illustrates the resultant lower neck forces versus time for the forward and rearward facing Hybrid III 3-year-old dummy model.

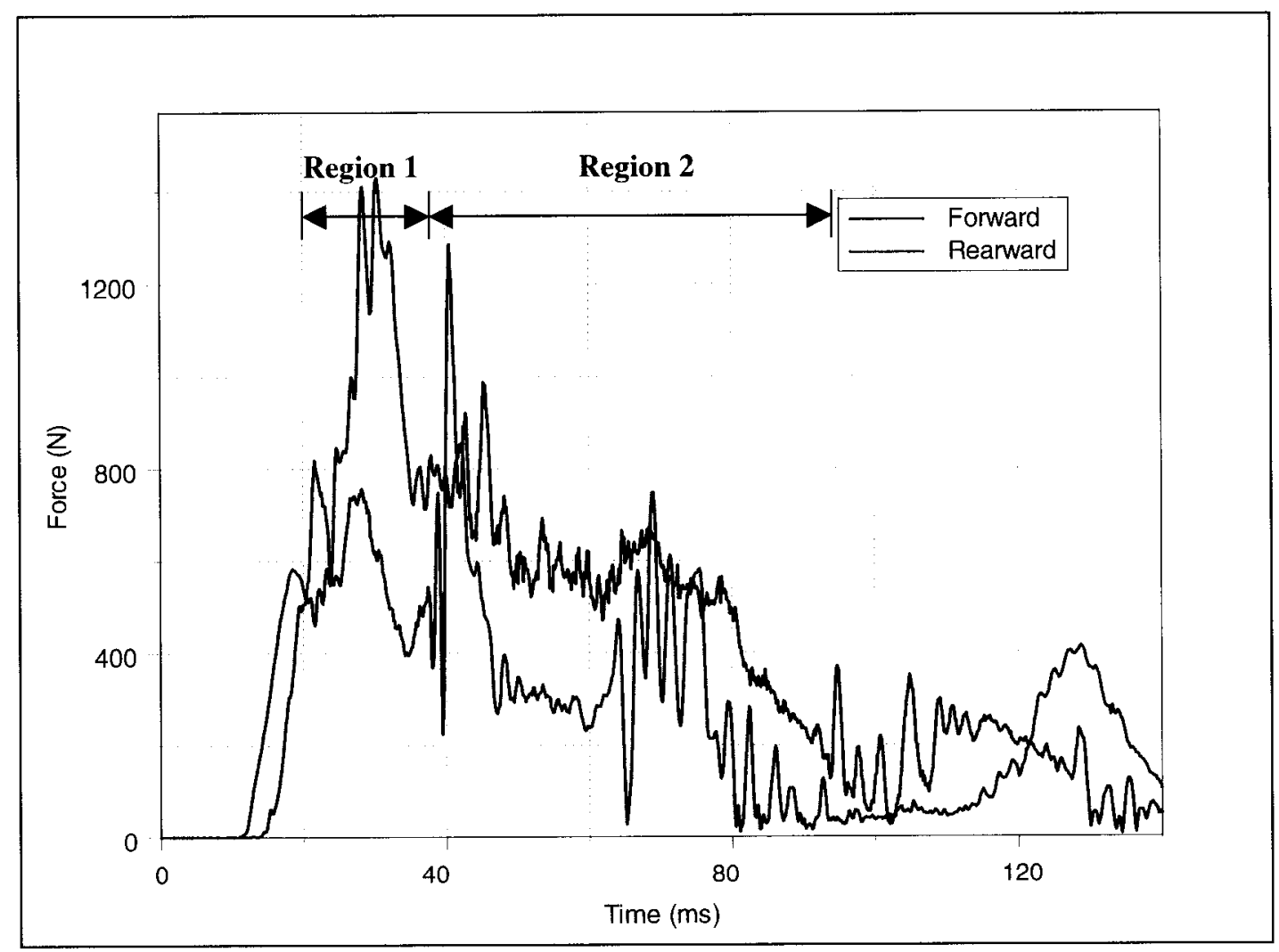

Figure 57. Resultant lower neck forces for forward and rearward facing simulations.

The force subjected to the Hybrid III 3-year old dummy's lower neck was at a peak value of $1300 \mathrm{~N}$ in the forward facing direction and $1450 \mathrm{~N}$ in the rearward facing situation. The peaks occurred in Region 1, as labeled in Figure 57. The peak regions lasted for a maximum of $20 \mathrm{~ms}$. When observing Region 2, it was noticed that higher loads occurred for a longer period of time for the forward facing child than for the rearward facing child. Region 2 spans approximately 80 ms. If a critical value of $500 \mathrm{~N}$ was chosen, it was observed that the forward facing Hybrid III 3-year-old child spent more time above that critical value than the rearward facing child. Again, it is known that the longer one sustains a load, the greater the potential for injury. It is understood that a high acceleration can be sustained for a very short period of time [34]. The longer one is subjected to an acceleration, the greater potential for injury. Therefore, in the lower neck, the 
force endured by the rearward facing child appears to achieve less potential for injury than for a forward facing child.

\subsubsection{Forward and rearward facing resultant upper neck moments}

Figure 58 illustrates the resultant upper neck moments versus time for the forward and rearward facing Hybrid III 3-year-old dummy model.

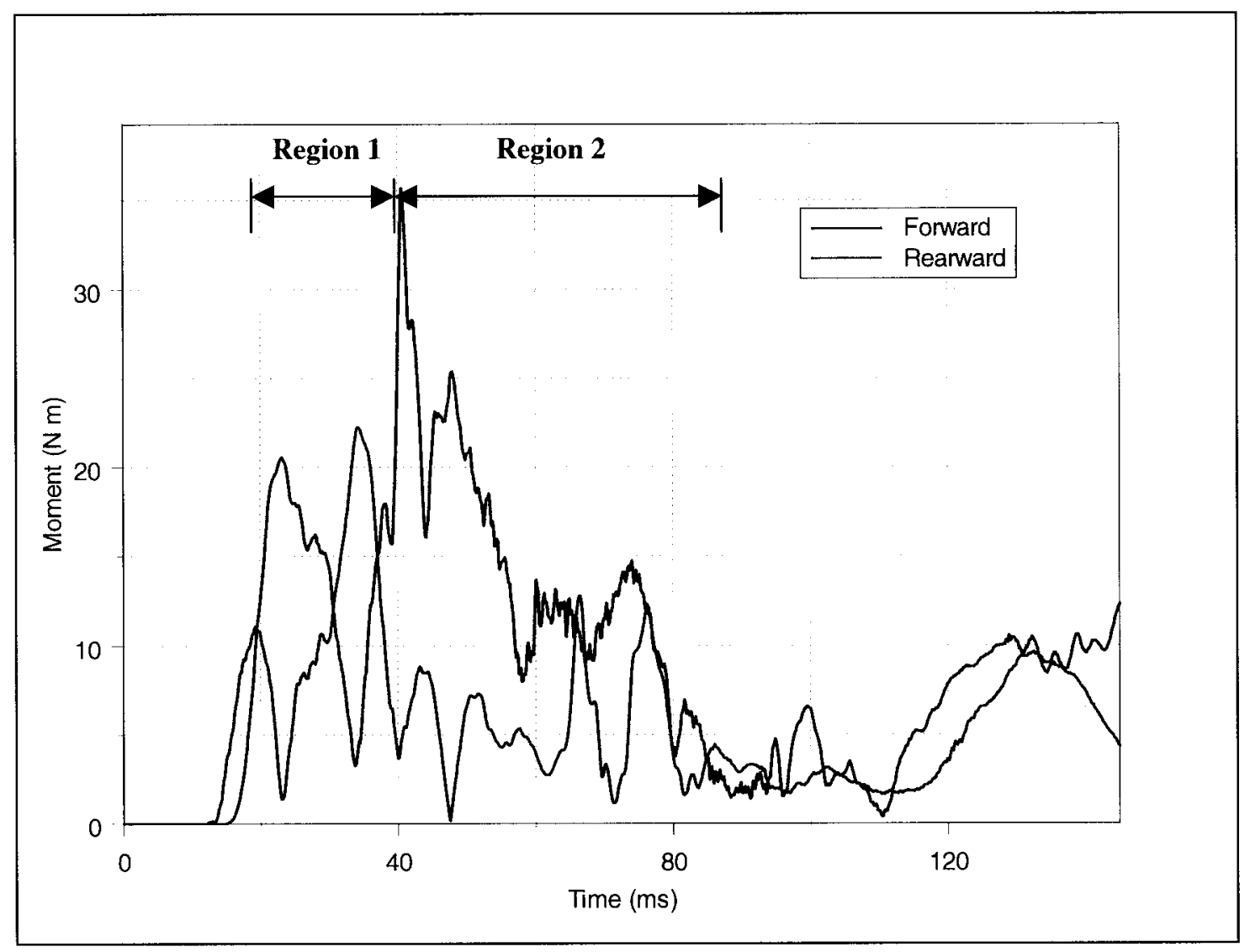

Figure 58. Resultant upper neck moments for forward and rearward facing simulations.

The forward facing Hybrid III 3-year old dummy faced a peak bending moment of slightly over $35 \mathrm{~N} \cdot \mathrm{m}$ whereas the rearward facing dummy model had a upper neck peak bending moment of $22 \mathrm{~N} \cdot \mathrm{m}$. The peak region, Region 1, occurred for $20 \mathrm{~ms}$, although the actual peak moments only lasted for a couple of milliseconds. In Region 2, the forward facing child sustained higher moments in the upper neck region then the child facing the rearward direction. Region 2 lasted 
for just over $40 \mathrm{~ms}$. Once again, due to work researched by DeSantis-Klinich et al. [34], it can be concluded that since the rearward facing child was subjected to a high value of moment for a greater duration of time than the forward facing child, there was less potential for injury in the rearward facing child safety seat.

\subsubsection{Forward and rearward facing resultant lower neck moments}

Figure 59 illustrates the resultant lower neck moments versus time for the forward and rearward facing Hybrid III 3-year-old dummy model.

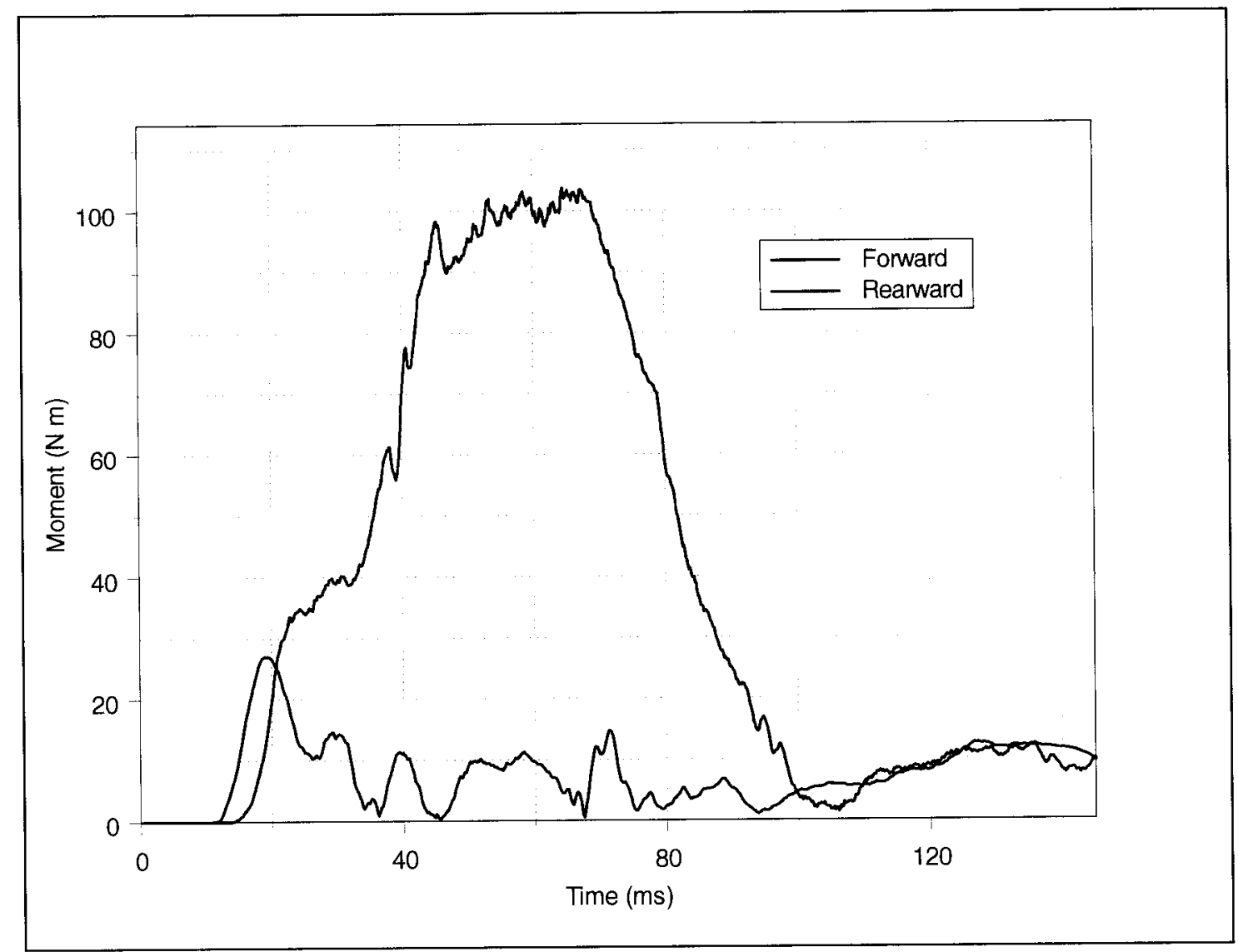

Figure 59. Resultant lower neck moments for forward and rearward facing simulations.

The forward facing Hybrid III 3-year old dummy model clearly sustained much higher bending moment in the lower neck than the rearward facing dummy model. The moment that resulted from rearward facing CRS peaked at approximately $27 \mathrm{~N} \cdot \mathrm{m}$. The moment resulting from the forward facing configuration illustrated a maximum plateau of approximately $100 \mathrm{~N} \cdot \mathrm{m}$. for 
approximately $25 \mathrm{~ms}$. This graph illustrated that there was a high potential for injury in the lower neck of a child in a frontal crash. The value of the peak moment in the upper neck in the forward facing position was almost three times as large as the value for the peak moment in the lower neck in the forward facing position. The rearward facing child safety seat would provide better safety against potential for injury in the lower neck region than the forward facing CRS.

Table 16 summarizes the forces and moments observed in the upper and lower neck of the Hybrid III 3-year-old child dummy model.

Table 16. Summary of forces and moments observed in the neck of Hybrid III 3-year-old child dummy model.

\begin{tabular}{|c||c||c|}
\hline Item & Forward Facing & Rearward Facing \\
\hline \hline Upper Neck Force (N) & 1200 & 1200 \\
\hline Duration of Pulse (ms) & 60 & 25 \\
\hline Lower Neck Force (N) & 1300 & 1450 \\
\hline Duration of Pulse (ms) & 80 & 20 \\
\hline Upper Neck Moment (Nm) & 35 & 22 \\
\hline Duration of Pulse (ms) & 40 & 20 \\
\hline Lower neck Moment (Nm) & 105 & 26 \\
\hline Duration of Pulse (ms) & 70 & 7 \\
\hline
\end{tabular}




\subsubsection{Head injury criteria}

Figure 60 illustrates the head injury criteria using a $15 \mathrm{~ms}$ sampling window for both the forward and rearward facing numerical simulations. The rearward facing Hybrid III 3-year-old dummy model sustained a higher peak $\mathrm{HIC}_{15}$ value than the forward facing model by a magnitude value of 35 . However, both values for $\mathrm{HIC}_{15}$ were significantly lower than the limit value of 570 .

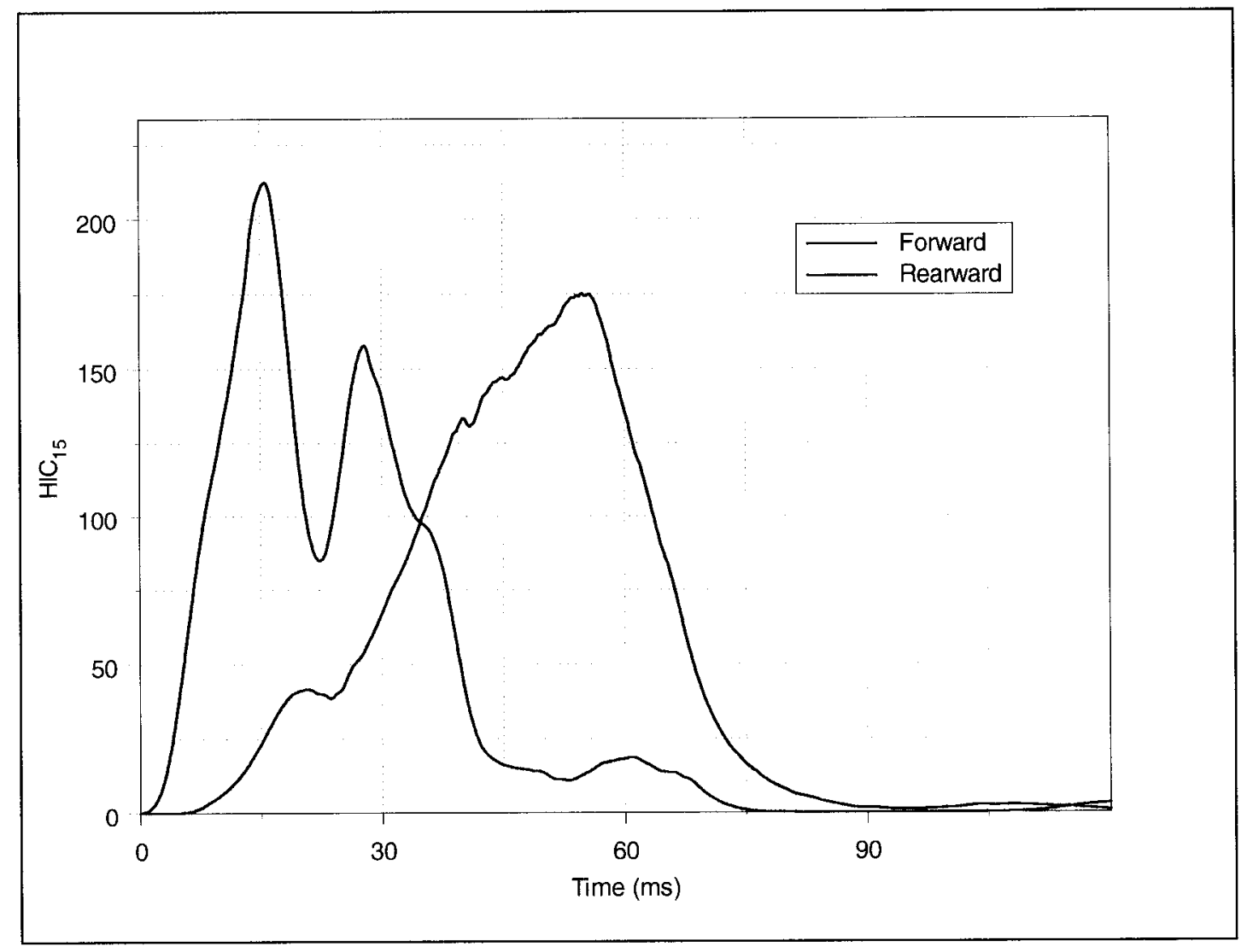

Figure 60 . Head injury criteria $-\mathrm{HIC}_{15}$ for forward and rearward facing simulations.

Although the peak was higher for the child in the rearward facing configuration, it occurred due to the initial impact of the head on the seat, forcing the head of the child to decelerate quicker. The head of the forward facing child decelerated slower but experienced high values of $\mathrm{HIC}_{15}$ for a longer period of time.

Figure 61 illustrates the head injury criteria using a $36 \mathrm{~ms}$ sampling window. Both the rearward and forward facing Hybrid III 3-year-old dummy models sustained a $\mathrm{HIC}_{36}$ below 350 which was below the recommended standard limit of 570 for this age group. 


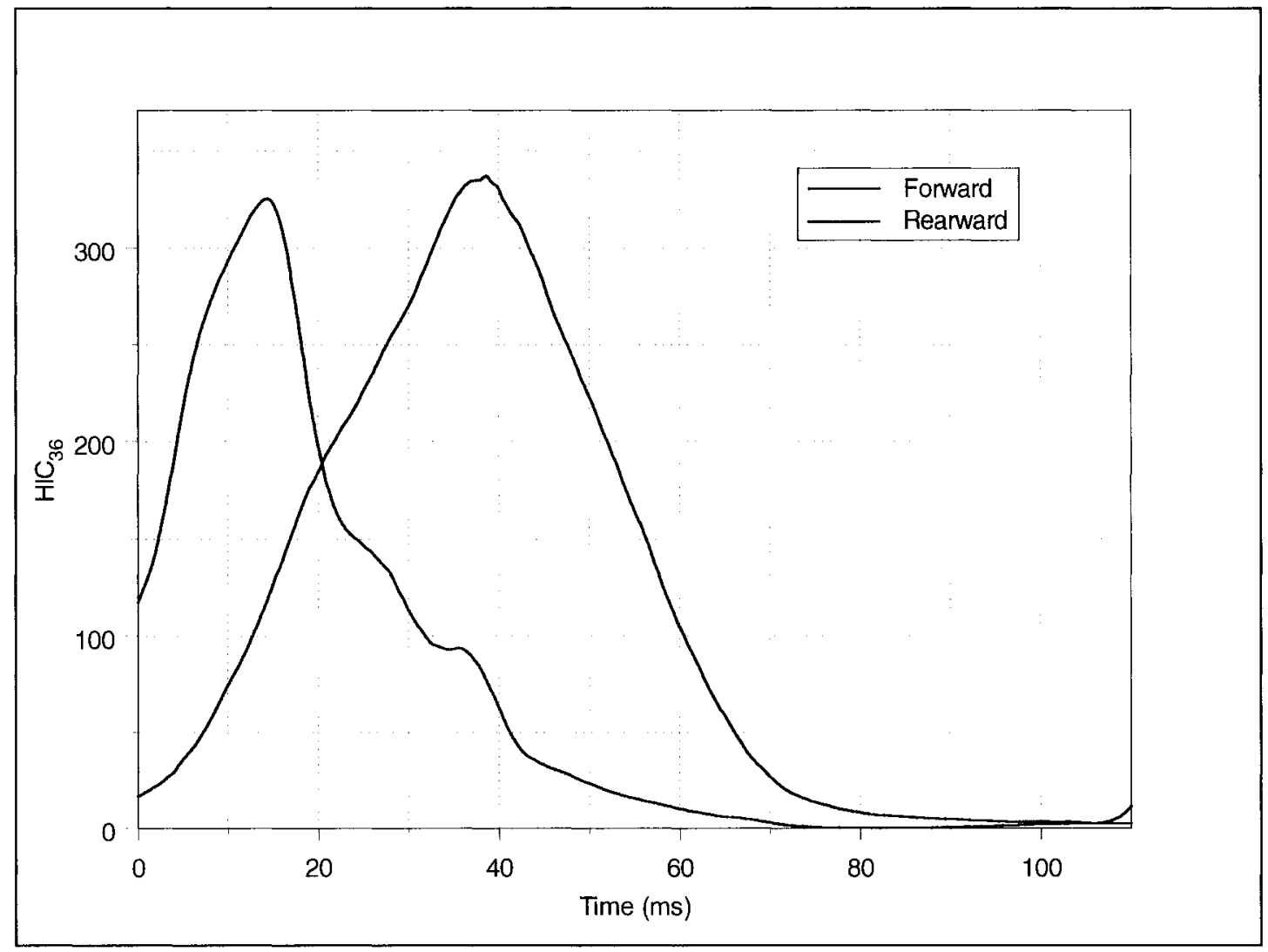

Figure 61 . Head injury criteria - $\mathrm{HIC}_{36}$ for frontward and rearward facing simulations.

Moreover, the child in the forward facing configuration was subjected to a higher value of $\mathrm{HIC}_{36}$ for a longer period of time than is the child in the rearward simulation. The values of the $\mathrm{HIC}_{36}$ were higher (by a small amount) than those for the $\mathrm{HIC}_{15}$ because of the greater time window allowed for analysis. This may be the reason for the delay in the implementation of $\mathrm{HIC}_{15}$ in FMVSS 213. There may exist the worry that the $\mathrm{HIC}_{15}$ would underestimate accelerations truly experienced by the head. 
Figure 62 is a replication of Figure 3, except for that it is zoomed into the area into which the $\mathrm{HIC}_{15}$ values obtained fall. In addition, there are reference lines indicating the peak value for the forward facing rearward facing configurations.

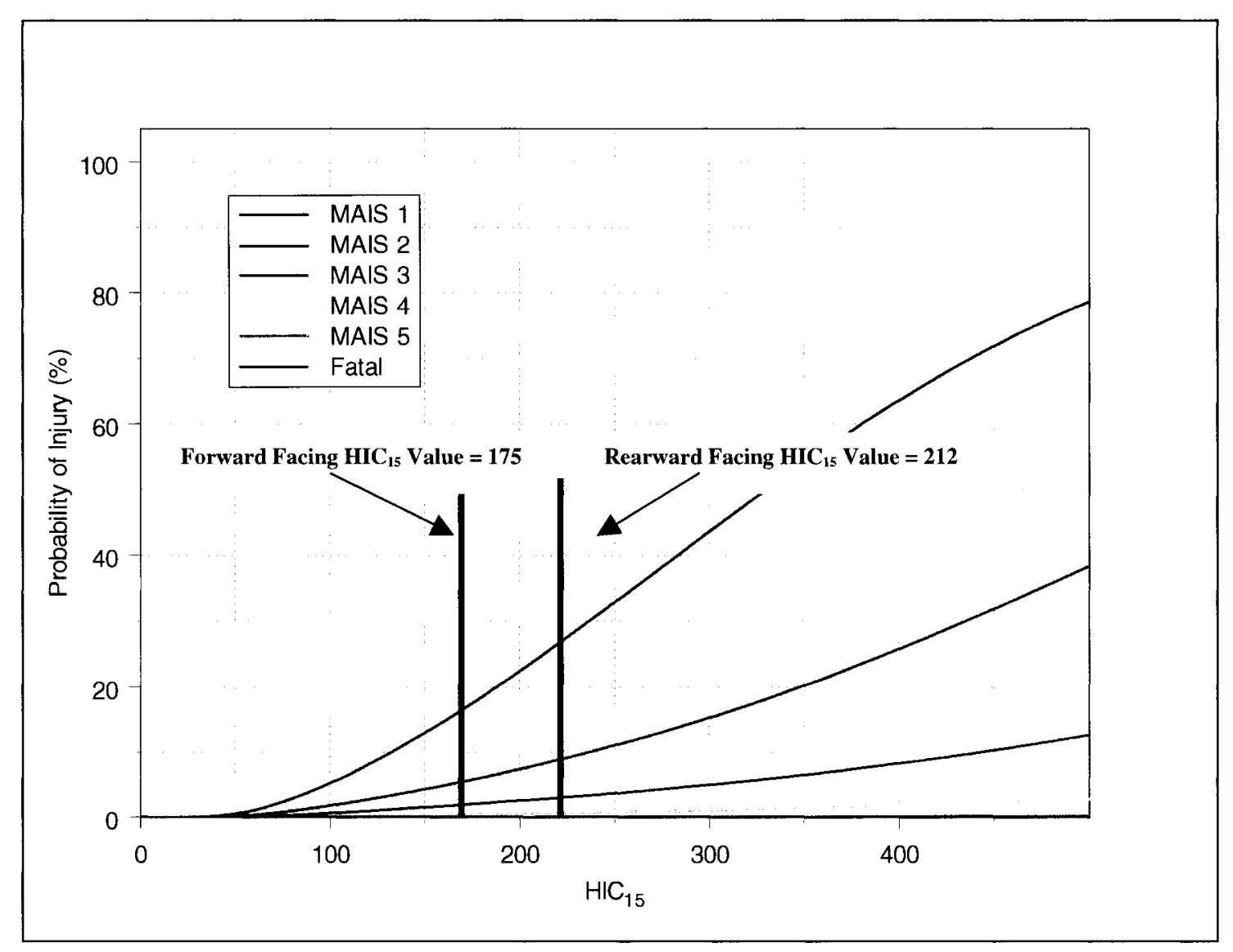

Figure 62. Probablity of injury versus head injury criteria - 500 HIC window.

The peak value for the $\mathrm{HIC}_{15}$ for the child in the rearward facing configuration was somewhat greater than that for the child in the forward facing configuration. The probabilities of sustaining the varying degrees of injury from these $\mathrm{HIC}_{15}$ values were summarized in Table 17. Table 17 also lists the peak HIC values for both the $15 \mathrm{~ms}$ and $36 \mathrm{~ms}$ windows. However there were no values found for the MAIS criteria for $\mathrm{HIC}_{36}$. 
Table 17. Probability of injury for forward and rearward facing configurations.

\begin{tabular}{|c||c|c|c|c|}
\hline \multirow{2}{*}{ HIC Value } & \multicolumn{2}{|c|}{ HIC $_{\mathbf{1 5}}$} & \multicolumn{2}{c|}{ HIC $_{36}$} \\
\cline { 2 - 5 } & Forward & Rearward & Forward & Rearward \\
\hline Peak Value & 174.93 & 212.3 & 336.88 & 325.16 \\
\hline Prob. of MAIS 1 (\%) & 18 & 27 & N/A & N/A \\
\hline Prob. of MAIS 2 (\%) & 6 & 9 & N/A & N/A \\
\hline Prob. of MAIS 3 (\%) & 2 & 3 & N/A & N/A \\
\hline Prob. of MAIS 4 (\%) & 0 & 0 & N/A & N/A \\
\hline Prob. of MAIS 5 (\%) & 0 & 0 & N/A & N/A \\
\hline Prob. of MAIS 6 (\%) & 0 & 0 & N/A & N/A \\
\hline
\end{tabular}

\subsubsection{Average head acceleration}

In this section, the head acceleration was averaged over specific time increments for both the forward and rearward facing configurations. The advantage of analyzing the data in this manner is that one is able to identify which configuration sustains higher loads for a longer duration of time. As published by Macaulay [36], it is understood that the longer a value of acceleration is sustained, the more susceptible to injury the occupant is. Table 18 and Figure 63 illustrates the average head accelerations versus time duration for the Hybrid III 3-year-old dummy model in the forward and rearward facing child safety seats.

Table 18. Forward and rearward facing average head acceleration values for time durations.

\begin{tabular}{|c||c||c|}
\hline \multirow{2}{*}{ Time Duration (ms) } & \multicolumn{2}{|c|}{ Average Head Acceleration (g's) } \\
\cline { 2 - 3 } & Forward Facing & Rearward Facing \\
\hline \hline 10 & 16.08 & 32.94 \\
\hline 20 & 16.98 & 31.92 \\
\hline 30 & 21.28 & 33.01 \\
\hline 40 & 23.43 & 29.44 \\
\hline 50 & 25.19 & 25.74 \\
\hline 60 & 25.25 & 23.82 \\
\hline 70 & 23.46 & 21.94 \\
\hline 80 & 21.48 & 19.53 \\
\hline 90 & 19.62 & 17.50 \\
\hline 100 & 18.39 & 15.92 \\
\hline 110 & 17.36 & 14.71 \\
\hline 120 & 16.23 & 14.26 \\
\hline
\end{tabular}


Figure 63 illustrates that for the majority of the time duration, the average head acceleration for the child in the forward facing child safety seat was higher than that for the child in the rearward facing configuration. This is important to note since the head injury criteria curves for the $15 \mathrm{~ms}$ time window did not show explicitly that the rearward facing child experiences less head accelerations. In this manner however, it was apparent that the forward facing child would experience higher head accelerations for the majority of the time.

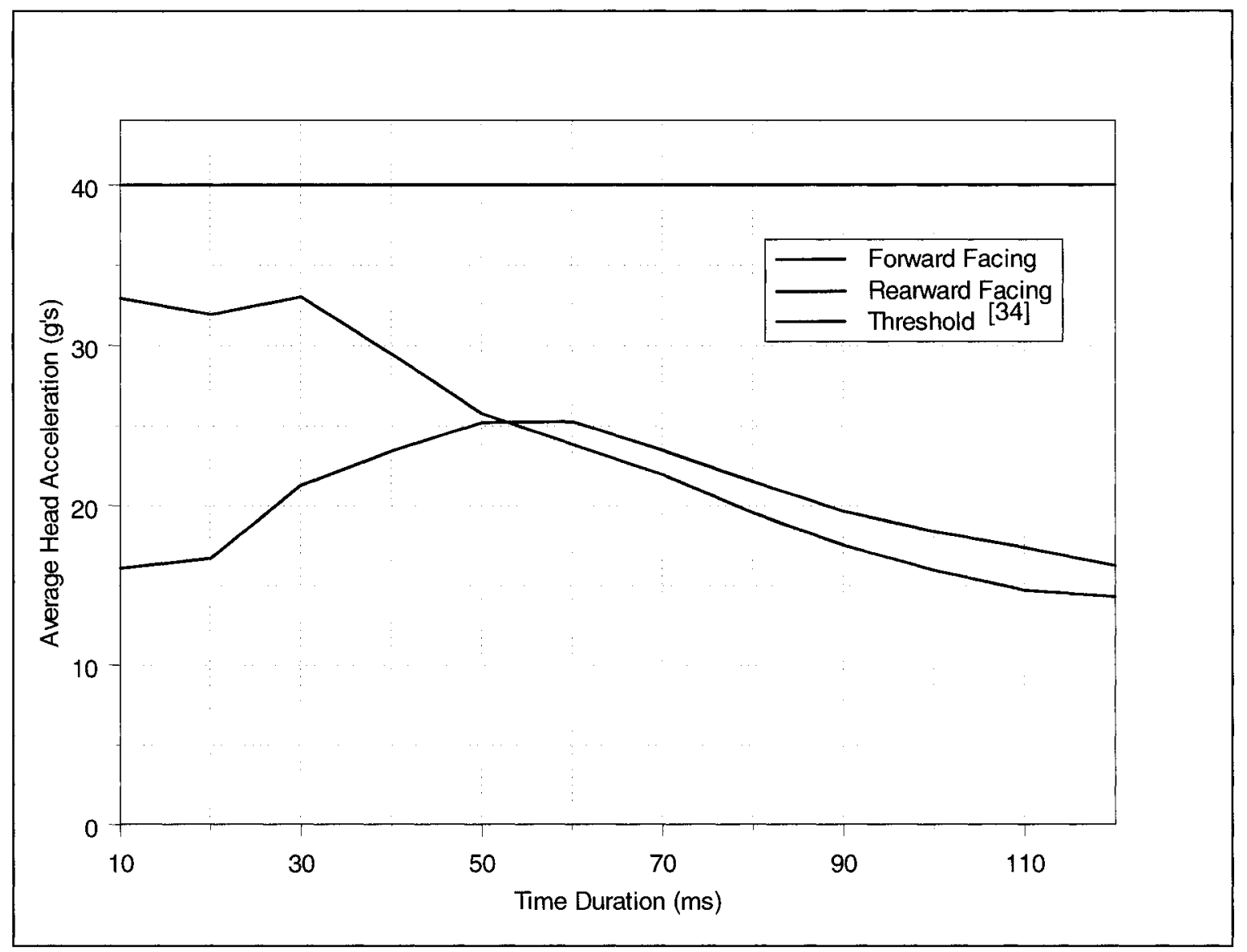

Figure 63. Forward and rearward facing average head acceleration and threshold acceleration versus time duration.

At the onset of the numerical simulations, it was observed that the rearward facing configuration experienced higher head accelerations than the forward facing configuration. Again, the time duration that the child sustains the accelerations is the key factor in determining the potential of injury [36]. After approximately $50 \mathrm{~ms}$ time duration, the forward facing child consistently sustained higher head accelerations. 
In Figure 8 the threshold impact acceleration was illustrated for a $50^{\text {th }}$ percentile adult male. According to Desantis-Klinich et al. [34], this curve would be scaled down if it were represent a 3-year-old child. If it were to be scaled to a 3-year-old child dummy, it would be scaled upwards. This phenomenon was detailed in the literature review. The data used to create that curve came from three sources. For the short duration of time, the onset of fracture in cadaver skulls striking a flat rigid plate were used. For intermediate duration of time, anaesthetized dogs were tested. Finally, for the long duration of time, the accelerations were estimated from accidental falls and volunteers. Therefore, if these sets of data are lumped together, it can be said that it is all human data, thereby allowing one to think that the threshold curve should be scaled down for a child. However, this study deals with Hybrid III 3-year-old dummy models. Hence, the curve should be scaled upwards. But it can only be scaled upwards if the original data comes from another anthropomorphic device, which it does not. Based on availability of data, the average head accelerations obtained for the forward and rearward facing configurations can be compared to the acceleration threshold curve as it is. The curve in Figure 8 eventually drops to a plateau of approximately $40 \mathrm{~g}$ 's. This was plotted as a straight line at a value of $40 \mathrm{~g}$ 's across the entire time duration to show that both the rearward and the forward simulations produced average head accelerations that were lower than the plateau of $40 \mathrm{~g}$ 's. This implied that both the forward and the rearward facing children were safe against severe head injury due to acceleration. Nevertheless, averaged over time, the rearward facing child was safer still against head injury due to acceleration than the forward facing child. 


\subsubsection{Average chest acceleration}

In this section, the chest acceleration was averaged over specific time increments for both the forward and rearward facing configurations. Again, the advantage of analyzing the data in this manner was that one is able to identify which configuration sustained higher loads for a longer duration of time. Table 19 and Figure 64 illustrate the average chest accelerations versus time duration for the Hybrid III 3-year-old dummy model in the forward and rearward facing child safety seats. Figure 64 also illustrates the whole body acceleration of rearward tolerance curve that was presented in the literature review. Essentially the tolerance curve represents the limit of acceleration that a human body $\left(50^{\text {th }}\right.$ percentile male) can withstand with respect to time [36]. There is no available data in the literature regarding the limitation of acceleration to the chest. Furthermore, there is no available data in the literature regarding these types of limitation to children or to child dummies. Hence, the comparison in Figure 64 was made due to lack of more appropriate data.

Table 19. Forward and rearward facing average chest acceleration values for time durations.

\begin{tabular}{|c|c|c|}
\hline \multirow{2}{*}{ Time Duration (ms) } & \multicolumn{2}{|c|}{ Average Chest Acceleration (g's) } \\
\hline & Forward Facing & Rearward Facing \\
\hline 10 & 26.93 & 29.91 \\
\hline 20 & 17.19 & 27.71 \\
\hline 30 & 29.90 & 29.34 \\
\hline 40 & 27.62 & 26.45 \\
\hline 50 & 26.32 & 24.10 \\
\hline 60 & 24.13 & 23.03 \\
\hline 70 & 21.50 & 21.09 \\
\hline 80 & 19.56 & 18.90 \\
\hline 90 & 17.81 & 16.97 \\
\hline 100 & 16.53 & 15.42 \\
\hline 110 & 15.29 & 14.33 \\
\hline 120 & 15.29 & 14.33 \\
\hline
\end{tabular}




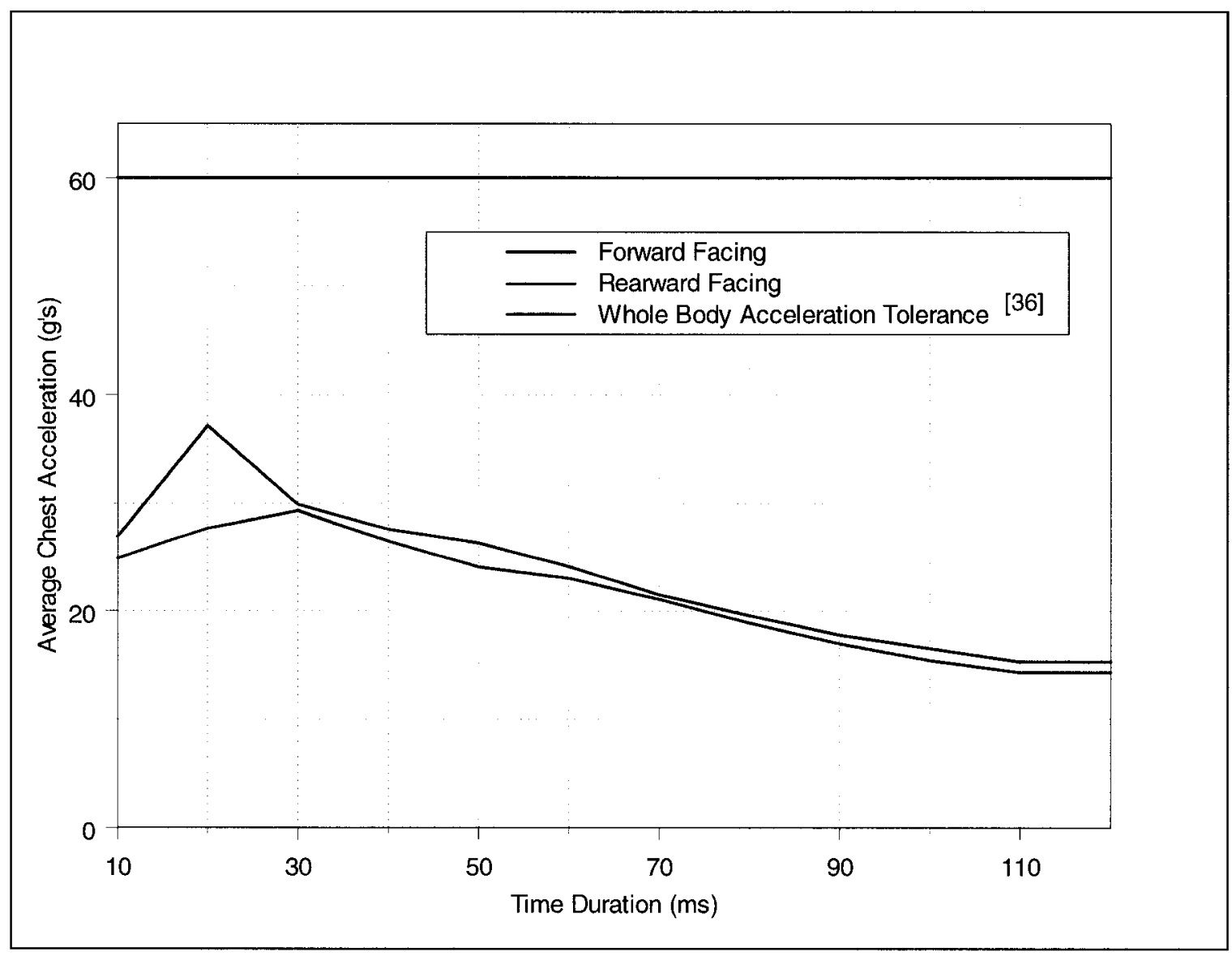

Figure 64. Forward and rearward facing average chest acceleration and whole body tolerance of rearward acceleration versus time duration.

Figure 64 illustrates that throughout the time duration, the average head acceleration for the child in the forward facing child safety seat was higher than that for the child in the rearward facing configuration. This was noteworthy because it implied that the forward facing child was more susceptible to chest injury or injury to vital organs within the chest area than the rearward facing child. 


\subsubsection{Neck injury criteria}

Figure 65 demonstrates the neck injury criteria $\left(\mathrm{N}_{\mathrm{ij}}\right)$ for the Hybrid III 3-year-old dummy model in the forward and rearward positions. The rearward facing curve was distinctly lower than the forward facing curve was. This implied that there was less potential for neck injury in the rearward facing position than in the forward facing position. The limit value for $\mathrm{N}_{\mathrm{ij}}$ is 1.0 . The rearward facing child surpassed this value slightly for only a short time. While the forward facing child reached values of over 1.5 .

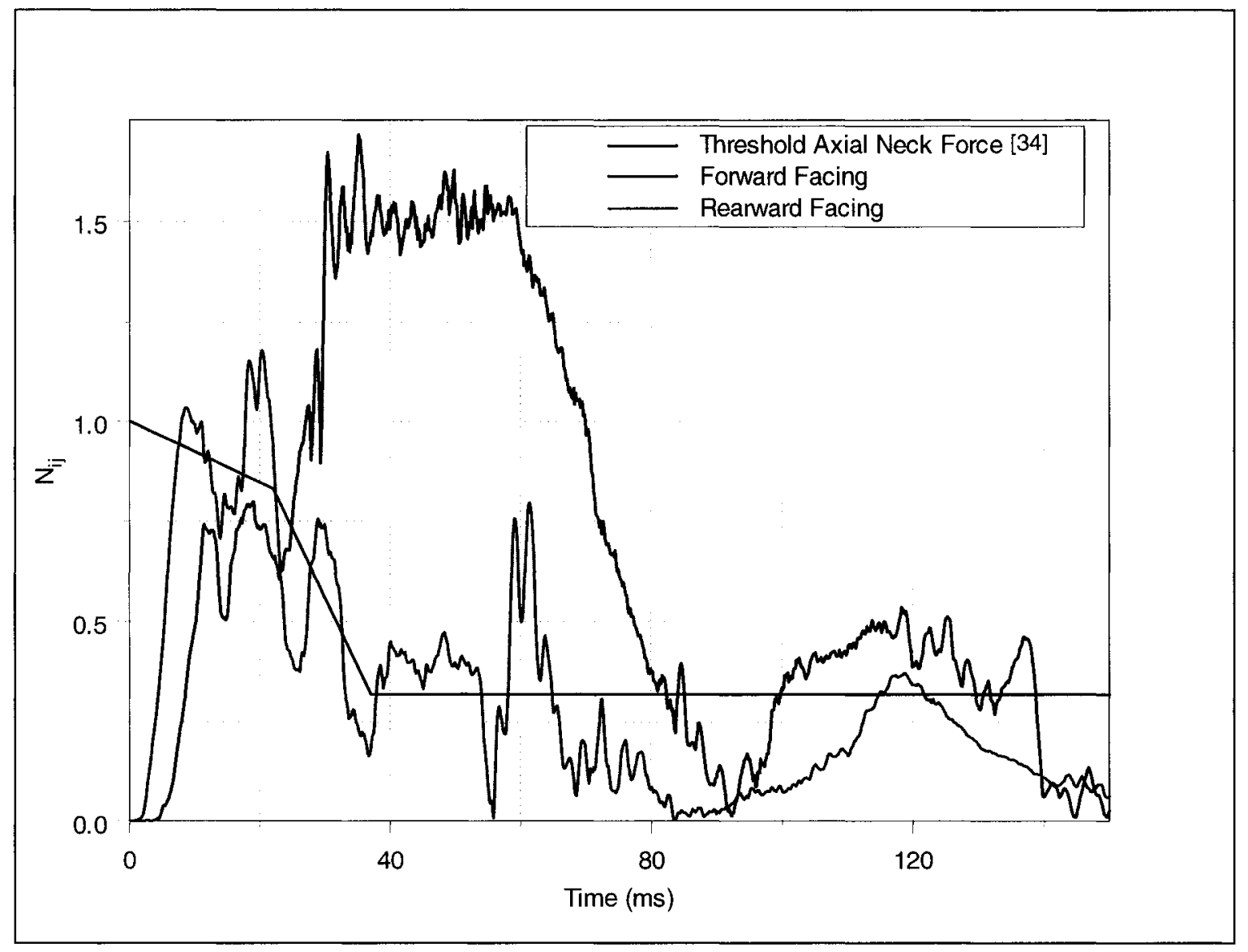

Figure 65. Normalized threshold axial neck force, forward facing $\mathrm{N}_{\mathrm{ij}}$, and rearward facing $\mathrm{N}_{\mathrm{ij}}$ versus time

Figure 65 also illustrates the normalized neck force tolerance curve from the publication by DeSantis-Klinich et al [34]. Clearly, the child in the forward facing CRS sustained a higher neck injury for longer periods of time than the child in the rearward facing configuration. In fact, the 
forward facing child's neck surpassed the tolerance limit for most of the time duration. This indicated that the length of time for which the neck was subjected to the levels of bending moments and forces was too long to prevent injury. Injury was most likely imminent in the neck of the forward facing child for the prescribed FMVSS 213 acceleration pulse. This observation was absent for the rearward facing child. The rearward facing child fell below the tolerance limit for the majority of the time duration.

A possible explanation for the greater potential for injury in the forward facing configuration is that the back of the seat cradled the head of the child in the rearward facing simulation and did not allow for as much bending as the child in the forward facing simulation experienced. The forward facing child had nothing to inhibit the forward motion due to the crash.

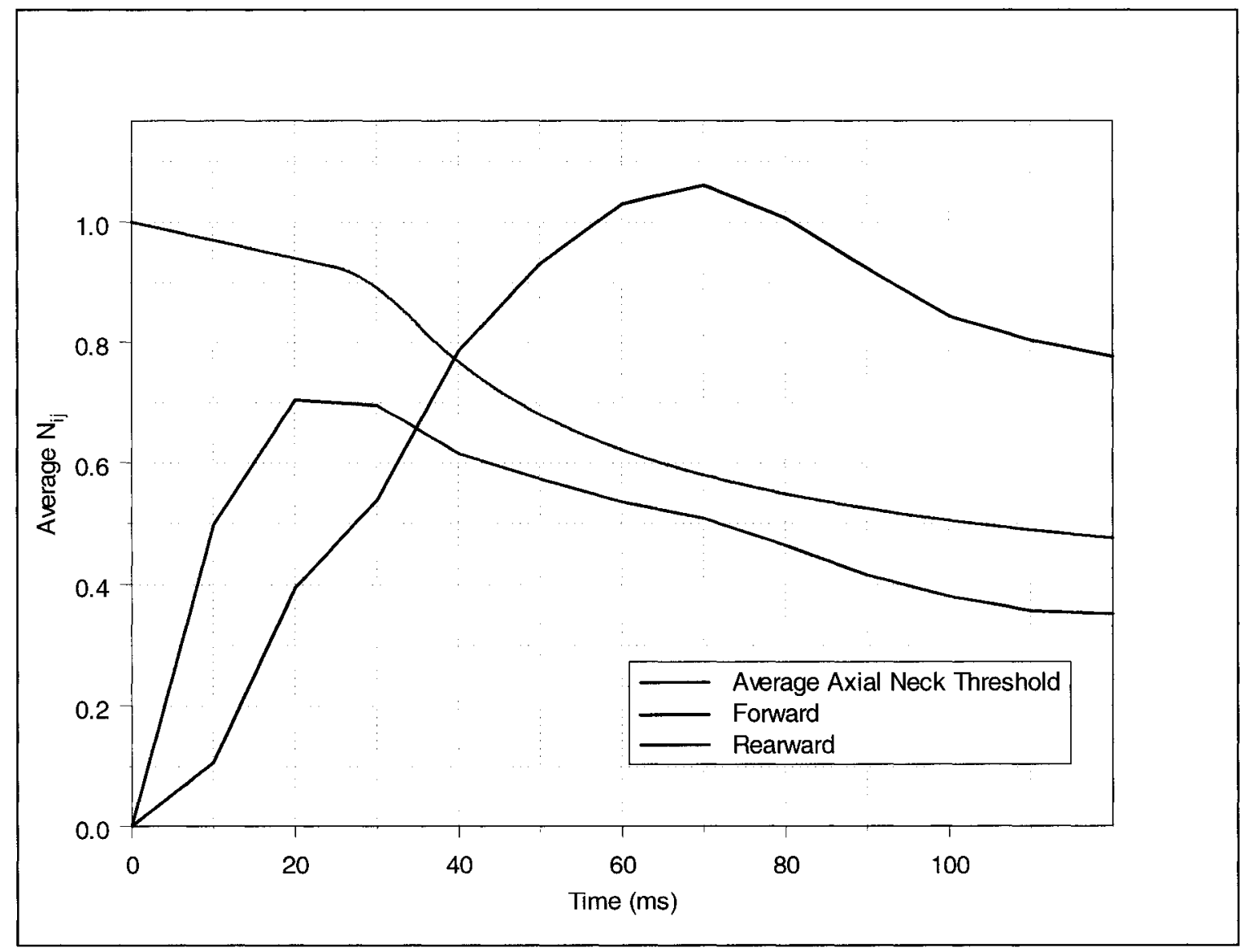

Figure 66. Average neck injury criteria and average normalized threshold axial force versus time duration for forward and rearward facing configurations. 
The child in the forward facing simulation also endured high average $\mathrm{N}_{\mathrm{ij}}$ values for a longer period of time. Averages were calculated and are listed in Table 20 and plotted in Figure 66. In addition, the average was calculated for the axial neck threshold curve illustrated in Figure 65 and plotted in Figure 66.

Table 20. Forward and rearward facing average $\mathrm{N}_{\mathrm{ij}}$ for time durations.

\begin{tabular}{|c||c||c|}
\hline \multirow{2}{*}{ Time Duration (ms) } & \multicolumn{2}{|c|}{ Average $\mathrm{N}_{\mathrm{ij}}$} \\
\cline { 2 - 3 } & Forward Facing & Rearward Facing \\
\hline 10 & 0.106 & 0.494 \\
\hline 20 & 0.394 & 0.714 \\
\hline 30 & 0.539 & 0.695 \\
\hline 40 & 0.786 & 0.615 \\
\hline 50 & 0.932 & 0.573 \\
\hline 60 & 1.030 & 0.535 \\
\hline 70 & 1.060 & 0.508 \\
\hline 80 & 1.006 & 0.463 \\
\hline 90 & 0.923 & 0.415 \\
\hline 100 & 0.884 & 0.380 \\
\hline 110 & 0.804 & 0.357 \\
\hline 120 & 0.776 & 0.352 \\
\hline
\end{tabular}

In the onset of the curves in Figure 66, the rearward facing configuration experienced higher average $\mathrm{N}_{\mathrm{ij}}$ values. However, at approximately $35 \mathrm{~ms}$, the forward facing configuration began to experience higher average $\mathrm{N}_{\mathrm{ij}}$ values and continued to do so for the remainder of the time duration. This was noteworthy because it implied that the forward facing configuration was more susceptible to neck injury based on the length of time that the child was subjected to the forces and moments in the neck. The rearward facing curve is consistently lower than the average axial neck threshold curve. 


\subsubsection{Qualitative comparison of forward and rearward numerical simulations}

Figure 67 illustrates the kinematics of the forward and rearward numerical simulation observations at the same moments in time. This allowed for direct visual comparison of the two configurations. The seat of the numerical simulations was made to be transparent so one can see the entire body movements of the Hybrid III 3-year-old dummy model. 


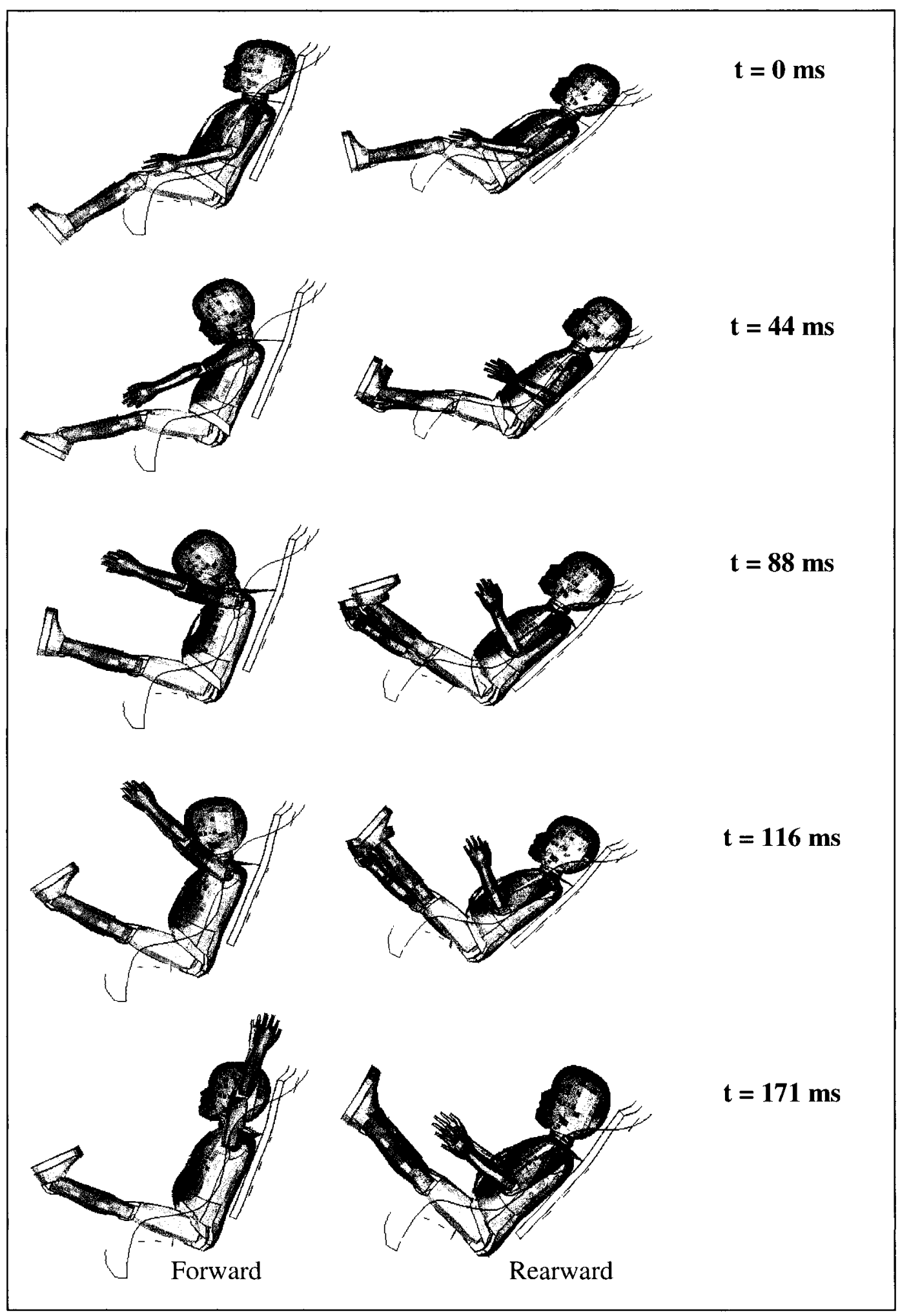

Figure 67. Forward and rearward numerical simulation images at exact time increments. 
In Figure 67, the forward and rearward facing Hybrid III 3-year-old dummy models exhibited completely different kinematic positions throughout the time of the simulation. Time $0 \mathrm{~ms}$ indicates the start of the numerical simulation. At time $44 \mathrm{~ms}$, the forward facing child was moved forward by the sudden impact whereas the rearward facing child was moved into the back of the child safety seat. At time $88 \mathrm{~ms}$, the rearward facing child fell into the back of the child safety seat once more as inertia drew the forward facing further away from the seat. The forward facing child's neck was beginning to bend severely when compared to that of the rearward facing child. In addition, the arms and legs of the forward facing child were fully extended outward. The legs of the rearward facing child were extended but the arms did not extend to the same degree as those of the forward facing child. At time $116 \mathrm{~ms}$, the forward facing child was returning back into the child safety seat whereas the rearward facing child was slightly moving away from the back of the seat and into the seat belt. By the time $171 \mathrm{~ms}$, the arms and legs of the forward facing child were fully extended upward and outward, respectively, and the head was impacting the rear of the seat. At this time the rearward facing child was still moving away from the seat and further into the seat belt.

It is clear from the images in Figure 67 that the bending of the neck, displacement of the head, and the extension of the limbs were much more severe for the child in the forward facing configuration. Qualitatively, the images project the safer configuration of seating for a 3-year-old child to be rearward facing.

The forces and moments on the upper and lower neck of the Hybrid III 3-year-old dummy were lower in the rearward facing configuration. The HIC in both the 15 and $36 \mathrm{~ms}$ windows were comparable, and the $\mathrm{N}_{\mathrm{ij}}$ in the rearward facing configuration was considerably lower.

These qualitative images accompanied by the quantitative data provided in this section indicated that a more appropriate child seating configuration, with regards to occupant safety, was the rearward facing configuration. 


\section{CONCLUSIONS AND FUTURE WORK}

The correlation between the observations obtained from the forward facing experimental sled test and the forward facing numerical simulations conducted in this research provided a base for comparison of a number of different crash scenarios involving the Hybrid III 3-year-old dummy. Injury potential from numerically simulating a forward versus a rearward facing child was accomplished. Through these numerical simulations it was concluded that for a 3-year-old child, the rearward facing configuration is safer in terms of occupant injury to the head and neck. The following is as list of conclusions that were made based on the experiments and simulations conducted in this research.

1. The child in the forward facing CRS as well as in a rearward facing CRS experienced a peak upper neck force of $1200 \mathrm{~N}$. However, the time durations of the force pulses were $60 \mathrm{~ms}$ and $20 \mathrm{~ms}$ for the forward facing and rearward facing configurations, respectively. The forward facing child experienced high loads in the upper neck and for a more substantial duration of time.

2. The child in the forward facing CRS experienced a peak lower neck force of $1300 \mathrm{~N}$ and the child in a rearward facing CRS experienced a peak lower neck force of $1450 \mathrm{~N}$. However, the time durations of the force pulses were $80 \mathrm{~ms}$ and $20 \mathrm{~ms}$ for the forward facing and rearward facing configurations, respectively. The forward facing child experienced high forces in the lower neck for a longer period of time.

3. The child in the forward facing CRS experienced a peak bending moment in the upper neck of $35 \mathrm{~N} \cdot \mathrm{m}$ and the child in the rearward facing CRS experienced a peak bending moment of $22 \mathrm{~N} \cdot \mathrm{m}$ in the upper neck. However, the time durations of the bending moment pulses were $45 \mathrm{~ms}$ and $20 \mathrm{~ms}$ for the forward facing configuration and the rearward facing configuration, respectively. The forward facing child experienced high bending moment in the upper neck for a longer period of time.

4. The child in the rearward facing CRS experienced a peak bending moment in the lower neck of $105 \mathrm{~N} \cdot \mathrm{m}$ and the child in the rearward facing CRS experienced a peak bending moment of $26 \mathrm{~N} \cdot \mathrm{m}$ in the lower neck. However, the time durations of the bending 
moment pulses were $70 \mathrm{~ms}$ and $7 \mathrm{~ms}$ for the forward facing and the rearward facing configurations, respectively.

5. The $\mathrm{HIC}_{15}$ for the child in the forward facing CRS configuration was 174.93 and for the child in the rearward facing CRS configuration, the $\mathrm{HIC}_{15}$ was 212.3. The $\mathrm{HIC}_{36}$ for the child in the forward facing CRS configuration was 336.9 and for the child in the rearward facing CRS configuration, the $\mathrm{HIC}_{36}$ was 325.2. Both configurations yielded $\mathrm{HIC}$ values lower than the proposed limits. Where the $15 \mathrm{~ms}$ window is considered, the rearward facing child experienced slightly higher HIC values for a short period of time. Where the $36 \mathrm{~ms}$ window is considered, the rearward facing child sustained slightly lower HIC values than the forward facing child did.

6. On average, the child in the rearward facing CRS configuration sustained less head acceleration for the majority of the test. While the average head acceleration for the child in the forward facing CRS configuration was consistently greater.

7. On average, the child in the rearward facing CRS configuration sustained less chest acceleration for the entire test. The child in the forward facing CRS configuration experienced consistently higher average chest accelerations.

8. The $\mathrm{N}_{\mathrm{ij}}$ was substantially lower for the child in the rearward facing CRS configuration. The peak $\mathrm{N}_{\mathrm{ij}}$ value for the child in the forward facing CRS configuration was 1.6 and for the child in the rearward facing CRS configuration, the peak $\mathrm{N}_{\mathrm{ij}}$ value was 1.2 . When plotted with the normalized axial force threshold, it was observed that the forward facing child was above the limit by approximately $50 \%$ for approximately $50 \%$ of the test. This implied that is a potential for severe damage in the neck region for a child who was facing forward.

9. Kinematically, the motions of the head, neck, and other limbs were quite severe for the forward facing child. The rearward facing child had one impact with the back of the seat initially. For the most part, however, the back of the seat absorbed the energy of the crash and saved the child from potentially severe neck injury. 
Future work in this area may include better defining the crash test characteristics including the deformability of the child safety seat, the deformability of the seat belt, and the allowance for relative displacement between the sled bench and the child safety seat. Essentially, the FE model can be refined to consider all the sled test situations.

Once refinement is achieved, the testing of out of position child occupants can be considered. The effect of slouching and sleeping can be taken into account, as children are rarely seated upright in a child safety seat.

In addition, other than facing a 3-year-old child in a rearward child safety seat, further safety considerations could be explored for forward facing children. For instance, there is potential for developing a toque-like device to fit over the head of a child in a forward facing child safety seat. This device would then be restrained in a spring-damper combination that would not allow for relative motion of the head with respect to the child safety seat and not using unnecessary forces on the neck of the child to do so. This idea was conceived by the advisor of the author of this research as well as through brainstorming between the advisor and the author. The idea was inspired by the HANS (Head and Neck Support) device; a restraint system may have helped prevent the injury that killed four NASCAR drivers in the year 2000. Although the physiology of the head and necks of children and adults are quite different, when an adult reaches such high velocities and accelerations, as seen in car racing, the head and neck muscles of an adult respond in much the same as those of a child.

In brief, the outcome of this research is based on the finding that there are safer methods of restraining children in motor vehicles. Although properly used child safety seats save lives and prevent injuries, there is more that can be done. This research is a starting point for further research and development into this area and hopefully for a safer vehicle environment for children. 


\section{REFERENCES}

1. Statistics Canada. Major Causes of Death. April 26, 2003. Government of Canada. Accessed December, $2003<$ http://142.206.72.67/02/02b/02b_003_e.htm>.

2. M. K Sachs and S. M Tombrello. "Car Seat Safety: Buckling Up Isn't Always Enough." Gerber Pediatric Basics Volume 90 (2000): pp.10-24.

3. K. Weber. "Rear-Facing Restraint for Small Child Passengers." UMTRI Research Review Volume 25 (1995): pp. $12-17$.

4. M. Mousny, C.Saint-Martin, E. Danse, J.J. Rombouts. "Unusual Upper Cervical Fracture in a 1-Year-Old Girl." Journal of Pediatric Orthopaedics Volume 31 (2001): pp. 590-593.

5. A. Howard, A.M. McKeag, L. Rothman, A. German, I. Hale, Aly Emam, W. Altenhof, R. Turchi. "Cervical Spine Injuries in Children Restrained in Forward Facing Child Restraints." Proceedings of the Canadian Multidisciplinary Road Safety Conference XIII (2003).

6. B.A.,Skold. "An Improved ISOFIX system for rearward-facing child seats." Child Occupant Protection in Motor Vehicle Crashes Volume 3 (1999) pp. 161 - 164.

7. C. Tingval. Children in Cars: Some aspects of the safety of children as car passengers in road traffic accidents. Stockholm: Almqvist \& Wikssell Periodical Company, 1987.

8. D.R. Durbin, E. Bhatia, J.H. Holmes, K.N. Shaw, J.V. Werner, W. Sorenson, F.K. Winston. "Partners for child passenger safety: a unique child-specific crash surveillance system." Accident Analysis \& Prevention Volume 33 (2001): pp. 407 - 412.

9. National Highway Traffic Safety Administration. Federal Motor Vehicle Safety Standards; Child Restraint Systems; Final Rule. Washington: GPO, 2003.

10. B. Fildes, J. Charlton, M. Fitzharris, K. Langwieder, T. Hummel. "Injuries to children in child restraints." Institute for Vehicle Safety Volume 8 (2003): pp. 277 - 284.

11. S. Fuchs, M. Barthel, A.M. Flannery, K.K. Christoffel. "Cervical Spine Fractures Sustained by Young Children in Forward Facing Car Seats." Pediatrics Volume 84 (1989): pp. 348 354.

12. B. Kamren, M. Koch, A. Kullgren, A. Lie, C. Tingvall, S. Larsson, T. Turbell. "The Protective Effects of Rearward Facing CRS: An Overview of Possibilities and Problems associated with Child Restraints for Children Aged 0-3 Years." $\quad$ Society of Automotive Engineers 933093 (1993): pp. 113-118.

13. K. Langwieder, T. Hummel, and F. Finkbeiner. "Injury risks of children in cars depending on the type of restraint." Child Occupant Protection in Motor Vehicle Crashes Volume 3 (1999): pp. $37-57$. 
14. K.DeSantis-Klinich, G.M. Hulbert, L.W. Schneider. "Estimating Infant Head Injury Criteria and Impact Response Using Crash Reconstruction and Finite Element Modeling." Stapp Car Crash Journal Volume 46 (2002): pp. $2-30$.

15. N. Yoganadan, S. Kumaresan, F.A. Pintar, T.A. Gennarelli . "Biomechanical Tolerance Criteria for Paediatric Populations." Child Occupant Protection in Motor Vehicle Crashes Volume 3(1999): pp. 97 - 112.

16. WSU Science and Engineering Library. Kids in the Car. Detroit, MI: Wayne State University, 2002.

17. A. Kullgren, M. Krafft, A. Nygren, C. Tingvall. "Neck Injuries in Frontal Impacts: Influence of Crash Pulse Characteristics on Injury Risk." Accident Analysis and Prevention Volume 32 (2000): pp. 197-205.

18. K.B. Arbogast, E.K. Moll, S.D. Morris, F.K. Winston. "Child Occupant Protection: A Summary of Current Safety Recommendations." Preventative Care Update Volume 8 (2001): pp. $141-148$.

19. C.S. Gotschall, S. Luchter. "Head Injuries to Motor Vehicle Occupants Aged 0 -5 Years." Child Occupant Protection in Motor Vehicle Crashes Volume 3 (1999): pp. 17 - 28.

20. F.K. Winston, D.R. Durbin, E. Bhatia, J. Werner, W. Sorenson. "Patterns of inappropriate restraint for children in crashes." Child Occupant Protection in Motor Vehicle Crashes Volume 3 (1999): pp. 59 - 70.

21. D.S. Diekema, D.B. Allen. "Odontoid Fracture in a Child Occupying a Child Restraint Seat." Pediatrics Volume 82 (1988): pp. $117-119$.

22. D.F. Huelke, G.M. Mackay, A. Morris, M. Bradford. "Car Crashes and Non-Head Impact Cervical Spine Injuries in Infants and Children." Society of Automotive Engineers 920563 (1992).

23. BMW World. The Car Seat - Protecting Your Kids. January 2004. BMW World. Accessed December $2003<$ http://www.bmwworld.com/bmw/kids/car_seats.htm>.

24. Fact Monster. Total U.S. Population. January, 2003. Fact Monster. Accessed February, 2004 <http://www.factmonster.com/ipka/A0004997.html>.

25. CIA - The World Factbook. Canada. January 2003. CIA - The World Factbook. Accessed February, $2004<$ http://www.cia.gov/cia/publications/factbook/geos/ca.html>.

26. World Fact Book. Sweden Population. January 2003. World Factbook. Accessed February, $2004<\mathrm{http} / /$ www.education.yahoo.com/reference/sw/popula.html $>$.

27. Hospital for Sick Kids, Dr. Andrew Howard. Personal Interview. April 2002.

28. A. German, W.T. Gardner, A.W. Howard, M. Mackay, R.M. Letts. "Mechanisms of Lap Belt and Airbag Injuries in Children." Child Occupant Protection in Motor Vehicle Crashes Volume 3 (1999): pp. $81-96$. 
29. A. Eman, K. Sennah, A. Howard, I. Hale. "Multi-body Dynamic Simulations of Forward Facing Child Occupants Under Varying Crash Pulses." Proceedings of the Canadian Multidisciplinary Road Safety Conference XIII (2003).

30. E. Lau, R. Ray, C.S. Parenteau. "Characteristics of children in rollover collisions." Child Occupant Protection in Motor Vehicle Crashes Volume 3 (1999): pp. 3 - 16.

31. A.R. Burdi, D.F. Huelke, R.G. Snyder, G.H. Lowrey. "Infants and Children in the Adult World of Automobile Safety Design: Pediatric and Anatomical Considerations for Design of Child Restraints." Journal of Biomechanics Volume 2 (1969): pp. $267-280$.

32. A. Howard. "Re: Differences in Annulus Fibers of Adults and Children." Email to Author. July 26, 2003.

33. K. Weber. "Crash Protection for Child Passengers: A Review of Best Practice." UMTRI Research Review Volume 31, Number 3 (2000): pp. 1- 27.

34. K. DeSantis-Klinich, R.A. Saul, G. Auguste, S. Backaitis, M. Kleinberger. Techniques for Developing Child Dummy Protection Reference Values. NHTSA Event Report, Docket Submission \# 74-14 Notice 97 Item 069, 1996.

35. L. Parker. Hughston Health Alert. 2003. Hughston Sports Medicine Foundation. Accessed December $2003<\underline{\text { http://www.hughston.com/hha/a.cspine.htm }>\text {. }}$

36. M.A. MacAulay. Introduction to Impact Injury. New York: Chapman and Hall, 1987.

37. Code of Federal Regulations: Department of Transportation; Parts $400-999$. Washington: GPO, 1995.

38. Injury Criteria and Injury Criteria Performance Limits. January 2002. National Highway Traffic Safety Administration. Accessed January 2003

$<$ http://www.nhtsa.gove/cars/rules/rulings/AAirBagsSNPRM/PEA/pea-IIl.n.pdt>.

39. K.U. Schmitt, M.H. Muser, P. Niederer. "A New Neck Injury Criterion Candidate for RearEnd Collisions Taking Into Account Shear Forces and Bending Moments." Swiss Federal Institute of Technology. Accessed December 2003 <www.agu.ch/pdf/ESV_paper.pdf $>$.

40. Mythos Anatomy. Skeletal System.WebMDAnatomy. Accessed December 2003 $<$ http://www.mythos.com.webmd/Content.aspx?P=SKULL\&E=92>.

41. T.J. Kennedy. Occipital Condyle. 2003. NSIR Technologies. Accessed December 2003 $<$ http://www.nsirtech.com/mountains.html $>$.

42. Meet the Drivers. EuroNCAP. Accessed January 2003. $<$ http:/home.zonnet.nl/CitroenCrashTest/how-tests-r-done.html $>$

43. Engineering Research AB. Description of Dummies. Accessed January 2003. $<$ http://www.erab.se/products/dummies/FTSS dummies.htm> 
44. What You Need to Know About. The History of Crash Test Dummies. Accessed January 2003. <http://inventors.about.com/library/inventors/blcrashtestdummies1.htm>

45. General Motors. Protecting Occupants - Dummies. Accessed January 2003.

$<$ http://www.gm.com/company/gmability/safety/protect occupants/dummies/mertz 010702. html>

46. T.B. Khalil and T.C. Lin. "Simulation of the Hybrid III Dummy Response to Impact by Nonlinear Finite Element Analysis." Society of Automotive Engineers, $38^{\text {th }}$ Stapp Car Crash Conference Proceedings (1994): pp 325-343.

47. F.K. Winston, K.B. Arbogast, L.A. Lee, R.A. Menon. "Computer Crash Simulations in the Development of Child Occupant Safety Policies." Archives of Pediatrics and Adolescent Medicine Volume 154 (2000): pp. $276-280$.

48. First Technology Safety Systems. LS-DYNA Model of the Hybrid III 3 Year Old Child Dummy Version 2.3 B2. Troy, MI: First Technology Safety Systems and Ove Arup \& Partners Detroit Limited, 2000.

49. Livermore Software Technology Corporation. LS-DYNA Material Model Manual. Livermore, CA: Livermore Software Technology Corporation, 1998.

50. Livermore Software Technology Corporation. LS-DYNA Keyword Manual. Livermore, CA: Livermore Software Technology Corporation, 1998.

51. Livermore Software Technology Corporation. LS-DYNA Theoretical Manual. Livermore, CA: Livermore Software Technology Corporation, 1998.

52. S. Alexopolous. "Re: Material Properties of Seat Belt Webbing." Email to Author. November 13, 2002.

53. Medical Dictionary Search Engine. "Abbreviated Injury Scale." Medical Dictionary Search Engine. Accessed September 2003 $<$ http://www.books.md/A/dic/abbreviatedinjuryscale.php $>$. 
8. APPENDICES 


\section{Appendix A - Abbreviated Injury Scale}




\section{Appendix A - Abbreviated Injury Scale}

The Abbreviated Injury Scale (AIS) is an anatomical scoring system which was first introduced in 1969. According to the Medical Search Engine [53], AIS is a classification system for assessing impact injury severity developed and published by the American Association for Automotive Medicine. The AIS is used for coding single injuries and is a basis for the methods of assessing multiple injuries or for assessing cumulative effects of more than one injury. The assessment of multiple injuries is achieved by the maximum abbreviated injury scale (MAIS), the injury severity score (ISS), and the probability of death score (pods). It has been revised and updated several times as to provide "reasonably accurate" ranking of the severity of injury. The latest revision of the AIS score took place in 1990.

Injuries are ranked on a scale of 1 to 6 , with 1 being minor, 5 severe, and 6 an injury which cannot be survived. This represents the threat to life associated with an injury and is not meant to represent a comprehensive measure of severity. The Abbreviated Injury Scale does not grade its ranks as a typical scale does. In other words, the difference between AIS1 and AIS2 is not the same as that between AIS4 and AIS 5.

The AIS scale primarily defines the threat to life: approximately 99 percent for AIS 6, 46 percent for AIS 5, 31 percent for AIS 4, and declining to 0 percent for AIS 1. This scale is also used to reflect the seriousness of the consequences for survivors.

The following table describes the qualitative nature of the Abbreviated Injury Scale.

Abbreviated injury scale.

\begin{tabular}{|c|c|}
\hline AIS Score & Injury \\
\hline \hline 1 & Minor \\
\hline 2 & Moderate \\
\hline 3 & Serious \\
\hline 4 & Severe \\
\hline 5 & Critical \\
\hline 6 & Unsurvivable \\
\hline
\end{tabular}




\section{Appendix B - Contact Types}




\section{Appendix B - Contact types}

Generally, a dummy model consists of two types of contact algorithms - internal contact surfaces and additional contact surfaces [41]. The internal contact surfaces are the permanent and necessary for the dummy model. The additional contact surfaces are defined by the user and they would vary depending on the analysis. The following table lists the types of internal contact algorithms used.

Types of internal contact algorithms used in Hybrid III 3-year-old dummy model [41].

\begin{tabular}{|c||c|}
\hline Contact Type & Contact Keyword \\
\hline \hline Type 3 & ${ }^{*}$ CONTACT_SURFACE_TO_SURFACE_TITLE \\
\hline Type 4 & ${ }^{*}$ CONTACT_SINGLE_SURFACE_TITLE \\
\hline Type 5 & ${ }^{*}$ CONTACT_NODES_TO_SURFACE_TITLE \\
\hline Type 13 & ${ }^{*}$ CONTACT_AUTOMATIC_SINGLE_SURFACE_TITLE \\
\hline Type 26 & ${ }^{*}$ CONTACT_AUTOMATIC_GENERAL_TITLE \\
\hline
\end{tabular}

There are a total of 13 internal contact algorithms used within the Hybrid III 3-year-old dummy model and they are all listed in the following table. 
Contact entities and contact type for Hybrid III 3-year-old dummy.

\begin{tabular}{|c||c|}
\hline Contact Entity & Contact Type \\
\hline Front Top Slit & 4 \\
\hline Front Middle Slit & 4 \\
\hline Front Bottom Slit & 4 \\
\hline Rear Top Slit Contact & 4 \\
\hline Rear Middle Slit & 4 \\
\hline Rear Bottom Slit & 4 \\
\hline Cable to Neck & 3 \\
\hline Ribs to Leaf Spring and Bib & 13 \\
\hline Cable to Spine & 3 \\
\hline Spine Rear Top to Jacket & 3 \\
\hline Bib to Spine box Top & 13 \\
\hline Front Jacket to Sternum & 3 \\
\hline Jacket to Bib & 3 \\
\hline Jacket to Abdomen & 3 \\
\hline Rear Jacket & 13 \\
\hline 1st Rib to Top Rib Stop & 5 \\
\hline 6th Rib to Low Rib Stop & 5 \\
\hline Jacket to Ribs & 3 \\
\hline Pelvis to Abdomen & 26 \\
\hline Pelvis to Skin Jacket & 26 \\
\hline Head to Skin Jacket & 26 \\
\hline Arms to Body Parts & 3 \\
\hline Abdomen Foam Interior & 13 \\
\hline
\end{tabular}




\section{Appendix C - Numerical Algorithms Used In Calculating Injury Criteria}




\section{Appendix C - Numerical algorithm}

The following are numerical algorithms that were employed using MathCAD software in order to calculate $\mathrm{HIC}, \mathrm{N}_{\mathrm{ij}}$, and all average values with respect to time. Also, the numerical algorithm for the SAE J211 $2^{\text {nd }}$ order Butterworth filter that was used to filter the experimental and numerical raw data.

\section{Head Injury Criteria Algorithm}

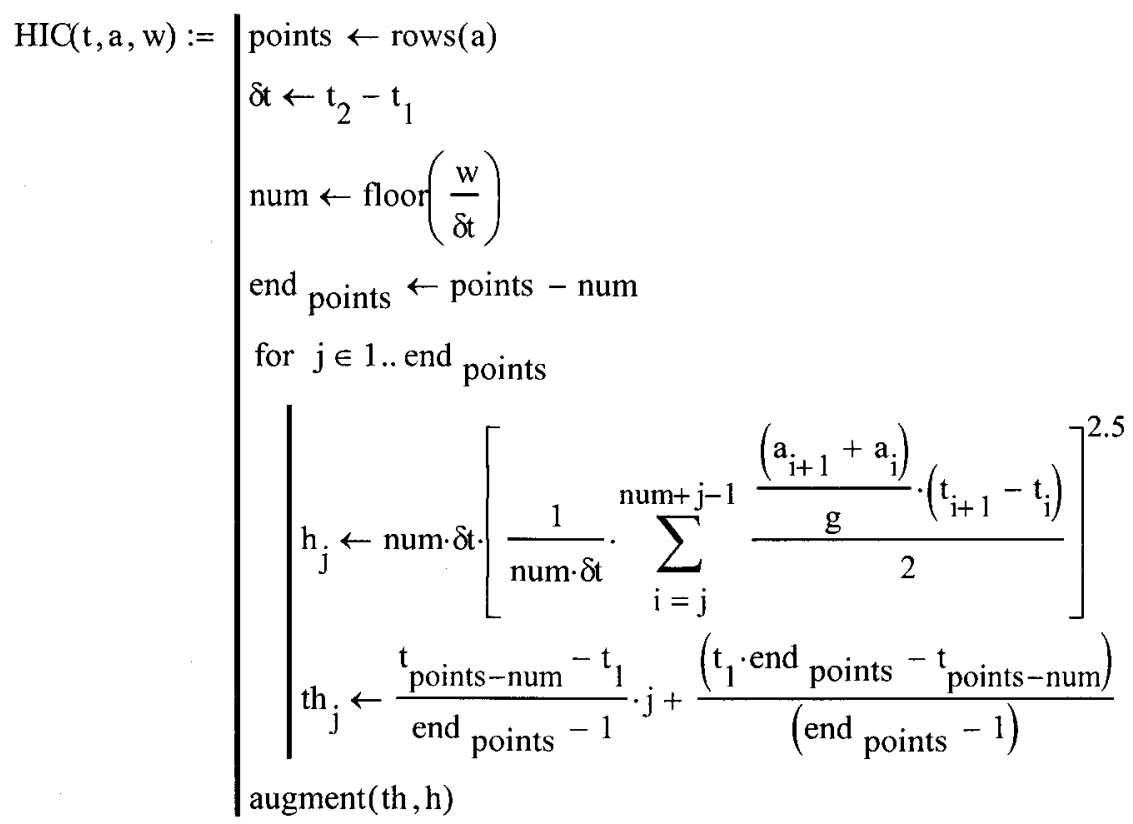

\section{Normalized Neck Injury Criteria}

$$
\text { NICF, M }:=\mid \begin{aligned}
& \text { for } i \in 1 . . \operatorname{rows}(\mathrm{F}) \\
& \mid \begin{array}{l}
\mathrm{Fzc}_{\mathrm{i}} \leftarrow \mathrm{if}\left(\mathrm{F}_{\mathrm{i}}>0 \cdot \mathrm{N}, 2120 \mathrm{~N},-2120 \mathrm{~N}\right) \\
\mathrm{Myc}_{\mathrm{i}} \leftarrow \mathrm{if}\left(\mathrm{M}_{\mathrm{i}}>0 \cdot \mathrm{N} \cdot \mathrm{m}, 68 \cdot \mathrm{N} \cdot \mathrm{m},-27 \cdot \mathrm{N} \cdot \mathrm{m}\right)
\end{array} \\
& \mathrm{NIC}_{\mathrm{i}} \leftarrow \frac{\mathrm{F}_{\mathrm{i}}}{\mathrm{Fzc}_{\mathrm{i}}}+\frac{\mathrm{M}_{\mathrm{i}}}{\mathrm{Myc}_{\mathrm{i}}}
\end{aligned}
$$




\section{Average Calculation}

$$
\text { Average }(x, y):=\mid \begin{aligned}
& n \leftarrow \operatorname{rows}(x) \\
& a \leftarrow \frac{1}{x_{n-2}-x_{2}} \cdot \sum_{m=2}^{n-2} \frac{1}{2}\left(y_{m}+y_{m-1}\right) \cdot\left(x_{m}-x_{m-1}\right)
\end{aligned}
$$




\section{SAE J211 $2^{\text {nd }}$ Order Butterworth Filter}

$$
\begin{aligned}
& \text { SAEJ21 } 1(\mathrm{t}, \mathrm{Acc}, \mathrm{CFC}):=\mid \mathrm{n} 1 \leftarrow \text { rows }(t) \\
& \text { sum } \leftarrow 0 \text {. } \\
& \text { for } i \in 1 . . n 1-1 \\
& \mid \begin{array}{l}
D t_{i} \leftarrow t_{i+1}-t_{i} \\
\text { sum } \leftarrow \operatorname{sum}+D t_{i}
\end{array} \\
& \mathrm{~T} \leftarrow \frac{\text { sum }}{\mathrm{n} 1-1} \\
& \mathrm{w}_{\mathrm{d}} \leftarrow 2 \cdot \pi \cdot \mathrm{CFC} 2.0775 \\
& \mathrm{w}_{\mathrm{a}} \leftarrow \frac{\sin \left(\mathrm{w}_{\mathrm{d}} \cdot \frac{\mathrm{T}}{2}\right)}{\cos \left(\mathrm{w}_{\mathrm{d}} \cdot \frac{\mathrm{T}}{2}\right)} \\
& \mathrm{a}_{0} \leftarrow \frac{\mathrm{w}_{\mathrm{a}}^{2}}{\left(1.0+\sqrt{2} \cdot \mathrm{w}_{\mathrm{a}}+\mathrm{w}_{\mathrm{a}}^{2}\right)} \\
& \mathrm{a}_{1} \leftarrow 2 \cdot \mathrm{a}_{0} \\
& \mathrm{a}_{2} \leftarrow \mathrm{a}_{0} \\
& \mathrm{~b}_{1} \leftarrow-2 \cdot \frac{\left(w_{a}^{2}-1\right)}{\left(1+\sqrt{2} \cdot w_{a}+w_{a}^{2}\right)} \\
& \mathrm{b}_{2} \leftarrow \frac{\left(-1+\sqrt{2} \cdot \mathrm{w}_{\mathrm{a}}-\mathrm{w}^{2}\right)}{\left(1+\sqrt{2} \cdot \mathrm{w}_{\mathrm{a}}+\mathrm{w}_{\mathrm{a}}^{2}\right)} \\
& \text { filter } 1_{1} \leftarrow 0 \cdot g \\
& \text { filterl }_{2} \leftarrow 0 \cdot \mathrm{g} \\
& \text { filter } 2_{1} \leftarrow 0 \cdot \mathrm{g} \\
& \text { filter } 2_{2} \leftarrow 0 \cdot \mathrm{g} \\
& \mathrm{j}_{\text {end }} \leftarrow \mathrm{n} 1-2 \\
& \text { for } \mathrm{j} \in 3 . . \mathrm{j} \text { end } \\
& \text { filter }_{\mathbf{j}} \leftarrow \mathrm{a}_{0} \cdot \mathrm{Acc}_{\mathrm{j}}+\mathrm{a}_{1} \cdot \mathrm{Acc}_{\mathrm{j}-1}+\mathrm{a}_{2} \cdot \mathrm{Acc}_{\mathrm{j}-2}+\mathrm{b}_{1} \cdot \text { filter }_{\mathrm{j}-1}+\mathrm{b}_{2} \cdot \text { filter }_{\mathrm{j}-2} \\
& \text { for } j \in 3 . . j \text { end } \\
& \text { filter } 1_{-}{ }_{j} \leftarrow \text { filter } 1_{j_{\text {end }}}(\mathrm{j}-1) \\
& \text { for } j \in 3 . . j \text { end } \\
& \text { filter } 2_{j} \leftarrow a_{0} \cdot \text { filter } 1_{-} 1_{j}+a_{1} \cdot \text { filter } \__{-}{ }_{j-1}+a_{2} \cdot \text { filter } \__{-}{ }_{j-2}+b_{1} \cdot \text { filter }{ }_{j-1}+b_{2} \cdot \text { filter } 2_{j-2} \\
& \text { for } \mathrm{j} \in 3 . . \mathrm{j}_{\text {end }} \\
& \text { filter } 2_{-}{ }_{j} \leftarrow \text { filter }_{\mathrm{j}_{\text {end }}}(\mathrm{j}-1) \\
& \text { filter2_1 }
\end{aligned}
$$




\section{Appendix D - Material Models}




\section{Appendix D - Material models}

This section describes in brief detail the material input characteristics for all parts except the Hybrid III dummy model. The following table describes the part identification, section identification, material identification, element formulation, and thickness. This is so that one can identify the part, material and section in the LS-DYNA input deck which has been provided on the $\mathrm{CD}$ in the back pocket of this study.

Part identification numbers and element formulations.

\begin{tabular}{|c|c|c|c|c|c|}
\hline Part Name & PID & SECID & MID & ELFORM & Thickneess \\
\hline \hline SEAT & 112478 & 112478 & 112478 & 2 & 1 \\
\hline BELT & 212479 & 212479 & 212479 & 9 & 1.25 \\
\hline CHEST CLASP & 212480 & 212480 & 212480 & 2 & 1 \\
\hline WAIST CLASP & 212481 & 212480 & 212480 & 2 & 1 \\
\hline FOAM INSERT & 212482 & 212481 & 212481 & 2 & solid \\
\hline
\end{tabular}

1. This is the LS-DYNA input material model for the polypropylene seat. It was modeled as a rigid entity, but there are material characteristics that need to be specified such as the Poisson's ratio, density and Young's modulus. This material model was also used to characterize the plastic clasps on the seat belt system of the child safety seat.

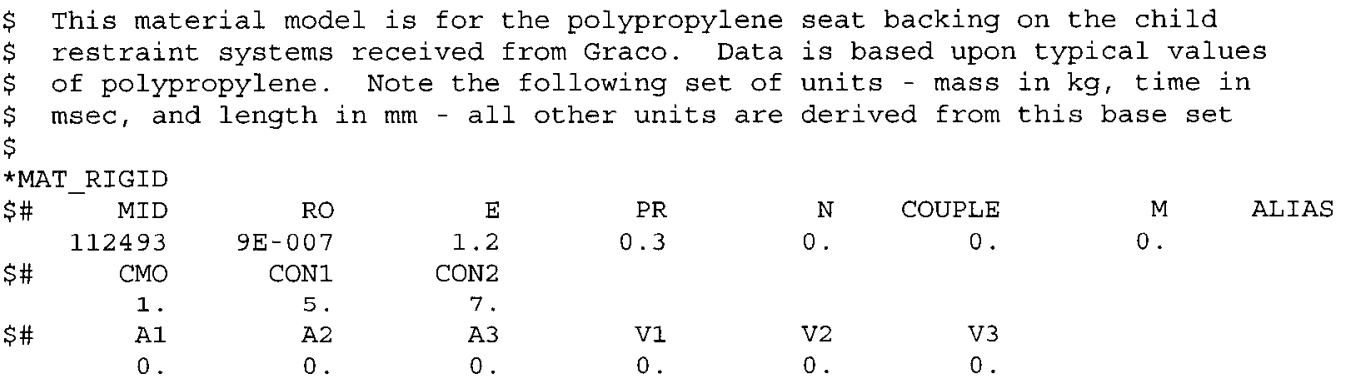

$\begin{array}{lll}\mathrm{V} 1 & \mathrm{~V} 2 & \mathrm{~V} 3 \\ 0 . & 0 & 0\end{array}$


2. This is the LS-DYNA input material model for the seat belt fabric. This model is commonly used for seat belts and airbags.

$\begin{array}{lrr}\text { *MAT_FABRIC } & \\ \text { \$\# } & \text { MID } & \text { RO } \\ & 212494 & 8.41 \mathrm{E}-007 \\ \text { \$\# } & \text { GAB } & \text { GBC } \\ & 0 . & 0 . \\ \text { \$\# } & \text { AOPT } & \text { FLC } \\ & 0 . & 0 .\end{array}$

EA
4.
GCA
0.
FAC
0.

$E B$
0.
CSE
0.
ELA
0.

EC
0.
EL
0.
LNRC
PRBA
0.3
PRL
FORM

0 .

$\begin{array}{rr}\text { PRCA } & \text { PRCB } \\ 0 . & 0 . \\ \text { LRATIO } & \text { DAMP } \\ 0 . & 0.2\end{array}$

3. The following material model represents the foam insert for the child safety seat. The input was obtained by several compressive tests. The loading portion of the model is input directly as seen in the *DEFINE_CURVE portion of this material model. The unloading is characterized by the shape factor (SHAPE) and the hysteretic unloading factor (HU). These values were obtained through a trial and error simulation method described in the Experimental Procedure section of this study. 
\$ THIS MATERIAL MODEL IS FOR THE FOAM BACKING ON THE CHILD SEAT

$\$ E$ and SFO scaled up by $25 x$

*MAT_LOW_DENSITY_FOAM

\begin{tabular}{|c|c|c|c|c|c|c|c|c|}
\hline \$\# & MID & RO & $\mathrm{E}$ & LCID & $\mathrm{TC}$ & $\mathrm{HU}$ & BETA & DAMP \\
\hline & 212511 & $5.017 \mathrm{E}-08$ & $5.463 \mathrm{E}-03$ & 1 & & 0.1 & 0.0 & 0.5 \\
\hline 8 & SHAPE & FAIL & BVFLAG & ED & BETAI & KCON & REF & \\
\hline
\end{tabular}

$\star$ DEFINE CURVE

$\$$ a scale factor of $1.0 \mathrm{e}-06$ has been used to convert from $\mathrm{kg}, \mathrm{mm}, \mathrm{s}$ to $\mathrm{kg}, \mathrm{mm}, \mathrm{ms}$

LCID or of $1.0 \mathrm{e}-06$

SFA SFO OFFA OFFO DATTYP

1 (MM, KG, S)

1.0

2. $5 \mathrm{E}-05$

\$ STRAIN (MM, KG, S)

0.013265306

STRESS (MM, KG, S)

0.026530612

0.039795918

0.053061224

0.066326531

0.079591837

0.092857143

0.10612245

0.11938776

0.13265306

0.14591837

0.15918367

0.17244898

0.18571429

0.19897959

0.2122449

0.2255102

0.23877551

0.25204082

0.26530612

0.27857143

0.29183673

0.30510204

0.31836735

0.33163265

0.34489796

0.35816327

0.37142857

0.38469388

0.39795918

0.41122449

0.4244898

0.4377551

0.45102041

0.46428571

0.47755102

0.49081633

0.50408163

0.51734694

0.53061224

0.54387755

0.55714286

0.57040816

0.58367347

0.59693878

0.61020408

0.62346939

0.63673469

0.65

3.0791636

6.02553

8.2201181

9.3274012

9.673192

9.893332

10.026602

10.133754

10.302508

10.558311

10.853809

11.13803

11.38413

11. 59942

11.793801

11.977172

12.159432

12.350482

12.560221

12.797543

13.062313

13.349622

13.654519

13.972053

14.297273

14.625993

14.959434

15.301142

15.654673

16.023581

16.411421

16.821034

17.251576

17.70102

18.169336

18.669364

19.219045

19.83478

20.520329

21. 273307

22.091893

22.981223

23.95088

25.010519

26.169792

27.438354

28.82586

30.341963

31.996317

134

Reproduced with permission of the copyright owner. Further reproduction prohibited without permission. 


\section{Appendix E - Compressive Foam Study}




\section{Appendix E - Compressive foam study}

Several samples of foam that was characteristic of the foam insert used in the actual child safety seat were subjected to compressive testing. In LS-DYNA, the low-density foam material model requires on only to input the loading curve. The unloading curve is characterized by two main inputs; or the hysteretic unloading factor (HU), and the shape factor (SHAPE). These values are attained by a trial and error method. Ten simulations were carried out to mimic the compressive tests, each simulation with varied hysteretic unloading and shape factors. The load-deflection data was plotted and compared to the experimental curve. The curve that most closely resembled the experimental curve was chosen to represent the foam in the child safety seat.

The following figure shows the experimental load-deflection curve along with all simulation trials that were carried out.

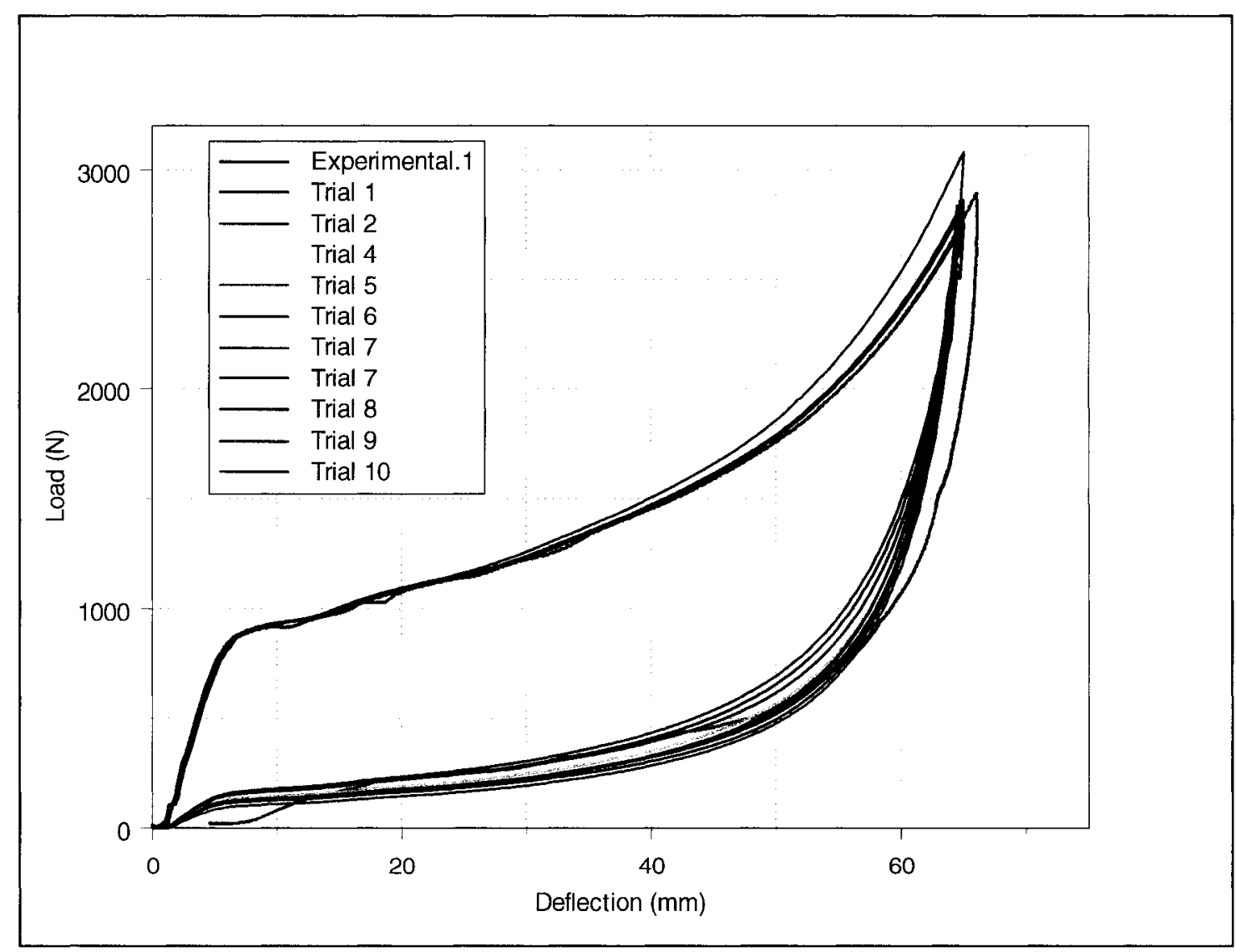

Load versus deflection for trial numerical simulations. 
Trial 1 was chosen to represent the foam. The hysteretic factor and shape factor used were 0.1 and 5.0, respectively. The following figure compares the experimental curve and the curve obtained from Trial 1.

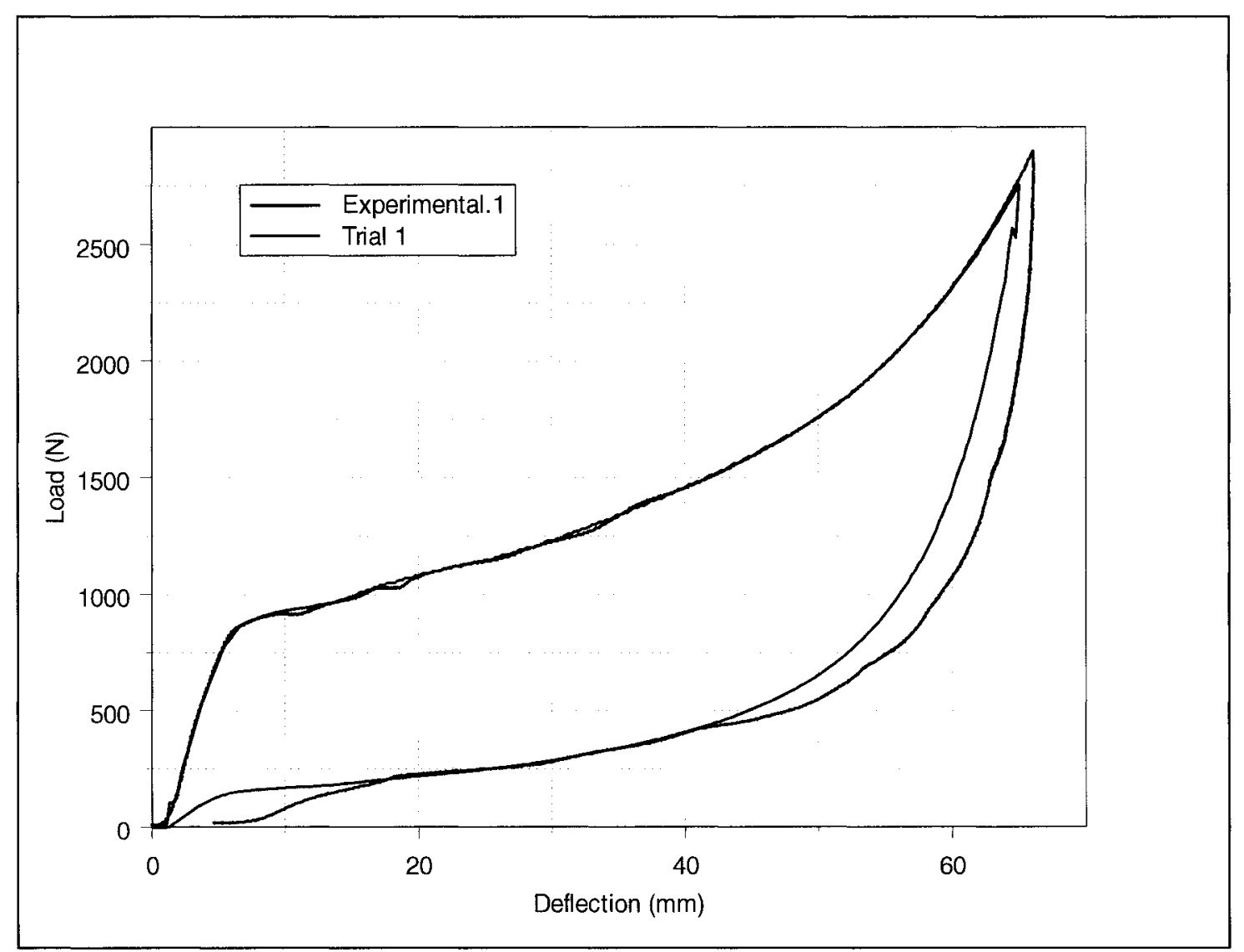

Experimental curve and numerical curve for foam model verification. 
The following table lists the hysteretic and shape factors used in the trial and error simulations

Trial HU and SHAPE values used in foam study.

\begin{tabular}{|c||c||c|}
\hline Trial & HU & SHAPE \\
\hline \hline 1 & 0.1 & 5 \\
\hline 2 & 0.1 & 4.5 \\
\hline 3 & 0.1 & 6.5 \\
\hline 4 & 0.05 & 7.5 \\
\hline 5 & 0.1 & 7.5 \\
\hline 6 & 0.05 & 7.5 \\
\hline 7 & 0.06 & 7.5 \\
\hline 8 & 0.15 & 6 \\
\hline 9 & 0.07 & 6.5 \\
\hline 10 & 0.1 & 8.5 \\
\hline
\end{tabular}




\section{VITA AUCTORIS}

Rita F. Turchi was born in 1978 in Windsor, Ontario. She graduated from Holy Names High School in Windsor in 1997. From there she went on to the University of Windsor where she obtained a Bachelor of Applied Science in Mechanical Engineering with Materials Option and Co-op. She began her graduate studies at the University of Windsor in Fall 2001 and was granted a Natural Sciences and Engineering Research Council (NSERC) scholarship, Ontario Graduate scholarship (OGS), a University of Windsor tuition scholarship, and the Automotive Women's Alliance (AWA) scholarship. She is currently a candidate for the Masters of Applied Science degree in Mechanical Engineering at the University of Windsor and hopes to graduate in Winter 2004. 